Renan Fernandes Bastos

\title{
Sistema de Gerenciamento para Carga e Descarga de Baterias (Chumbo- Ácido) e para Busca do Ponto de Máxima Potência Gerada em Painéis Fotovoltaicos Empregados em Sistemas de Geração Distribuída
}

\begin{abstract}
Dissertação de Mestrado apresentada à Escola de Engenharia de São Carlos, da Universidade de São Paulo, como requisito para obtenção do Título de Mestre em Ciências, Programa de Engenharia Elétrica
\end{abstract}

Área de Concentração: Sistemas Dinâmicos.

Orientador: Prof. Dr. Ricardo Quadros Machado

\author{
São Carlos
}

2013

Trata-se da versão corrigida da dissertação. A versão original se encontra disponível na EESC/USP que aloja o Programa de Pós-Graduação de Engenharia Elétrica. 


\section{AUTORIZO A REPRODUĈ̃O TOTAL OU PARCIAL DESTE TRABALHO, POR QUALQUER MEIO CONVENCIONAL OU ELETRÔNICO, PARA FINS DE ESTUDO E PESQUISA, DESDE QUE CITADA A FONTE.}

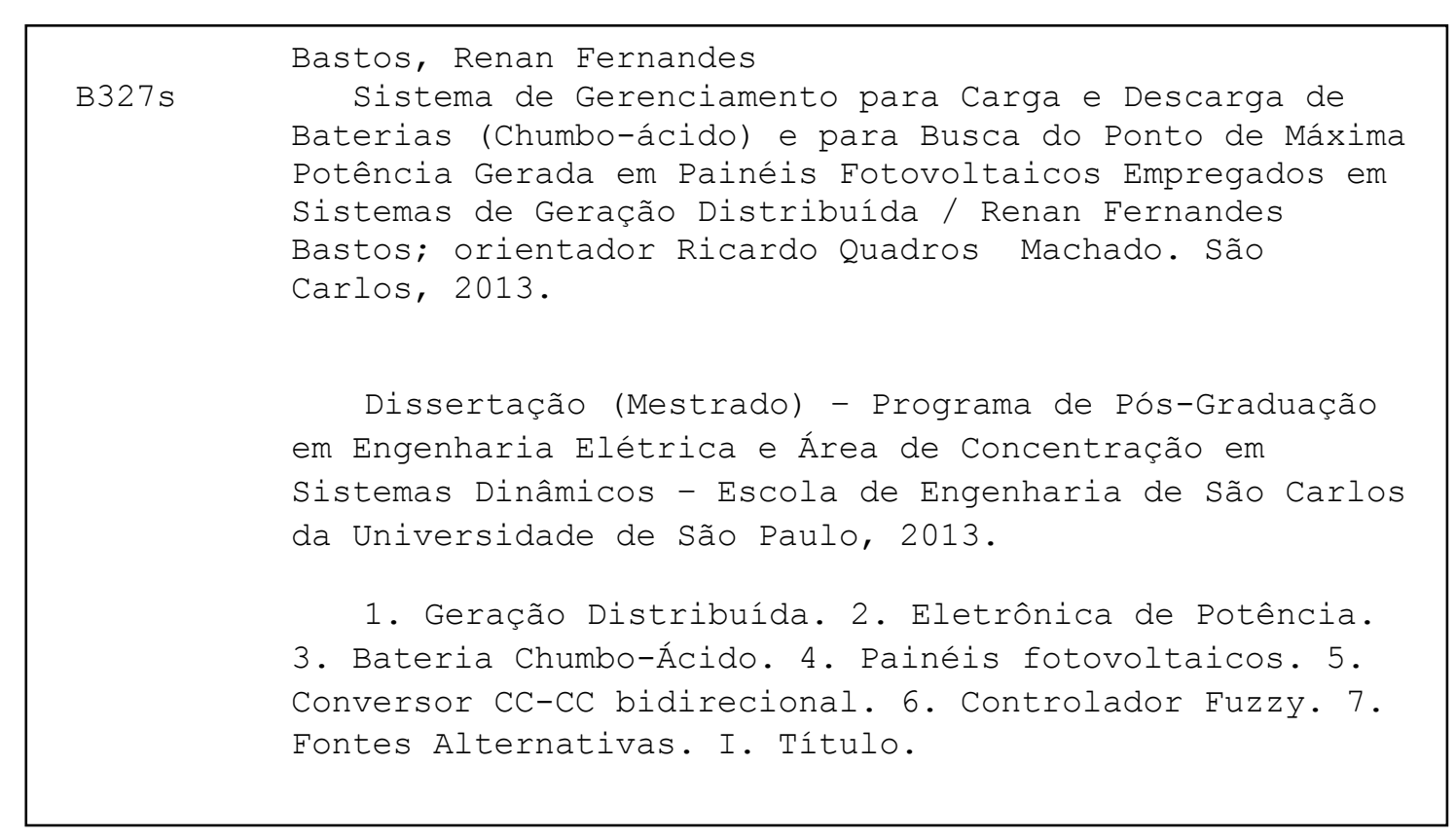




\section{FOLHA DE JULGAMENTO}

Candidato: Engenheiro RENAN FERNANDES BASTOS.

Título da dissertação: "Sistema de gerenciamento para carga e descarga de baterias (chumbo-ácido) e para busca do ponto de máxima potência gerada em painéis fotovoltaicos e empregados em sistemas de geração distribuída".

Data da defesa: $24 / 01 / 2013$

\section{Comissão Julgadora:}

Prof. Dr. Ricardo Quadros Machado (Orientador)

(Escola de Engenharia de São Carlos/EESC)

Prof. Dr. José Roberto Boffino de Almeida Monteiro

(Escola de Engenharia de São Carlos/EESC)

Prof. Dr. Leandro Michels

(Universidade Federal de Santa Maria/UFSM)
Resultado:

APROVADO

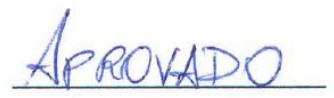

APROVADO

Coordenador do Programa de Pós-Graduação em Engenharia Elétrica e Presidente da Comissão de Pós-Graduação:

Prof. Titular Denis Vinicius Coury 



\section{Agradecimentos}

Em primeiro lugar, agradeço a minha família pelo apoio, exemplo e pela minha formação como pessoa. Em especial aos meus pais e meus irmãos que me acompanharam nesta longa jornada. A livia, por estar junto comigo durante este percurso apesar da distância. Aos meus avós Lalado, Leia, Niniza, aos meus tios e tias e primos que torcem por mim.

Aos amigos e professores da UFV, que toram possível o sonho chegar até aqui.

Aos amigos que fiz em São Carlos, companheiros da Rep. Alabama, Goias, Rodolpho, Paulo e Fabão pela companhia e amizade.

Muito obrigado aos companheiros de trabalho do LAC e LAFAPE, Amilcar, Giovani, Nilton, Fernando, Guido, Giann, Rodolpho e Cassius, pela amizade, discussões, aprendizados e brincadeiras, aos quais sem eles este trabalho não seria possível.

Agradeço também a todos os funcionários do departamento pelas contribuições e pela boa vontade em sempre nos ajudar.

Ao Prof. Ricardo, pela confiança em mim depositada durante a execução deste trabalho, pelo incentivo, dedicação, paciência e amizade, obrigado por contribuir com a minha formação acadêmica. Agradeço também a professora Vilma, pela constante contribuição e suporte na pesquisa.

Enfim, a todas as pessoas que torceram pelo meu sucesso e que não foram citadas aqui, meu muito obrigado.

Agradeço a Escola de Engenharia de São Carlos pelas instalações e serviços, além do CNPq pelo apoio financeiro desta pesquisa. 



\section{Sumário}

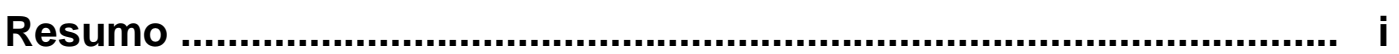

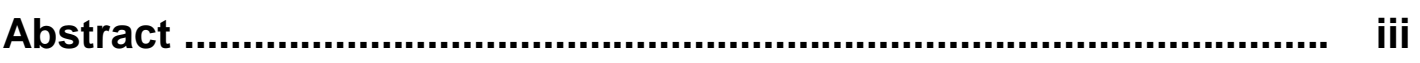

Lista de figuras ..................................................................................

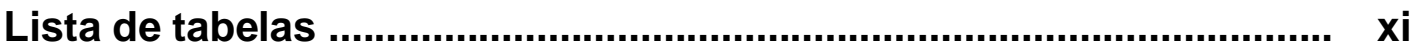

Siglas e abreviaturas ….................................................................. xiii

Lista de símbolos por ordem de aparição ......................................... Xv

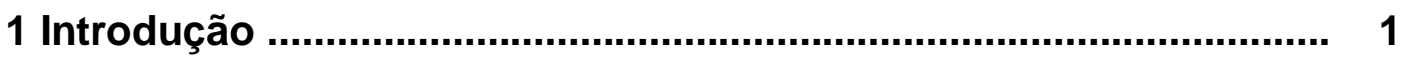

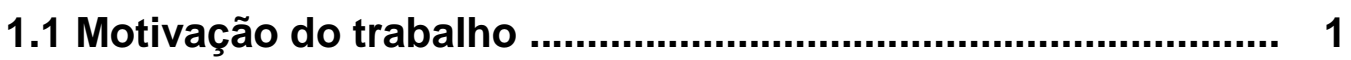

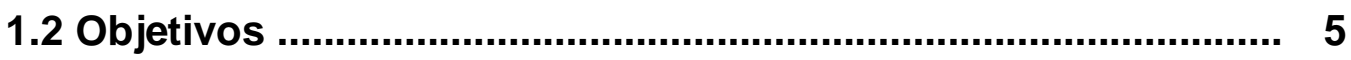

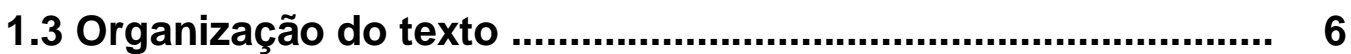

2 Aspectos gerais ........................................................................... 7

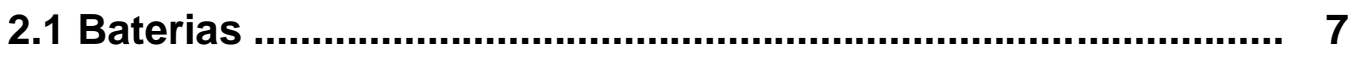

2.1.1 Visão geral ................................................................ 7

2.1.2 Aspectos construtivos ................................................. 10

2.1.3 Características elétricas ............................................ 10

2.1.4 Estado de carga interativo (SOC interativo) ................... 13

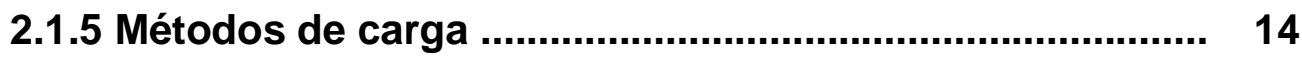

2.2 Descrição do sistema ............................................................. 17

2.2.1 Painel fotovoltaico e modelo generalizado ..................... 17

2.2.2 MPPT - P\&O ........................................................... 22

2.2.3 Conversor CC-CC bidirecional ...................................... 23

2.2.4 Modelo do conversor no modo Boost (Step-Up) ............ 26

2.2.5 Modelo do conversor no modo Buck (Step-Down) ......... 27

2.2.6 Modelo de pequenos sinais para os conversores .......... 29

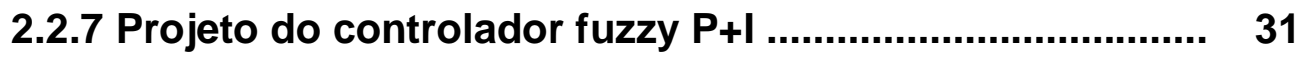

2.2.8 Modelo linearizado do painel fotovoltaico ..................... 37

2.2.9 Modelo do conversor Boost acoplado ao modelo linearizado do painel ......................................................... 40

2.3 Sistema de injeção de potência na rede .................................. 43

2.4 Considerações finais .......................................................... 45

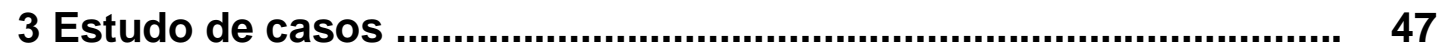




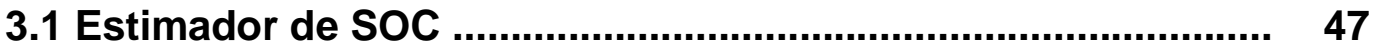

3.2 Circuito Bidirecional ............................................................ 49

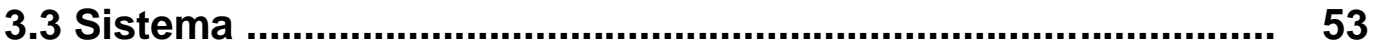

3.4 Sistema completo com alterações nas condições atmosféricas...................................................................... 57

3.5 Sistema completo com variação contínua na irradiação solar 60

3.6 Considerações finais ............................................................. 64

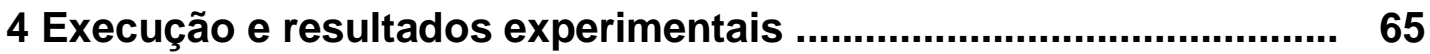

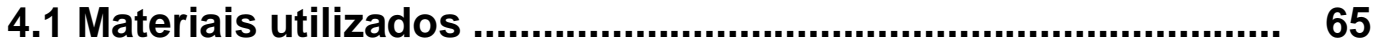

4.2 Resultados experimentais ................................................. 70

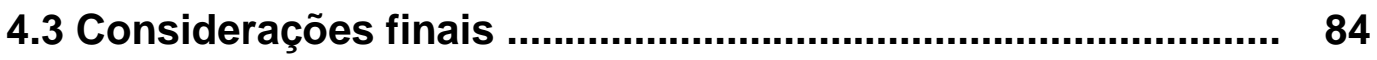

5 Conclusões e trabalhos futuros ................................................... 87

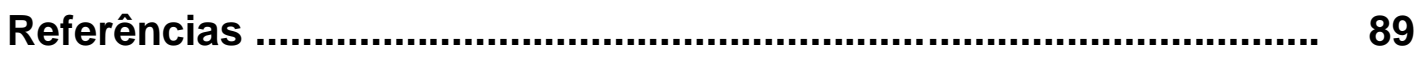




\section{Resumo}

BASTOS, R. F. (2013). Sistema de Gerenciamento para Carga e Descarga de Baterias (Chumbo-Ácido) e para Busca do Ponto de Máxima Potência Gerada em Painéis Fotovoltaicos Empregados em Sistemas de Geração Distribuída. Dissertação (Mestrado) - Escola de Engenharia de São Carlos, Universidade de São Paulo, 2013.

O presente trabalho visa o desenvolvimento de um sistema de carga e descarga de baterias de chumbo-ácido para sistemas de geração distribuída acoplada a um conjunto de painéis fotovoltaicos e conectada à rede elétrica. $O$ conjunto de painéis opera de forma a maximizar a energia gerada através de um algoritmo MPPT (Maximum Power Point Tracking) e a rede elétrica opera como rota para o excedente produzido pelos painéis. Para que a bateria possa ser carregada e descarregada com eficiência evitando sobrecargas e descarregamentos profundos, uma metodologia de estimação do estado de carga da bateria é implementada visando um controle mais eficiente (maximizando a vida útil da bateria) e um melhor aproveitamento da energia armazenada. Para o gerenciamento da carga e descarga do banco de baterias é utilizada uma topologia bidirecional (Boost-Buck) com controlador fuzzy $\mathrm{P}+\mathrm{l}$ para estabilização de corrente ou tensão. Em relação à técnica de controle para o sistema PV, um controlador PI clássico é utilizado para regular a tensão terminal e ponto de máxima potência que é definido por um algoritmo de perturbação e observação (P\&O). Para validar os controladores e os modelos teóricos desenvolvidos é construído um protótipo do sistema. São analisados, também, o comportamento do sistema de carga das baterias e painel fotovoltaico sob condições extremas como queda abrupta de irradiação solar, desconexão inesperada dos painéis e mudanças no ponto ótimo de funcionamento dos mesmos.

Palavras chave: Geração Distribuída, Eletrônica de Potência, Bateria Chumboácido, Painéis Fotovoltaicos, Conversor CC-CC Bidirecional, Controlador fuzzy, Fontes Alternativas. 


\begin{abstract}
BASTOS, R. F. (2013). Management System for charging and discharging of batteries (lead acid) and Search for the Maximum Power Point Generated on Photovoltaic Panels Employed in Distributed Generation Systems. Dissertation (Master's degree) - Escola de Engenharia de São Carlos, Universidade de São Paulo, 2013.
\end{abstract}

The present work aims to develop a system of charging and discharging leadacid batteries for distributed generation connected to a set of photovoltaic panels, and used in grid connected applications. The set of panels operates to maximize the energy produced by means of an MPPT (Maximum Power Point Tracking) algorithm and the power grid absorbs the extra power produced by the panels. For charging and discharging the battery pack and to prevent overload and deep discharge, a methodology for estimating the state of charge is implemented in order to obtain an efficient control technique (maximizing battery life), and more efficient use of the stored energy. To manage the charging and discharging of the battery bank a bidirectional topology (Boost-Buck) with fuzzy $\mathrm{P}+\mathrm{I}$ controller for stabilization of current or voltage is used. To regards the PV control technique, a classical PI controller is employed to regulate the PV terminal voltage, and the maximum power point is determined by a perturb and observe (P\&O) algorithm. To validate the controllers and the theoretical models developed is built a prototype system, and analyzed the behavior of the batteries charger and photovoltaic panel under extreme environmental conditions such as abrupt decrease of solar irradiation, unexpected panels disconnection and changes of the maximum power point of the panels.

Key words: Distributed Generation, Power Electronics, Lead-Acid Battery, PV Arrays, Bidirectional DC-DC Converter, Fuzzy Controller, Alternative Sources. 


\section{Lista de figuras}

Figura 1.1. Distribuição das fontes primárias de energia ................... 1

Figura 1.2. Crescimento das fontes alternativas .............................. 2

Figura 1.3. Comparação entre as reservas de combustíveis fósseis atuais e o potencial de geração de energia a partir do sol

Figura 1.4. Irradiação solar durante um dia, onde os picos de irradiação ocorrem entre 11 e 13 horas

Figura 1.5 Fluxo de potência do sistema, onde a potência da bateria pose ser positiva ou negativa

Figura 2.1. Desgaste de uma bateria de chumbo-ácido em função da profundidade da carga

Figura 2.2. Efeito da temperatura na vida útil da bateria de chumboácido

Figura 2.3. Efeito da temperatura na capacidade disponível

Figura 2.4. Estado de carga $x$ tensão de circuito aberto para uma bateria de chumbo-ácido

Figura 2.5. Tempo de estabilização

Figura 2.6. Tensão dinâmica da bateria durante descarga, C/20 representa descarga em regime de 20 horas

Figura 2.7. Método a dois níveis de tensão 16

Figura 2.8. Tensão e corrente, método dois níveis 17

Figura 2.9. Modelo generalizado de uma célula solar

Figura 2.10. Curva característica corrente $\mathrm{x}$ tensão de um módulo KC130TM, para diferentes níveis de irradiação

Figura 2.11. Curva potência $x$ tensão, módulo KC130TM, para diferentes níveis de irradiação

Figura 2.12. Circuito de controle da tensão terminal e circuito equivalente com a carga do secundário referida ao primário 22

Figura 2.13. Algoritmo MPPT por P\&O

Figura 2.14. Comportamento da tensão e da potência, durante o regime permanente utilizando algoritmo MPPT por $\mathrm{P} \& O$ com passo fixo 
Figura 2.15. 'Cuk Bidirecional e 'Cuk Bidirecional Isolado .................. 24

Figura 2.16. Dual Full Bridge ................................................... 24

Figura 2.17. Conversor Buck-Boost bidirectional ...................... 25

Figura 2.18. Modos de operação ............................................... 25

Figura 2.19. Conversor Buck-Boost Bidirecional com controle ........... 25

Figura 2.20. Boost chave fechada ............................................... 26

Figura 2.21. Boost chave aberta ................................................ 27

Figura 2.22. Buck com chave fechada.......................................... 27

Figura 2.23. Buck com chave aberta ........................................... 28

Figura 2.24. Diagrama de Bode em malha aberta para a planta $\mathrm{G}(\mathrm{s})$ Boost não compensada e compensada com controlador PI .............. 32

Figura 2.25. Diagrama de Bode em malha fechada para planta $G(s)$ Boost compensada com controlador PI ......................................... 33

Figura 2.26. Sistema de controle proposto fuzzy $\mathrm{P}+\mathrm{l} \ldots \ldots \ldots \ldots \ldots \ldots \ldots \ldots . . . . . . . . . . .34$

Figura 2.27. Superfície fuzzy de um controlador fuzzy PD+l, contendo duas entradas ........................................................ 35

Figura 2.28. Funções de pertinência de entrada ajustadas manualmente

Figura 2.29. Funções de pertinência de saída ajustadas manualmente .......................................................................... 36

Figura 2.30. Superfície fuzzy obtida pela defuzzyficação pelo método do centroide

Figura 2.31. Linearização em torno do ponto de máxima potência (PMP) para módulo fotovoltaico KC 130TM

Figura 2.32. Circuito linear equivalente no ponto de máxima potência 39

Figura 2.33. Modelo do painel linearizado acoplado ao conversor Boost

Figura 2.34. Modelo linearizado do painel acoplado ao Boost com chave ligada

Figura 2.35. Modelo linearizado do painel acoplado ao Boost com chave desligada

Figura 2.36. Diagrama de Bode para o modelo linearizado do painel 
acoplado ao conversor Boost

Figura 2.37. Sistema de controle do painel fotovoltaico 42

Figura 2.38. Sistema de injeção trifásico e equivalente 43

Figura 2.39. Corrente drenada do barramento CC para um inversor trifásico e para o sistema simplificado considerado na Figura 2.38 ..... 44 Figura 2.40. Sistema de controle fuzzy $\mathrm{P}+\mathrm{l}$, aplicado no controle da tensão do barramento $\mathrm{CC}$

Figura 3.1. Bloco da bateria e modelos

Figura 3.2. Corrente de entrada e corrente amostrada, SOC real e SOC estimado e Erro de estimação

Figura 3.3. Diagrama do circuito bidirecional, utilizando o controle fuzzy $\mathrm{P}+\mathrm{I}$ desenvolvido

Figura 3.4. Tensão e corrente da bateria durante a carga

Figura 3.5. Tensão e corrente da bateria quando a corrente é invertida em $0,3 \mathrm{~s}$

Figura 3.6. Zoom sobre a inversão de corrente

Figura 3.7. Mudança da variável de controle e inversão do sentido de condução do conversor bidirecional utilizando controlador fuzzy $\mathrm{P}+$ I...

Figura 3.8. Mudança da variável de controle utilizando o controle clássico PI

Figura 3.9. Modelo do sistema completo

Figura 3.10. Corrente de carga da bateria, para uma referência de 2 A e em seguida uma inversão da corrente para $-2 \mathrm{~A}$ em $0,3 \mathrm{~s}$

Figura 3.11. Tensão comum no barramento $C C$ que foi ajustada em $120 \mathrm{~V}$. Em 0,3 s a corrente na bateria é invertida

Figura 3.12. Resposta do controlador de corrente na bateria com referência de $2 \mathrm{~A}$ e $-2 \mathrm{~A}$ em $0,3 \mathrm{~s}$

Figura 3.13. Tensão de referência gerada pelo algoritmo MPPT e tensão terminal sistema PV

Figura 3.14. Potência de referência gerada pelo algoritmo MPPT, potência produzida pelos painéis e potência total consumida pelas baterias e pela rede 
Figura 3.15. Rendimento total do sistema

Figura 3.16. Corrente de carga da bateria durante alteração da irradiação bruscamente em 0,3 s

Figura 3.17. Tensão comum do barramento CC durante alteração da irradiação bruscamente em 0,3 s

Figura 3.18. Tensão de referência gerada pelo algoritmo MPPT e tensão nos terminais do PV durante alteração da irradiação bruscamente em 0,3 s

Figura 3.19. Potência de referência gerada pelo algoritmo MPPT, potência produzida pelos painéis e potência total consumida 60

Figura 3.20. Rendimento do sistema entre $80 \%$ e $90 \%$ 60

Figura 3.21. Irradiação solar incidente sobre o painel

Figura 3.22. Corrente de carga da bateria durante alteração da irradiação

Figura 3.23. Tensão no barramento CC com diminuição da irradiação em rampa

Figura 3.24. Tensão de referência gerada pelo algoritmo MPPT e tensão terminal do sistema PV durante a variação da irradiação ....

Figura 3.25. Potência de referência gerada pelo algoritmo MPPT, potência produzida pelos painéis e potência total consumida

Figura 3.26. Rendimento do sistema

Figura 4.1. Diagrama do sistema 65

Figura 4.2. Diagrama da placa de condicionamento de sinais por canal

Figura 4.3. DSP Texas instruments eZdsp TMS320F28335

Figura 4.4. Módulo conversor Semikron Modelo SKS 21F $\mathrm{B} 6 \mathrm{U}+\mathrm{E} 1 \mathrm{CIF}+\mathrm{B} 6 \mathrm{Cl}$

Figura 4.5. Fonte emuladora de painéis Agilent

Figura 4.6. Curva $\mathrm{V} x \mathrm{I}$ a quatros parâmetros do emulador 68

Figura 4.7. Bateria Moura Clean para sistemas estáticos 68

Figura 4.8. Sistema construído 69

Figura 4.9. Protótipo construído 69

Figura 4.10. Osciloscópio Tektronix usado para extração dos 
resultados

Figura 4.11. Inicialização do sistema, onde a corrente de carga se ajusta a energia produzida, o ponto de máximo $\left(V_{m p}=40 \mathrm{~V}, I_{m p}=\right.$ $3 \mathrm{~A})$ é alcançado em menos de 10 interações do MPPT e a tensão $V_{c c}$ se estabiliza em $120 \mathrm{~V}$

Figura 4.12. Corrente de carga do banco de baterias em função da porção da energia gerada

Figura 4.13. Zoom durante o regime permanente

Figura 4.14. Adequação do sistema durante uma redução da irradiação incidente seguido de um aumento da irradiação

Figura 4.15 . Adequação do sistema durante uma queda de irradiação muito acentuada, seguido de uma recuperação

Figura 4.16. Funcionamento do sistema em caso de desconexão dos painéis

Figura 4.17. Funcionamento durante redução da tensão de máxima potência de $40 \mathrm{~V}$ para $38 \mathrm{~V}$

Figura 4.18. Curva $V \times$ I para um painel fotovoltaico com irradiação constante, variando a temperatura das placas

Figura 4.19. Funcionamento durante uma elevação da tensão de máxima potência de 38 para $40 \mathrm{~V}$.

Figura 4.20. Funcionamento do sistema durante inversão forçada da corrente

Figura 4.21. Situações de carga durante inversão de corrente 79

Figura 4.22. Inversão de corrente na bateria de -2 A para $2 \mathrm{~A}$ 80

Figura 4.23. Inversão de corrente na bateria de 2 A para -2 A 80

Figura 4.24. Simulação do sistema de carga de baterias da seção 3.2 com os ganhos iguais aos do protótipo

Figura 4.25. Inversão de corrente na bateria e efeitos sobre a tensão da bateria

Figura 4.26. Mudança da variável de controle durante o processo de carga

Figura 4.27. Situações de Fluxo durante o cálculo do rendimento do sistema 
Figura 4.28. LCD 16x2 monocromático indicando o SOC em porcentagem e em Ah além da potência instantânea sendo produzida

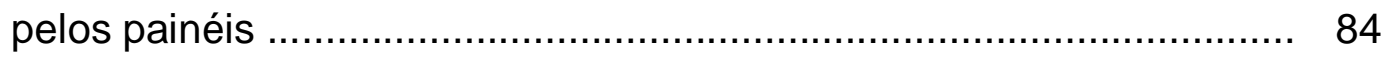

Figura 5.1. Sistema proposto para trabalhos futuros ........................ 88 


\section{Lista de tabelas}

Tabela 2.1 Características dos diversos tipos de baterias .................. 7

Tabela 2.2 Característica dos métodos de carga ............................. 15

Tabela 2.3 Rendimento dos diferentes tipos de células fotovoltaicas .... 19

Tabela 2.4 Regras do controlador fuzzy ...................................... 36

Tabela 2.5 Especificações elétricas do módulo solar KC 130TM ......... 38

Tabela 2.6 Parâmetros do modelo ajustado do conjunto fotovoltaico formado por dois módulos KC 130TM conectados em série ................ 38

Tabela 2.7 Parâmetros do conversor elevador de tensão .................... 38

Tabela 4.1 Rendimento do sistema experimental na situação 1 ........... 83

Tabela 4.2 Rendimento do sistema experimental na situação 2 .......... 83 
Siglas e abreviaturas

$\begin{array}{ll}\text { A/D } & \text { Conversor analógico para digital } \\ \text { CC } & \text { Corrente contínua } \\ \text { CA } & \text { Corrente alternada } \\ \text { DSP } & \text { Digital signal processor } \\ \text { FA } & \text { Fonte alternativa } \\ \text { GD } & \text { Geração distribuida } \\ \text { MPPT } & \text { Maximum power point tracking } \\ \text { P\&O } & \text { Perturbação e observação } \\ \text { PWM } & \text { Pulse width modulation } \\ \text { RNA } & \text { Rede neural artificial } \\ \text { SOC } & \text { State of Charge - Estado de Carga } \\ \text { PV } & \text { Painel fotovoltaico }\end{array}$




\section{Lista de símbolos por ordem de aparição}

\begin{tabular}{|c|c|c|}
\hline C & Capacidade da bateria & [Ah] \\
\hline$t_{o}$ & Instante inicial a carga da bateria & [s] \\
\hline$Q\left(t_{0}\right)$ & Carga da bateria no instante inicial & [Ah] \\
\hline$i$ & Corrente de carga da bateria & {$[\mathrm{A}]$} \\
\hline$\alpha_{\text {carga }}$ & Constante de rendimento de carga & {$[\%]$} \\
\hline$V_{s t}$ & Tensão de sobre tensão & [V] \\
\hline$V_{f}$ & Tensão de flutuação & [V] \\
\hline$V_{\min }$ & Tensão mínima de trabalho & [V] \\
\hline$I_{\min }$ & Corrente mínima de carga & [A] \\
\hline$I_{\max }$ & Corrente máxima de carga & {$[\mathrm{A}]$} \\
\hline$I_{\text {flut }}$ & Corrente de flutuação & {$[\mathrm{A}]$} \\
\hline$D_{1}$ & Diodo de recombinação de portadoras & \\
\hline$D_{2}$ & Diodo de recombinação de portadoras & \\
\hline G & Irradiação solar incidente & {$\left[\mathrm{w} / \mathrm{m}^{2}\right]$} \\
\hline$I_{p v}$ & Corrente induzida pela luz & {$[\mathrm{A}]$} \\
\hline$R_{p}$ & Resistência paralela equivalente do painel & {$[\Omega]$} \\
\hline$R_{S}$ & Resistência série equivalente do painel & [ $\Omega]$ \\
\hline$V_{t}$ & Tensão térmica do painel & [V] \\
\hline$I_{0}$ & Corrente de saturação dos diodos & {$[A]$} \\
\hline$a$ & Fator de idealidade do diodo & \\
\hline I & Corrente de saída do painel & {$[\mathrm{A}]$} \\
\hline$N_{s}$ & Número de células fotovoltaicas em série & \\
\hline$k$ & Constante de Boltzmann & {$\left[1.3806503 \times 10^{-23} \mathrm{j} / \mathrm{K}\right]$} \\
\hline$T$ & Temperatura do painel & {$[\mathrm{K}]$} \\
\hline$q$ & Carga do elétron & {$\left[1.60217646 \times 10^{-19} \mathrm{C}\right]$} \\
\hline$\alpha$ & Relação de transformação & \\
\hline$V_{e q}$ & Tensão do circuito equivalente do painel & {$[\mathrm{V}]$} \\
\hline$R_{e q}$ & Resistência equivalente do painel & {$[\Omega]$} \\
\hline$V_{c c}$ & Tensão no capacitor do barramento CC & [V] \\
\hline$V_{\text {bat }}$ & Tensão da bateria & [V] \\
\hline$L$ & Indutância do conversor Buck-Boost & {$[\mathrm{H}]$} \\
\hline$r_{L}$ & Resistência da indutância $L$ & {$[\Omega]$} \\
\hline$C_{1}$ & Capacitância do conversor na baixa tensão & {$[\mathrm{F}]$} \\
\hline$C_{2}$ & Capacitância do conversor na alta tensão & {$[\mathrm{F}]$} \\
\hline$H_{v}$ & Ganho do sensor de tensão & \\
\hline$H_{i}$ & Ganho do sensor de corrente & \\
\hline$d$ & Ciclo de trabalho do conversor & \\
\hline$r_{o n}$ & Resistência de condução da chave & {$[\Omega]$} \\
\hline$I_{L}$ & Corrente da indutância & {$[\mathrm{A}]$} \\
\hline$V_{c}$ & Tensão na capacitância & [V] \\
\hline$R_{c h}$ & Carga do circuito & [ $\Omega$ ] \\
\hline$I_{m p}$ & Corrente de máxima potência & {$[\mathrm{A}]$} \\
\hline$V_{m p}$ & Tensão de máxima potência & [V] \\
\hline
\end{tabular}




\section{1- Introdução}

\subsection{Motivação do trabalho}

Com a 1ำ revolução industrial e a descoberta do carvão que proporcionou o desenvolvimento das máquinas a vapor e, posteriormente, a utilização de petróleo, foi possível obter um rápido desenvolvimento tecnológico. Tal fato gerou uma total dependência de combustíveis fósseis por parte da sociedade de forma que a mesma não poderia mais se privar deles. Com o passar dos anos, a evolução tecnológica e o desenvolvimento das sociedades, novas formas de fontes de energia estão sendo buscadas como solução para os constates problemas mundiais de produção de bens de consumo (produção de eletricidade), o que resultou em investimento e esforço no desenvolvimento de fontes alternativas de energia (MOÇAMBIQUE, 2012).

Como resumo dessa análise, a Figura 1.1 descreve a distribuição global da energia produzida pelas principais fontes. Entretanto, com o atual panorama de aquecimento global, o esforço para reduzir tal dependência vem aumentando, gradativamente, em busca de novas fontes de energia limpa, revelando indícios de uma nova reestruturação.

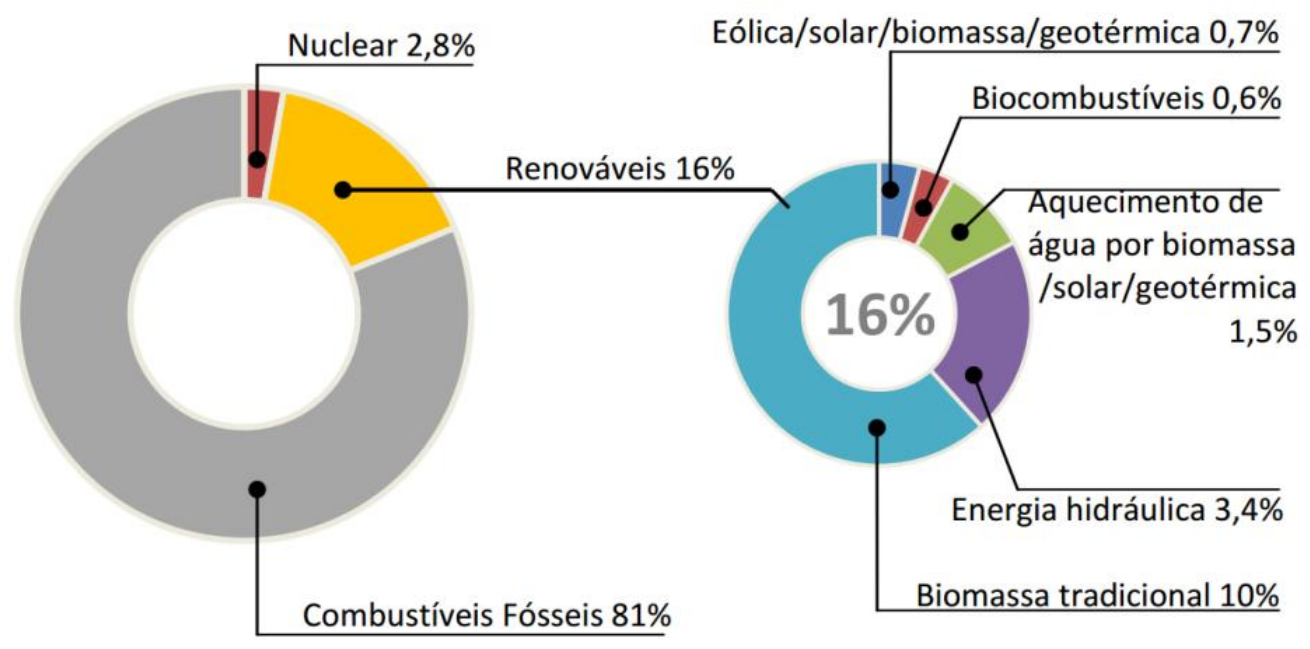

Figura 1.1 - Distribuição das fontes primárias de energia (REN21, 2011). 
Existem diversas tecnologias para a produção de eletricidade via fontes de energia alternativa, dentre elas é possível citar a geração por meio de centrais hidrelétrica, marés, turbinas eólicas, célula de combustível, painéis fotovoltaicos etc. Cada uma com suas particularidades, nichos de aplicação e limitações de funcionamento. Porém a geração de energia através de painéis fotovoltaicos tem se destacado, apresentando um crescimento elevado se comparado às outras fontes de energia, como pode ser visto pela Figura 1.2. Este crescimento se deve em grande parte a redução significativa dos custos de produção da energia solar, que estão na faixa de 4 USD/W a 6 USD/W com tendência de queda (MOÇAMBIQUE, 2012). Outro fator que impulsiona o crescimento da produção da energia solar é a disponibilidade e abundância do combustível, o sol. Na Figura 1.3 é possível observar a quantidade de energia solar incidente sobre a terra em comparação com as reservas dos demais combustíveis utilizados atualmente.

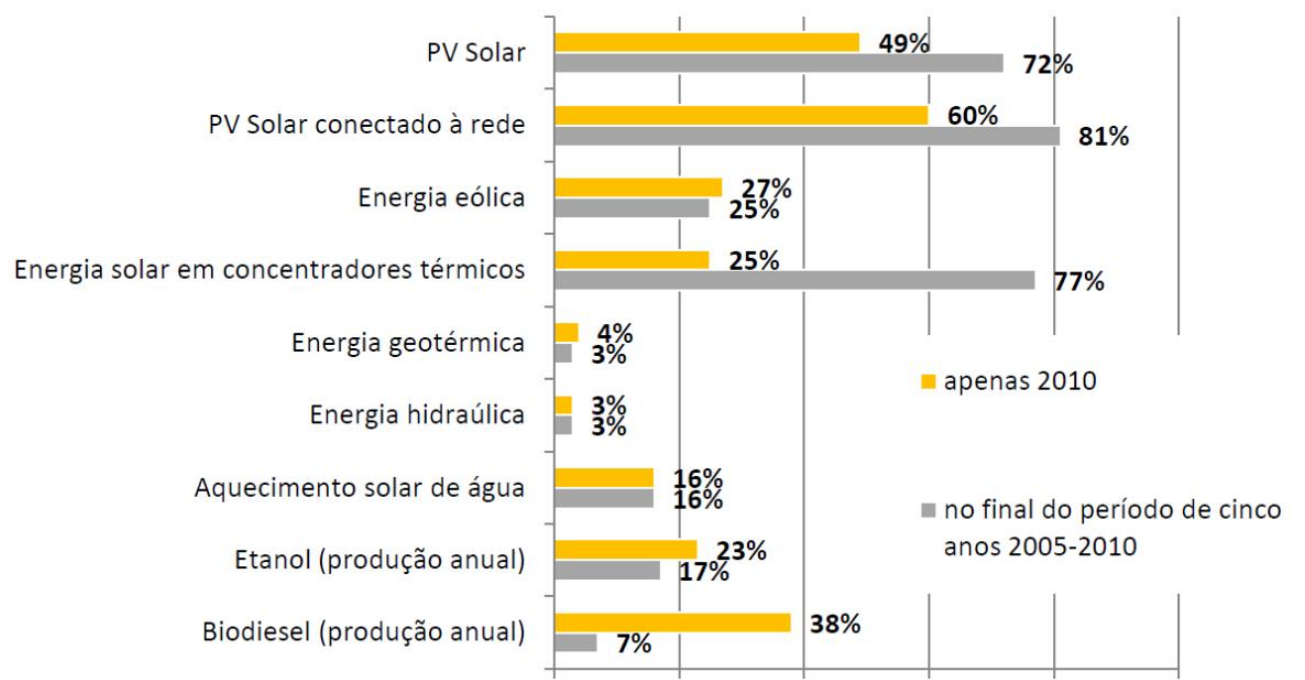

Figura 1.2 - Crescimento das fontes alternativas (REN21, 2011).

Outra vantagem clara da energia solar em relação às outras formas de produção de eletricidade, é que tais sistemas podem ser construídos em pequenos módulos, ou seja, não há a necessidade de criar grandes usinas ou uso de grandes áreas alagadas como no caso de usinas hidrelétricas. 


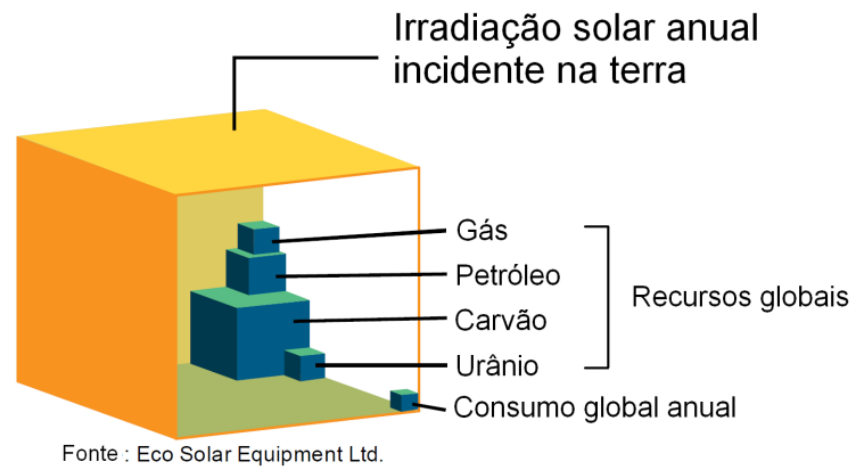

Figura 1.3 - Comparação entre as reservas de combustíveis fósseis atuais e o potencial de geração de energia a partir do sol (EPIA, 2008).

Entretanto, a energia solar não é uma energia que está disponível durante todo o dia, Figura 1.4, que mostra a incidência solar média em um dia, além disso, o período do dia no qual sua utilização é necessária é, justamente, durante o horário de pico de demanda que ocorre das 18 horas às 21 horas. Porém, é nesse período do dia que a energia solar gerada é quase nula. Logo, um sistema de armazenamento se torna imprescindível fazendo com que se possa armazenar o excesso de energia durante o pico de geração para suprir a demanda durante o pico do consumo (CÂNDIDO, 2010).

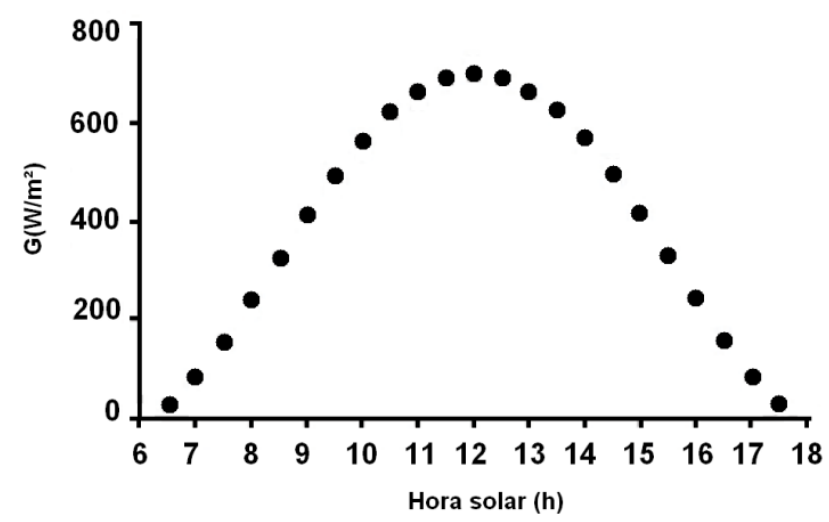

Figura 1.4 - Irradiação solar durante um dia, onde os picos de irradiação ocorrem entre 11 e 13 horas (SOUZA, SILVA e CEBALLOS, 2008).

$\mathrm{Na}$ literatura são encontrados sistemas de armazenamento através de banco de baterias e/ou armazenamento com ultra capacitores (FAKHAM, LU e FRANCOIS, 2011). O sistema de baterias apresenta uma densidade de energia maior, da ordem de algumas dezenas de $\mathrm{Wh} / \mathrm{kg}$ enquanto que os ultra capacitores possuem densidade de alguns Wh/kg (BURKE, 2007), além de vantagens econômicas em relação aos ultra capacitores, que possuem elevado custo (milhares de dólares). 
Entretanto, devido à alta densidade de potência dos ultra capacitores, estes podem entregar uma corrente muito mais elevada que as bateria (BURKE, 2007), cujas correntes elevadas reduzem a vida útil e aumentam as perdas.

Em geração distribuída, sistemas de armazenamento se tornam uma ferramenta extremamente importante em um cenário no qual as tarifas energéticas são determinadas pelo horário assim, pode-se maximizar os ganhos econômicos armazenando a maior quantidade possível de energia em horários em que a tarifa é reduzida, sendo esta energia vendida em horário de ponta, quando a tarifa possui maior valor agregado.

A Figura 1.5 representa o sistema estudado nesta dissertação, sendo formado por um conjunto de painéis fotovoltaicos acoplados a um banco de baterias através de um barramento $\mathrm{CC}$ comum e conectado a rede de distribuição através de um inversor. Para o gerenciamento da energia gerada pelos painéis, o sistema de armazenamento é controlado por um conversor CC-CC bidirecional, com capacidade de controlar tanto a carga quanto a descarga do banco a qualquer momento. A conexão com a rede funciona como uma rota de fuga para a energia disponível, dando a capacidade ao sistema de armazenar a energia gerada nos painéis e injetála na rede em momentos economicamente viáveis.

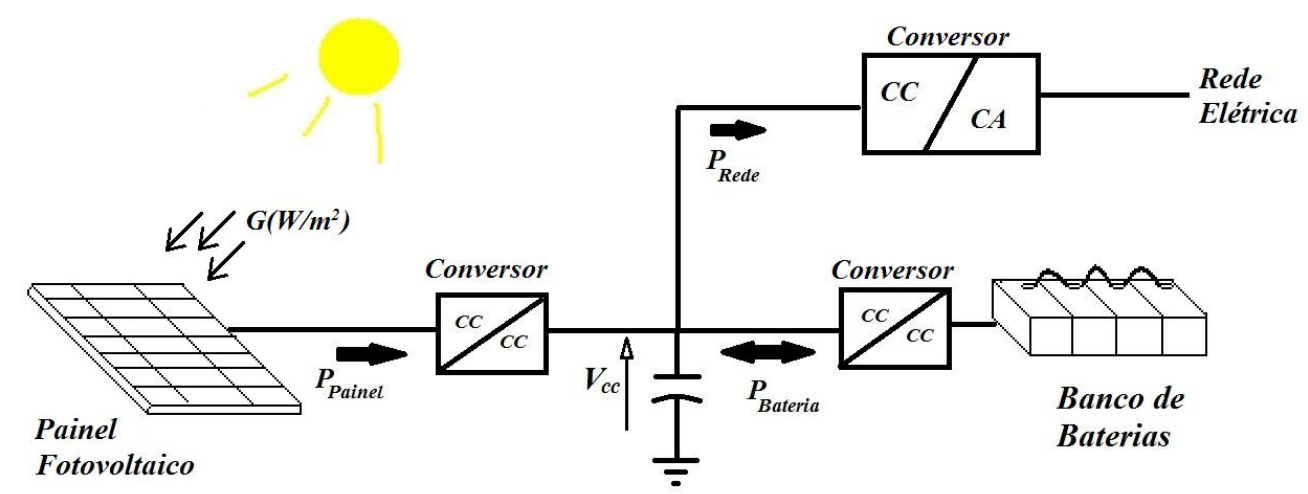

Figura 1.5 - Fluxo de potência do sistema, onde a potência da bateria pode ser positiva ou negativa.

As equações do balanço de potência do sistema são apresentadas a seguir, e relacionam as potências geradas ou drenadas com a estabilidade da tensão $V_{c c}$ do barramento CC. 


$$
\begin{gathered}
P_{\text {painel }}=\text { Dependente da irradiação } G\left(\mathrm{~W} / \mathrm{m}^{2}\right) \\
P_{\text {Painel }}=P_{\text {bateria }}+P_{\text {rede }} \\
P_{\text {painel }}=V_{c c}\left(I_{\text {bateria }}+I_{\text {rede }}\right)
\end{gathered}
$$

Em um sistema no qual a corrente de carga ou descarga das baterias $\left(I_{\text {bateria }}\right)$ é controlada em valores fixos determinados pelo algoritmo de carga, a Equação (2) nos diz que se deve controlar a corrente injetada para a rede elétrica de modo a equilibrar a potência gerada $\left(P_{\text {painel }}\right)$ a energia consumida pelo sistema, para que a tensão $V_{c c}$ se mantenha estável em um valor fixo definido (CÂNDIDO, 2010). Afundamentos na tensão $V_{c c}$ são decorrentes de um consumo $\left(P_{\text {bateria }}+P_{\text {rede }}\right)$ maior que a geração, assim como sobre-tensões advém de um consumo inferior ao que é gerado, logo nota-se que o sistema deve se adaptar a todo o momento devido à inconstância na potência gerada pelo conjunto de painéis.

\subsection{Objetivos}

Este trabalho tem o objetivo desenvolver um sistema de controle que seja capaz de gerenciar a operação dos painéis fotovoltaicos e das baterias de chumboácido junto ao ponto de máxima potência gerada e máxima eficiência, respectivamente, além do controle da tensão do barramento CC através do fluxo de potência do sistema.

Objetivos específicos:

> Implementar algoritmos por perturbação e observação (P\&O) para a busca do ponto de máxima potência (MPPT);

> Minimizar as oscilações sobre a tensão do barramento CC, independentemente, do modo de operação do sistema de carga e descarga das baterias;

$>$ Projetar controladores fuzzy de forma a melhorar a resposta dinâmica dos conversores CC-CC utilizados como interface nas baterias e nos painéis fotovoltaicos. 


\subsection{Organização do texto}

- Capítulo 2- Aspectos Gerais, nos quais serão apresentados os modelos e análises do sistema, caracterização do sistema, análise do fluxo de potência do sistema e projeto dos controladores.

- Capítulo 3 - Estudo de casos, neste capítulo serão apresentadas as simulações dos modelos da bateria, painel fotovoltaico e controladores do sistema, com intuito de verificar o desempenho dos mesmos para diversas situações de teste.

- Capítulo 4 - Execução, nesse capítulo será apresentada a proposta de execução do protótipo, os materiais e métodos utilizados.

- Capítulo 5 - Conclusões gerais e sugestões para trabalhos futuros. 


\section{Aspectos gerais}

\subsection{Baterias}

A tabela 2.1 mostra uma rápida comparação entre os tipos mais comuns de baterias presentes no mercado, destacando os principais atributos de desempenho e operacionais de cada uma.

Tabela 2.1 - Características dos diversos tipos de baterias (CÂNDIDO, 2010).

\begin{tabular}{|c|c|c|c|c|}
\hline & Chumbo-ácido & Ni-Cad & NiMh & Lithium-ion \\
\hline Custo inicial & Baixo & Médio & Médio & Baixo \\
\hline Custo a longo prazo & Alto & Médio & Médio & Baixo \\
\hline Segurança & Boa & Boa & Boa & Boa \\
\hline Impacto ambiental & Alto & Alto & Médio/Alto & Médio/Baixo \\
\hline Ciclos & $200^{*}$ & 250 & $400-500$ & $400-600$ \\
\hline Tensão nominal (V) & 2 & 1.2 & 1.2 & 3.4 \\
\hline $\begin{array}{c}\text { Densidade de } \\
\text { energia }(\mathrm{Wh} / \mathrm{Kg})\end{array}$ & 35 & 41 & 80 & 120 \\
\hline $\begin{array}{c}\text { Densidade de } \\
\text { energia volumétrica } \\
\left(\mathrm{Wh} / \mathrm{m}^{3}\right)\end{array}$ & 80 & 120 & 200 & 280 \\
\hline $\begin{array}{c}\text { Autodescarga por } \\
\text { mês (\%) }\end{array}$ & $<5$ & $<10$ & $<20$ & $<5$ \\
\hline Efeito memória & Não & Sim & Pouco & Não \\
\hline $\begin{array}{l}\text { Temperatura de } \\
\text { operação }\left({ }^{\circ} \mathrm{C}\right)\end{array}$ & $-15^{\circ} a+50^{\circ}$ & $-20^{\circ} a+50^{\circ}$ & $-20 \div a+60 \circ$ & $-20^{\circ} a+60^{\circ}$ \\
\hline Peso & Pesada & Leve & Leve & Muito leve \\
\hline Tempo de carga & Longo & Médio & Médio & Curto \\
\hline
\end{tabular}

* dependente da profundidade da descarga

As discussões nessa dissertação serão restritas às baterias de chumbo-ácido, pois as mesmas serão utilizadas no projeto devido a seu baixo custo inicial, robustez e adequação ao sistema.

\subsubsection{Visão geral}

A bateria de chumbo-ácido foi inventada em 1860 pelo francês Gastón Planté e desde que sua utilização se difundiu no início do século 20, poucas foram as 
alterações em sua composição, que é constituída, basicamente, de chumbo e ácido sulfúrico.

A bateria é um elemento que armazena energia elétrica na forma eletroquímica. Uma bateria não produz energia, somente armazena (COELHO, 2001). Em baterias recarregáveis, o processo de carga e descarga pode ser repetido por algumas centenas de vezes, nos quais para uma bateria de chumbo-ácido o número de ciclos de carga e descarga é inversamente proporcional à profundidade da descarga, ou seja, o quanto a bateria é descarregada antes de ser carregada novamente (Figura 2.1). A situação de operação mais danosa para uma bateria de chumbo-ácido é quando a mesma opera sob temperaturas elevadas, o que reduz sua vida útil (Figura 2.2) e aumenta sua capacidade de armazenamento (Figura 2.3) (MOURA, 2011; YUASA, 1999).

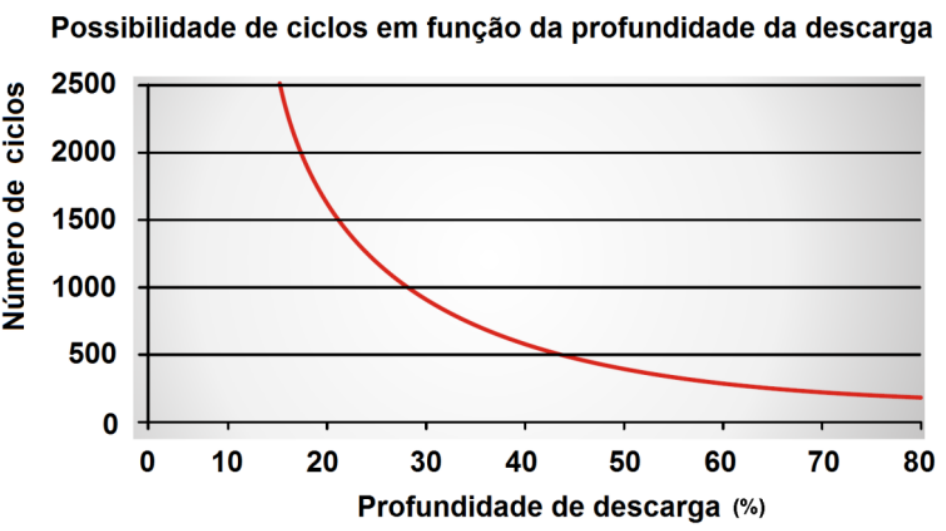

Figura 2.1 - Desgaste de uma bateria de chumbo-ácido em função da profundidade da carga (MOURA, 2011).

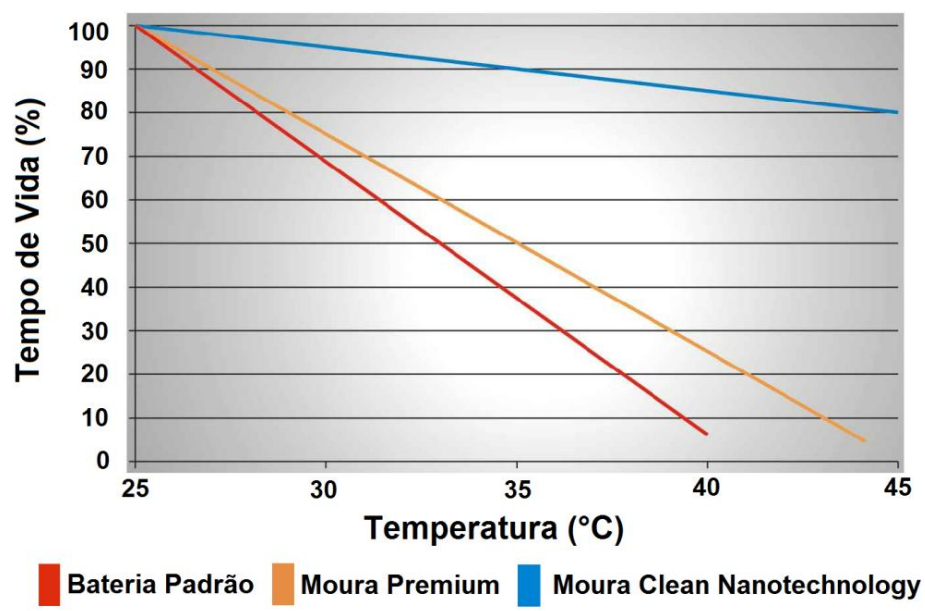

Figura 2.2 - Efeito da temperatura na vida útil da bateria de chumbo-ácido (MOURA, 2011). 


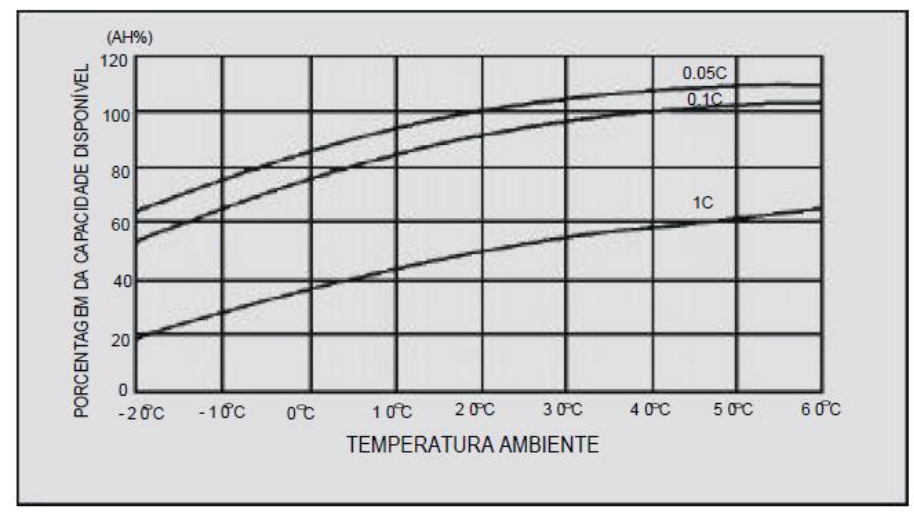

Figura 2.3- Efeito da temperatura na capacidade disponível (YUASA, 1999).

Até recentemente, o foco dos fabricantes era a redução do custo de produção em vez do aumento do desempenho, pois suas aplicações eram limitadas a sistemas de ignição de automóveis. Atualmente, o surgimento de novas tecnologias de baterias de chumbo-ácido vem crescendo para atender a nova gama de aplicações como: baterias para sistemas fotovoltaicos isolados da rede, sistemas de energia emergencial, sistemas de telecomunicação e etc.

Entretanto, as baterias de chumbo-ácido apresentam algumas desvantagens, tais como a dificuldade de determinar com precisão o SOC (State of Charge ou estado de carga, que é a quantidade de carga presente na bateria em relação a carga máxima), principalmente com o sistema em funcionamento (com carga ou descarga em andamento) e a baixa densidade de energia em relação aos outros tipos de bateria. Por outro lado, a durabilidade de uma bateria de chumbo-ácido é relativa, uma vez que a mesma depende do regime de carga e descarga e da temperatura de operação (COELHO, 2001).

As baterias não são $100 \%$ eficientes, sendo este rendimento proporcional à corrente drenada ou injetada, pois uma parte da energia é perdida na forma de calor nas resistências parasitas (internas à bateria). $\mathrm{O}$ rendimento típico de uma bateria de chumbo-ácido é de $85 \%$ e de uma bateria de níquel-cádmio de 65\% (COELHO, 2001). 


\subsubsection{Aspectos construtivos}

A principal diferença construtiva em relação às baterias reside no tipo de meio no qual as placas estão imersas, uma vez que existem baterias cujo meio é sólido, líquido ou gel (COELHO, 2001).

Baterias de gel contêm um ácido que é obtido através da adição de sílica gel, tornando o meio no qual as reações químicas são realizadas gelatinoso. Esta característica é vantajosa no que diz respeito à segurança, pois torna quase improvável o derramamento do ácido em caso de acidentes. Entretanto, ela possui a desvantagem de ser pouco tolerante a altas correntes, as quais produzem a formação de gases e podem danificá-las (COELHO, 2001).

Por outro lado, as baterias em meio sólido possuem os eletrodos imersos em material semelhante à lã de vidro, entretanto suas características são semelhantes às baterias de gel, ou seja, são pouco tolerantes a correntes elevadas e, por conseguinte, a altas temperaturas (COELHO, 2001).

Já as baterias de meio líquido possuem pequenas válvulas que têm como função a regulação da pressão interna, que se altera devido à formação de gases. Caso sejam recarregadas constantemente, a quantidade de água se reduz devido ao aquecimento, bem como sua vida útil (COELHO, 2001).

\subsubsection{Características elétricas}

Uma bateria típica de chumbo-ácido fornece em seus terminais aproximadamente 2,14 $\mathrm{V}$ por célula se, completamente, carregada (AYLOR, THIEME e JOHNSO, 1992), porém se não utilizada por algum tempo sua capacidade é reduzida devido à auto descarga. Assim uma tensão de flutuação deve ser imposta nos terminais da bateria quando a mesma não está em operação, valor este em torno de 2,2 V por célula (COELHO, 2001).

Por outro lado, um dos parâmetros mais importantes para avaliar uma bateria é o SOC, ele informa quanto de carga existe, o que evita sobrecargas ou descarregamentos excessivos, além disso, através desse parâmetro é possível o gerenciamento do processo de carga e descarga com mais precisão. O SOC pode ser determinado medindo-se as tensões em circuito aberto nos terminais das baterias (no caso de baterias chumbo-ácido) ou através da medição da acidez do 
eletrólito o que é muito difícil, pois as baterias são seladas (NG, MOO, et al., 2008). A tensão de circuito aberto de uma bateria de chumbo-ácido quando está completamente carregada, está em torno de 2,12 a 2,15 V por célula ou 12,7 a 12,9 $\mathrm{V}$ por bateria. A $50 \%$ de carga ela possui $2,03 \mathrm{~V}$ por célula e 1,95 $\mathrm{V}$ quando, totalmente, descarregada ( $0 \%$ de carga) (COELHO, 2001), ver Figura 2.4 .

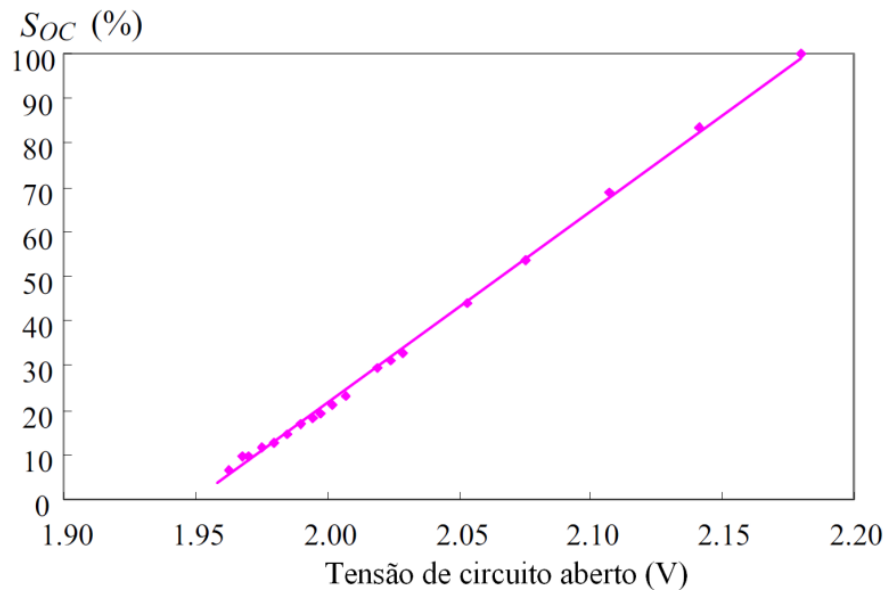

Figura 2.4- Estado de carga $x$ tensão de circuito aberto para uma bateria de chumbo-ácido (NG, MOO, et al., 2008).

Outro parâmetro indispensável para a estimação do SOC é o tempo de descanso ao qual a bateria deve ser submetida antes de ser realizada a medição da tensão terminal, pois assim que ela é desconectada do circuito de carga a tensão tende a se estabilizar, entretanto, esta estabilização depende de um equilíbrio químico interno que não é instantâneo, como pode ser visto na Figura 2.5. O tempo de descanso está em torno de $2 \mathrm{~h}$ para uma bateria de chumbo-ácido e a partir deste tempo a queda de tensão pode ser considerada como tensão de autodescarga (NG, MOO, et al., 2008). 


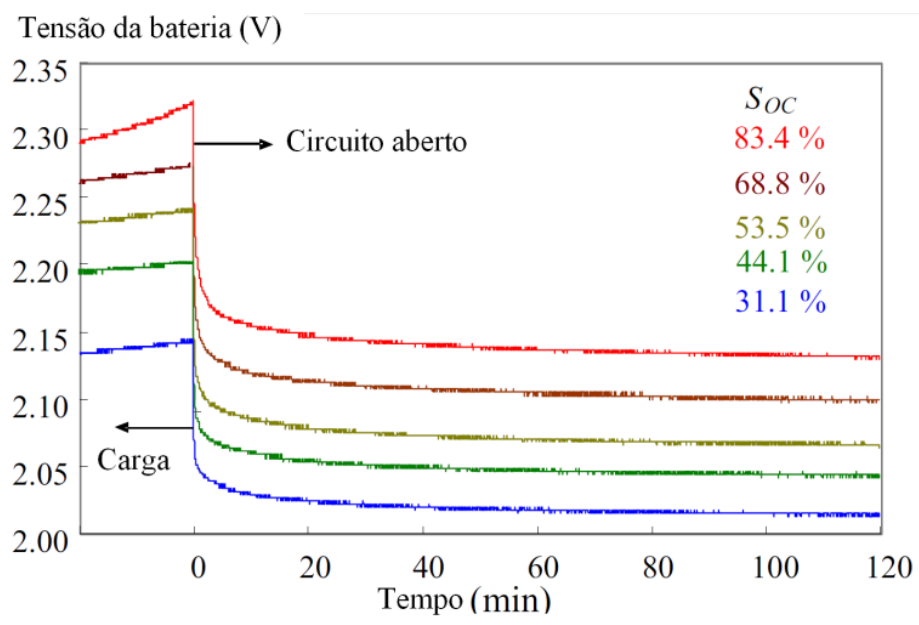

Figura 2.5 - Tempo de estabilização (NG, MOO, et al., 2008).

A tensão terminal dinâmica, que é medida nos terminais da bateria durante 0 processo de carga ou descarga, não pode ser utilizada como parâmetro para medição do SOC, pois ela varia proporcionalmente à corrente injetada ou drenada, ou seja, quanto maior à corrente drenada mais rápido a tensão decresce (Figura 2.6) (NG, MOO, et al., 2008; DEEPTI e RAMANARAYANAN, 2006).

Logo, durante o processo de carga ou descarga a tensão nos terminais da bateria não fornece subsídios para determinar o SOC, servindo apenas de limitante (NG, MOO, et al., 2008). Além disso, a tensão terminal não pode ultrapassar certos patamares para que a vida útil não seja comprometida, desta forma, é indispensável uma metodologia para estimar o SOC durante o processo de carga ou descarga (que será chamado de SOC interativo).

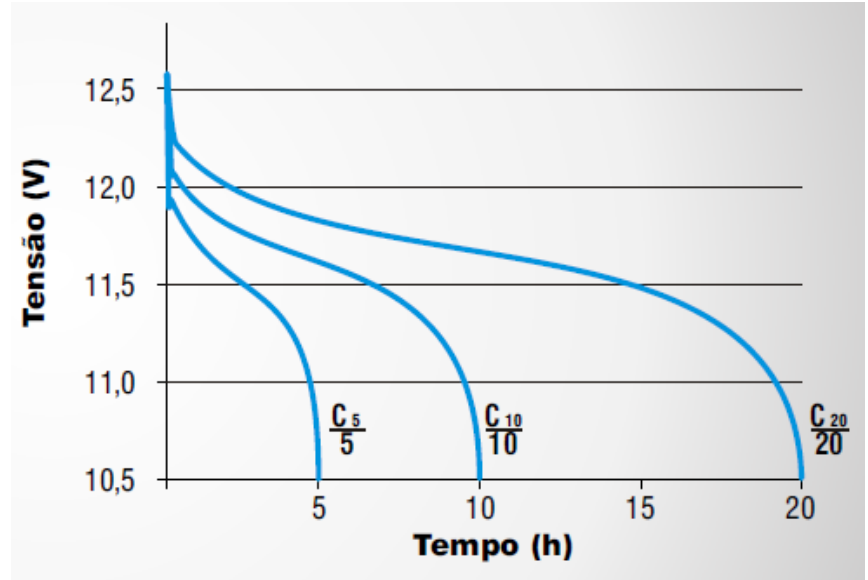

Figura 2.6-Tensão dinâmica da bateria durante descarga, C/20 representa descarga em regime de 20 horas (MOURA, 2011). 


\subsubsection{Estado de carga interativo (SOC interativo)}

Visto que a tensão terminal em circuito aberto pode fornecer o SOC para uma bateria em repouso e que a tensão terminal instantânea não fornece tais informações sobre o SOC para bateria de chumbo-ácido, a solução para a estimação do SOC interativo reside em um método misto que utiliza a tensão terminal de circuito aberto, juntamente com um método de integração da corrente injetada ou drenada da bateria (DEEPTI e RAMANARAYANAN, 2006). O método pode ser resumido pela equação (3) a seguir.

$$
\operatorname{SOC}(t)=\frac{Q\left(t_{0}\right)+\int_{t_{0}}^{t} i(t) d t}{\text { Capacidade Máxima }} 100 \%
$$

Onde $Q\left(t_{0}\right)$ representa o estado inicial, definido pela tensão de circuito aberto da bateria no instante inicial. A capacidade máxima é expressa em "Ah" e é uma característica própria de cada bateria. A integral representa toda a energia que flui para dentro ou para fora da bateria. Logo, o método se baseia em determinar o ponto inicial no qual a bateria se encontra e incrementar ou decrementar toda energia que flui através dela. Entretanto, este método não leva em consideração as perdas inerentes à bateria, assim o mesmo pode ser melhorado adicionando-se uma constante de perdas à integral, fazendo com que a equação (3) resulte na equação (4) (DEEPTI e RAMANARAYANAN, 2006).

$$
\operatorname{SOC}(t)=\frac{Q\left(t_{0}\right)+\int_{t_{0}}^{t} \alpha_{\text {carga }} \cdot i(t) d t}{\text { Capacidade Máxima }} 100 \%
$$

Sendo $\alpha_{\text {carga }}$ uma constante de eficiência de carga que é, inversamente proporcional à corrente, ou seja, quanto maior a corrente menor é a eficiência. Outro ponto a se destacar é o estado inicial $Q\left(t_{0}\right)$, pois a resolução do método está ligada à identificação do ponto inicial, assim o seu cálculo merece tanta atenção quando a integração da corrente de carga (DEEPTI e RAMANARAYANAN, 2006). 
O método de estimação definido pela equação (4) não é perfeito mesmo incluído uma constante de eficiência, ou seja, ele opera, adequadamente, para pequenos intervalos de tempo, pois à medida que o tempo de integração aumenta os erros acumulados, também aumentam. Logo, é recomendado aferir o valor do SOC através da medição da tensão de circuito aberto em intervalos nos quais ocorrem paradas do processo de carga (NG, MOO, et al., 2008).

\subsubsection{Métodos de carga}

Os fatores mais importantes para a carga de uma bateria são o tempo de carga disponível e o rendimento que se deve maximizar, porém ambos estão atrelados, uma vez que uma carga mais rápida requer uma corrente mais elevada, o que resulta em um rendimento menor, com isso, ambos devem ser tratados de forma a se obter um equilíbrio. Os limitantes do processo de carga são: a tensão terminal e a temperatura, já que tensões e temperaturas elevadas danificam e reduzem a vida útil da bateria (COELHO, 2001).

Os métodos vistos na literatura são cinco: corrente e tensão constante, potência constante, corrente pulsada e métodos mistos nos quais existem estágios de alternância entre os outros métodos (COELHO, 2001; ALVAREZ, MARCOS, et al., 2003; YIFENG e LIMIN, 2010; FENT, 1994).

$\mathrm{Na}$ Tabela 2.2 são apresentadas as características dos métodos de carga, sendo o método de corrente constante é o que apresenta os melhores resultados, pois, o mesmo, injeta uma corrente controlada evitando aquecimento. Porém, a tensão deve ser gerenciada durante todo o processo para evitar que a bateria fique exposta a tensões elevadas (valores maiores que os limites máximos permitidos pelo fabricante) e se deteriore (COELHO, 2001).

Já o método de tensão constante deve ser utilizado somente para pequenos intervalos de tempo, uma vez que a corrente tende a alcançar valores elevados, o que faz com que a temperatura deva ser observada para evitar aquecimento excessivo (COELHO, 2001). 
Tabela 2.2 - Características dos métodos de carga (COELHO, 2001).

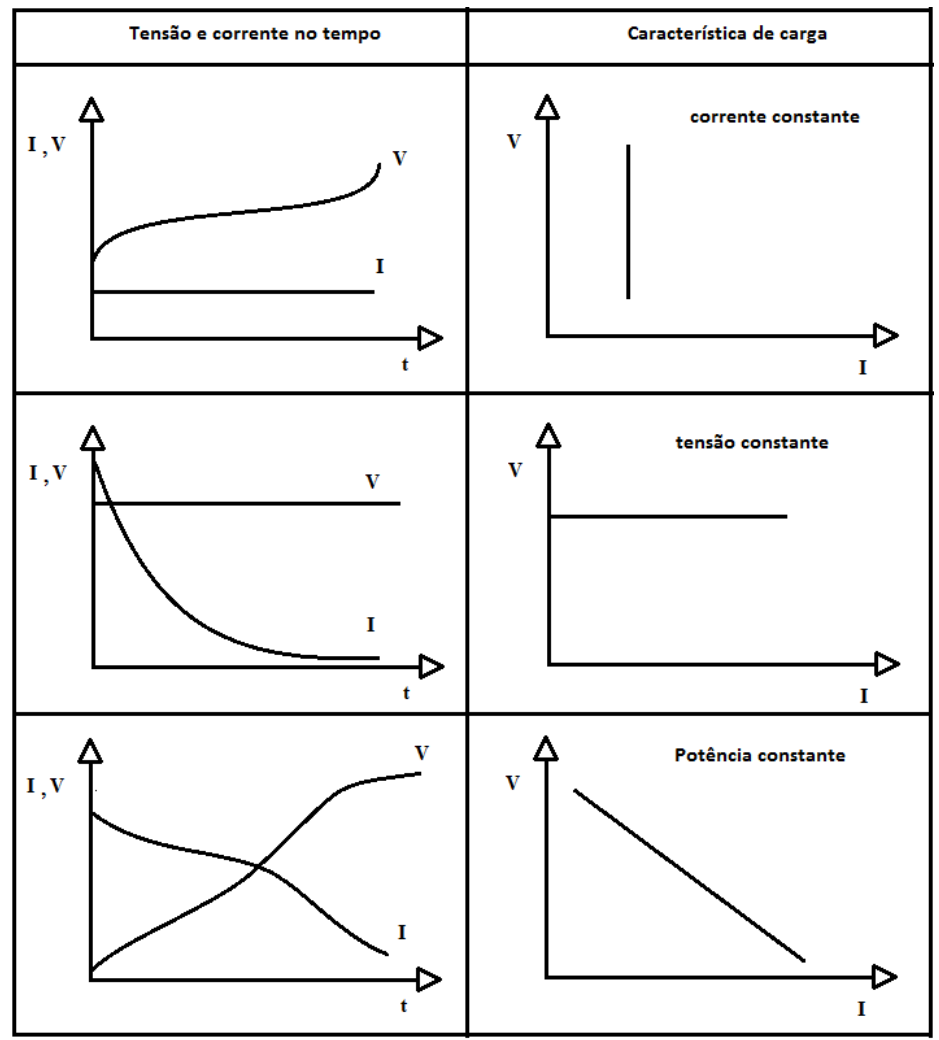

De acordo com o exposto acima, o método de potência constante deve ser utilizado somente para curtos intervalos de tempo associado à supervisão da temperatura. Entretanto, diferentemente do método de tensão constante, no qual a potência injetada diminui com o carregamento, neste método esta redução não ocorre, fazendo com que as perdas ôhmicas sejam superiores em relação ao método de tensão constante, devido à injeção de uma potência mais elevada durante todo o processo (COELHO, 2001).

Dos métodos mistos utilizados destaca-se o método a dois níveis de tensão. Este método se baseia na união das características dos métodos de corrente constante e do método de tensão constante, alternados de forma a utilizar as melhores características de cada um (COELHO, 2001; FENT, 1994), veja Figura 2.7 e Figura 2.8. 


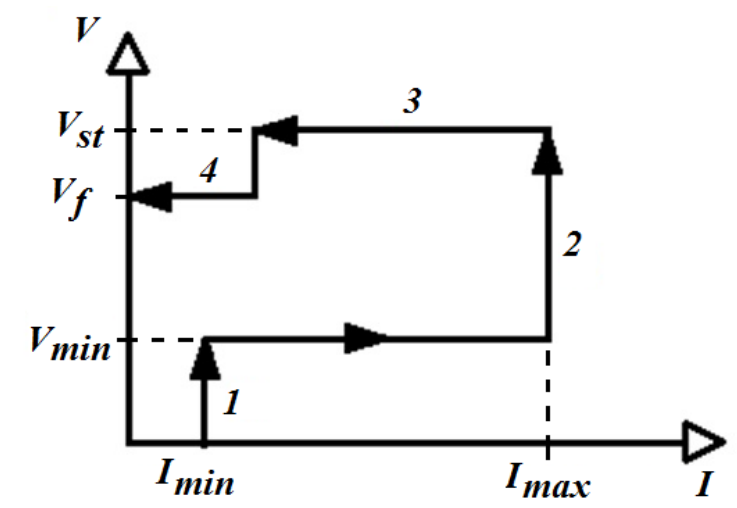

Figura 2.7 - Método a dois níveis de tensão (COELHO, 2001).

Supondo-se a bateria descarregada então é aplicado, ao primeiro estágio, uma corrente mínima controlada $I_{\text {min }}$ evitando com isso, picos de corrente e formação excessiva de gases. Esta etapa é mantida até que a bateria atinja uma tensão mínima de trabalho $V_{\min }$.

Ao ser alcançado $V_{\min }$, a bateria inicia o processo de carga na segunda etapa, injetando a corrente de carga desejada $I_{\max }$. Com a injeção de uma corrente de carga elevada, a tensão tende a subir a uma taxa proporcional à corrente, no momento em que ela atinge o valor máximo permitido pela bateria $V_{s t}$, a terceira etapa é iniciada fixando-se este valor de sobre tensão na bateria.

A terceira etapa tem a função de reduzir o tempo de carga por meio da regulação de uma sobre tensão $V_{s t}$. Como a tensão é fixa, a corrente de carga inicia um processo de queda à medida que a bateria se aproxima da carga completa.

Ao ser atingida a carga completa, inicia-se a quarta etapa que tem a função de compensar a auto descarga da bateria aplicando-se uma tensão de flutuação $V_{f}$, uma vez que a bateria está carregada e não está em operação. Após o uso da bateria, caso o processo de carga se inicie com uma carga diferente de zero, o processo necessita ser reiniciado a partir da segunda etapa.

Na Figura 2.8 é mostrada a representação do método a dois níveis de tensão. Nota-se que este método alia as melhores características do método de corrente constante e do método de tensão constante, pois limita a corrente no início do carregamento evitando aquecimento e a tensão ao final do processo não permitindo sobre tensões (FENT, 1994). Devido a essas características, este é o método aplicado no desenvolvimento deste trabalho. 


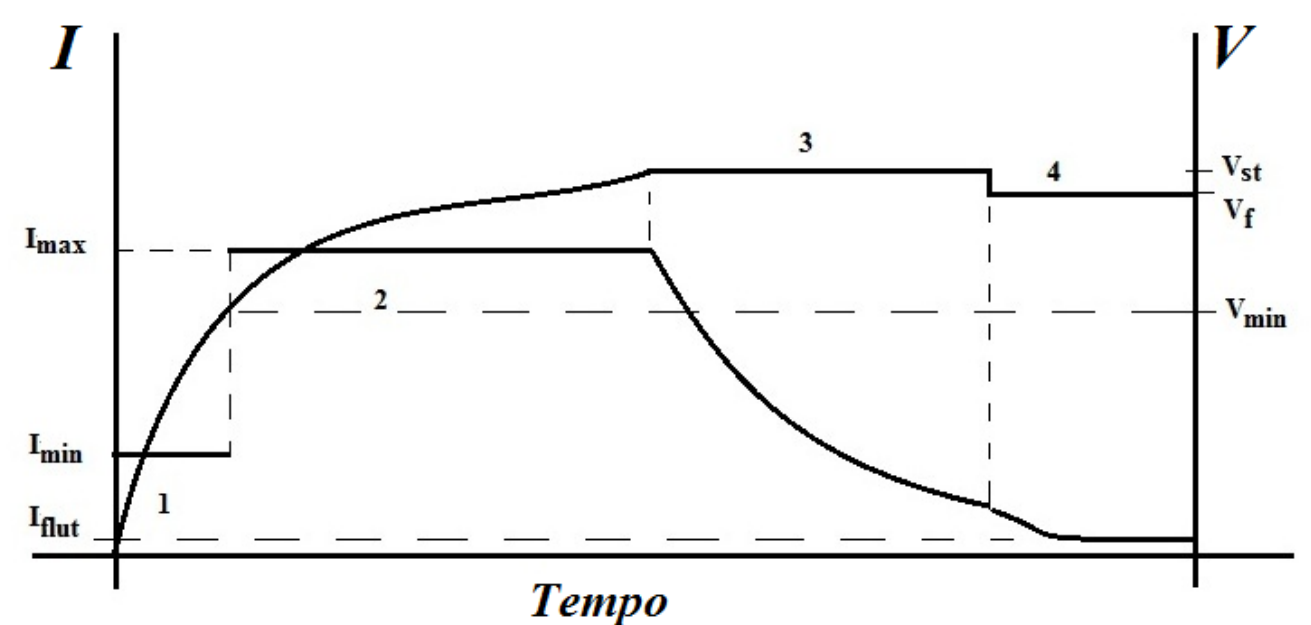

Figura 2.8 - Tensão e corrente, método dois níveis (COELHO, 2001).

\subsection{Descrição do sistema}

Nesta seção é descrito o sistema fotovoltaico, o sistema de carga e descarga das baterias quando acoplado ao painel fotovoltaico, as dificuldades deste tipo de conexão na busca do ponto de máximo utilizando o algoritmo MPPT por perturbação e observação (P\&O), além da modelagem do conversor bidirecional empregado no gerenciamento das baterias.

Os primeiros trabalhos de sistemas fotovoltaicos com potências consideráveis (acima de $10 \mathrm{~kW}$ ) conectados à rede elétrica, começaram a aparecer no início da década de oitenta e como exemplo é possível ser citado (MCCARTHY e WRIXON, 1987). Este trabalho realizado em 1987 é considerado como projeto piloto, descreve um sistema fotovoltaico de $50 \mathrm{~kW}$ de pico, montado em um propriedade rural no norte da Europa. O protótipo contava com um sistema de armazenamento com baterias de chumbo-ácido (600 Ah) e com cargas locais sendo conectado à rede elétrica através de inversores de frequência com uma estrutura muito semelhante à estrutura que é utilizada hoje em dia como em (FAKHAM, LU e FRANCOIS, 2011; SUN, ZHANG, et al., 2011) e é a estrutura adotada nesta dissertação de mestrado, Figura 1.5.

\subsubsection{Painel fotovoltaico e modelo generalizado}

O efeito fotovoltaico foi descoberto por Alexandre-Edmond Becquerel em 1839 que constatou a presença de uma diferença de potencial nos terminais de um 
semicondutor quando exposto a luz (CEPEL, 2006). Sendo que a origem deste fenômeno está embasada no efeito fotoelétrico, que ocorre quando fótons atingem a superfície de um metal com energia suficiente para permitir a liberação dos elétrons.

A célula fotovoltaica é basicamente uma junção $p-n$ de um semicondutor (normalmente de silício) que quando exposto à luz libera elétrons em torno de um circuito elétrico fechado (RODRIGUEZ e AMARATUNGA, 2007). A taxa de elétrons gerados depende do fluxo de luz incidente e da capacidade de absorção do semicondutor (VILLALVA, GAZOLI e FILHO, 2009).

Quanto à tecnologia utilizada, as células fotovoltaicas são classificadas como de primeira, segunda ou terceira geração (EPIA, 2011). Na primeira geração estão as células de silício cristalino ( $\mathrm{c}-\mathrm{Si}$ ) feitas a partir de fatias finas retiradas de um único cristal ou bloco de silício. Fazem parte deste grupo as células mono e policristalinas de silício (mc-Si e pc-Si), respectivamente. As monocristalinas são, entre todas, as células fotovoltaicas as mais eficientes, no entanto, requerem um custo maior na produção.

As células da segunda geração baseiam-se na tecnologia de filme fino (thin film), construídas através da deposição de camadas finíssimas de material fotossensível sobre um suporte de baixo custo, tais como vidro, aço inoxidável ou plástico. Dentre as mais comuns estão às células de silício amorfo $(\mathrm{a}-\mathrm{Si})$ e de telureto de cádmio (CdTe) (MOÇAMBIQUE, 2012).

Recentemente, as tecnologias da terceira geração, as quais se incluem: concentradores fotovoltaicos, células termo fotovoltaicas e células fotovoltaicas orgânicas. Os concentradores fotovoltaicos de silício ou da multijunção de outros semicondutores concentram mediante lentes a irradiação direta da luz solar para as células fotovoltaicas, necessitando de um sistema de rastreamento contínuo em relação ao sol. Por outro lado, as células termo fotovoltaicas são usadas em sistemas híbridos (térmico e elétrico), já as células fotovoltaicas orgânicas, são constituídas por cadeias de polímeros semicondutores de baixo custo, mas ainda com baixa eficiência, inferior a 10 \% (MAYER, SCULLY, et al., 2007; YUAN, WANYI, et al., 2010) (Tabela 2.3). 
Tabela - 2.3 - Rendimento dos diferentes tipos de células fotovoltaicas (EPIA, 2011).

\begin{tabular}{|c|c|c|c|c|c|c|c|}
\hline & \multicolumn{6}{|c|}{ Tecnologia } \\
\hline & & \multicolumn{2}{|c|}{ Silício Cristalino } & \multicolumn{2}{|c|}{ Filme Fino } & \multirow{2}{*}{$\begin{array}{c}\text { Concentrador } \\
\text { Multijunção }\end{array}$} & \multirow[t]{2}{*}{ Orgânica } \\
\hline \multirow{3}{*}{ 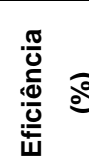 } & & $(\mathrm{mc}-\mathrm{Si})$ & (PC-Si) & (a-Si) & CdTe & & \\
\hline & Célula & $16-22$ & $14-18$ & $4-8$ & $10-11$ & $30-38$ & $<10$ \\
\hline & Módulo & $13-19$ & $11-15$ & $4-8$ & $10-11$ & $\sim 25$ & $<10$ \\
\hline
\end{tabular}

O modelo generalizado da célula fotovoltaica é baseado na natureza da junção p-n e representa com precisão as células do tipo cristalina de silício (GOW e MANNING, 1999) através de uma fonte de corrente controlada pela luz incidente $\left(I_{p v}\right)$, resistências série e shunt $\left(R_{s}\right.$ e $\left.R_{p}\right)$ e dois diodos $\left(D_{1}\right.$ e $\left.D_{2}\right)$ que representam o efeito da recombinação das portadoras (Figura 2.9). Estes cinco parâmetros do modelo generalizado variam de acordo com a temperatura e irradiação, não sendo uma relação trivial, sobretudo em relação à irradiação (ORTIZ-RIVERA e PENG, 2004). O valor de $R_{s}$ altera, principalmente, a corrente de curto circuito do painel $\left(I_{s c}\right)$, enquanto $R_{p}$ altera a tensão de circuito aberto $\left(V_{o c}\right)$ (MOÇAMBIQUE, 2012).

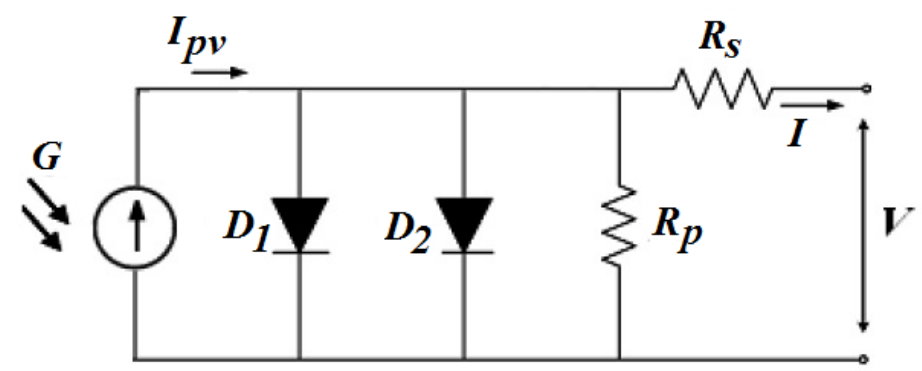

Figura 2.9 - Modelo generalizado de uma célula solar (MOÇAMBIQUE, 2012).

O modelo do painel fotovoltaico pode ser expresso pela equação (5), que é apresentada em (VILLALVA, GAZOLI e FILHO, 2009; MOCAMBIQUE, MACHADO e OLIVEIRA, 2011; VILLALVA, 2010). A equação I x V característica do módulo é não linear e implícita, ou seja, necessita de métodos iterativos para ser solucionada, entretanto todos dados necessários para sua solução estão presentes nos datasheets do fabricante (MOCAMBIQUE, MACHADO e OLIVEIRA, 2011).

$$
I=I_{p v}-I_{0}\left[\exp \left(\frac{V+R_{S} I}{V_{t} a}\right)-1\right]-\frac{V+R_{S} I}{R_{p}}
$$


$I_{p v}$ é a corrente induzida pela luz, $I_{0}$ é a corrente de saturação do diodo, a é o fator de idealidade do diodo, $R_{s}$ é a resistência série equivalente do módulo e $R_{p}$ é a resistência equivalente em paralelo do módulo, $V_{t}=N_{s} k T / q$ é a tensão térmica do painel com $N_{s}$ células conectadas em série, $k$ é a constante de Boltzmann $\left[1,3806 \times 10^{-23} \mathrm{~J} / K\right], T(K)$ é a temperatura da junção $\mathrm{p}$-n, $q$ é a carga elementar do elétron $\left[1,602176 \times 10^{-19} \mathrm{C}\right]$. A corrente $I_{p v}$ depende tanto do nível de irradiação $(G)$, quanto da temperatura $(T)$ do painel, enquanto que $I_{0}$ depende apenas de $T$ (MOÇAMBIQUE, 2012; VILLALVA, GAZOLI e FILHO, 2009).

A Figura 2.10 mostra a relação não linear entre corrente e tensão sendo que o ponto no qual a potência extraída do painel é máxima está identificado por $\Delta$. É nesse local que o algoritmo MPPT deve operar. A Figura 2.11 mostra a relação entre potência e tensão, da mesma forma que os pontos marcados indicam os pontos de máxima potência (MOÇAMBIQUE, 2012).

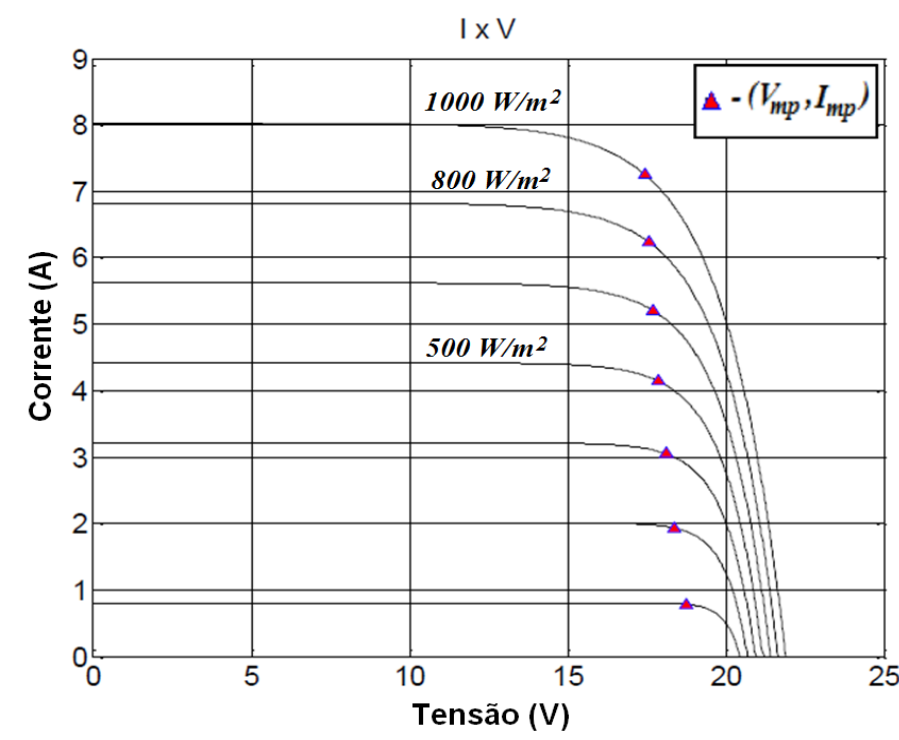

Figura 2.10 - Curva característica corrente x tensão de um módulo KC130TM, para diferentes níveis de irradiação (MOÇAMBIQUE, 2012). 


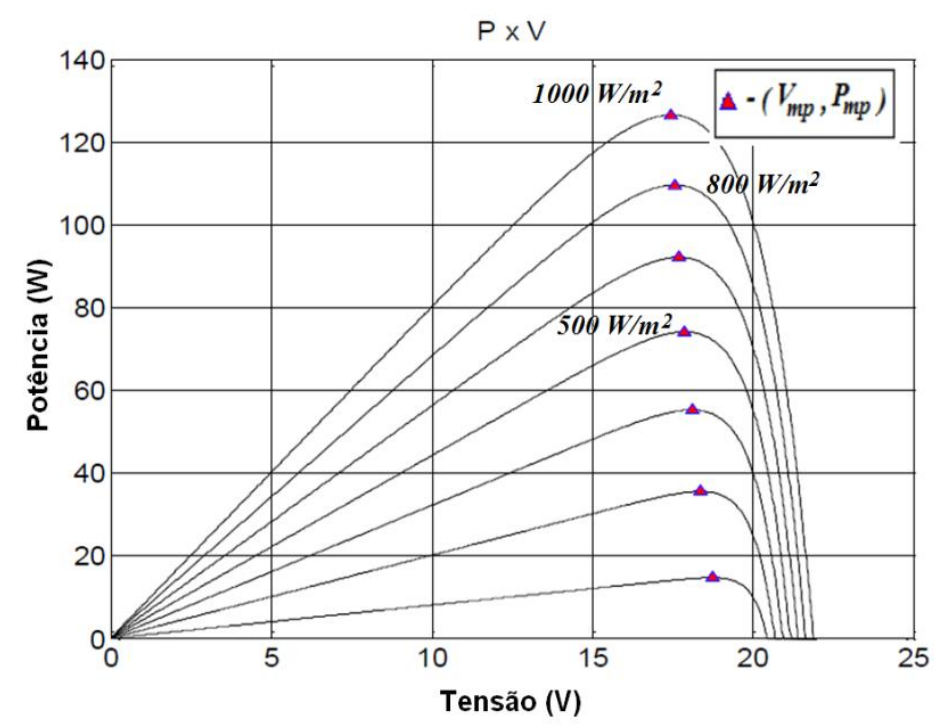

Figura 2.11 - Curva potência $x$ tensão, módulo KC130TM, para diferentes níveis de irradiação (MOÇAMBIQUE, 2012).

Logo, nota-se que manipulando a tensão terminal é possível controlar a potência de saída e o rendimento do painel. Entretanto, para modificar o valor da tensão nos terminais de um painel fotovoltaico é necessária a utilização de um circuito conversor, no qual alterando o valor da resistência equivalente vista pelo painel, varia-se assim, a tensão terminal. Na Figura 2.12, é mostrado o circuito responsável pela manipulação da tensão terminal do painel (tensão entre os pontos A e B), sendo este circuito programado para buscar a máxima potência de saída utilizando um algoritmo MPPT.

Para analisar esse circuito, é utilizada a analogia com transformadores, cuja carga é referida do secundário para o primário, dessa forma, a mesma pode ser escrita como uma função da variável $\alpha$ (relação de transformação do conversor), ou seja, controlando o ponto de operação do conversor controla-se a carga vista pelo painel, consequentemente, a tensão em seus terminais (Equação 6). Logo, em termos de teoria de circuitos, o algoritmo de busca da máxima potência MPPT trabalha de forma a igualar a impedância vista pelo painel $\left(R / \alpha^{2}\right)$ à impedância série equivalente $\left(R_{e q}\right)$ do próprio painel.

$$
V=V_{e q} \frac{\frac{R}{\alpha^{2}}}{R_{e q}+\frac{R}{\alpha^{2}}}
$$

Onde $V_{e q}$ e $R_{e q}$ são os equivalentes do circuito Thévenin do painel linearizado em torno do ponto de interesse. 


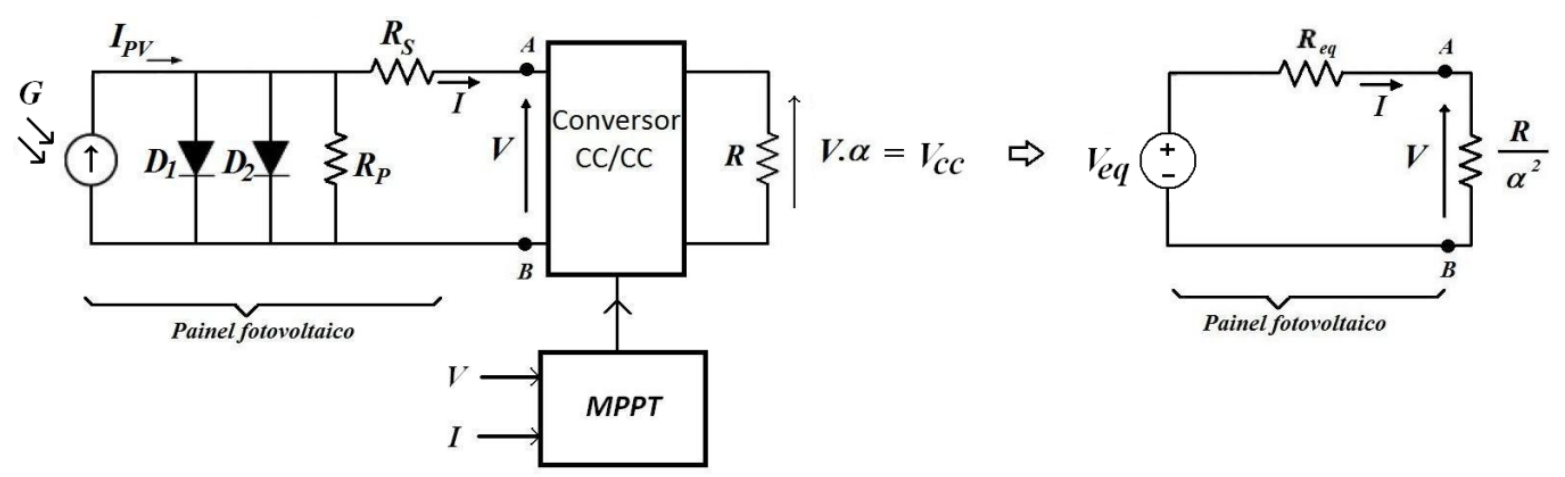

Figura 2.12 - Circuito de controle da tensão terminal e circuito equivalente com a carga do secundário referida ao primário.

\subsubsection{MPPT - P\&O}

O algoritmo MPPT por P\&O é um método de busca do ponto de máxima potência e se baseia no procedimento mostrado na Figura 2.13, podendo ser resumido da seguinte forma: a tensão nos terminais do painel é perturbada em um determinado sentido (aumentada ou reduzida) e a potência é analisada. Se ocorrer um aumento da potência o sentido da perturbação é mantido, caso contrário, o sentido da perturbação é invertido (MOÇAMBIQUE, 2012).

Esse procedimento de perturbação e observação é mantido até que o ponto de máxima potência seja alcançado. Como consequência do método $P \& O$, a potência e a tensão de saída são oscilantes em torno do ponto de máxima potência (Figura 2.14), reduzindo sua eficiência. Estas oscilações podem ser minimizadas reduzindo o tamanho do passo $(\Delta V)$, entretanto a diminuição do passo interfere diretamente no tempo de convergência do método. Como solução a essas limitações são empregados os algoritmos de passo variável, nos quais o passo é reduzido à medida que o ponto de máxima potência se aproxima (MOÇAMBIQUE, 2012; VILLALVA, 2010; FEMIA, PETRONE, et al., 2005). 


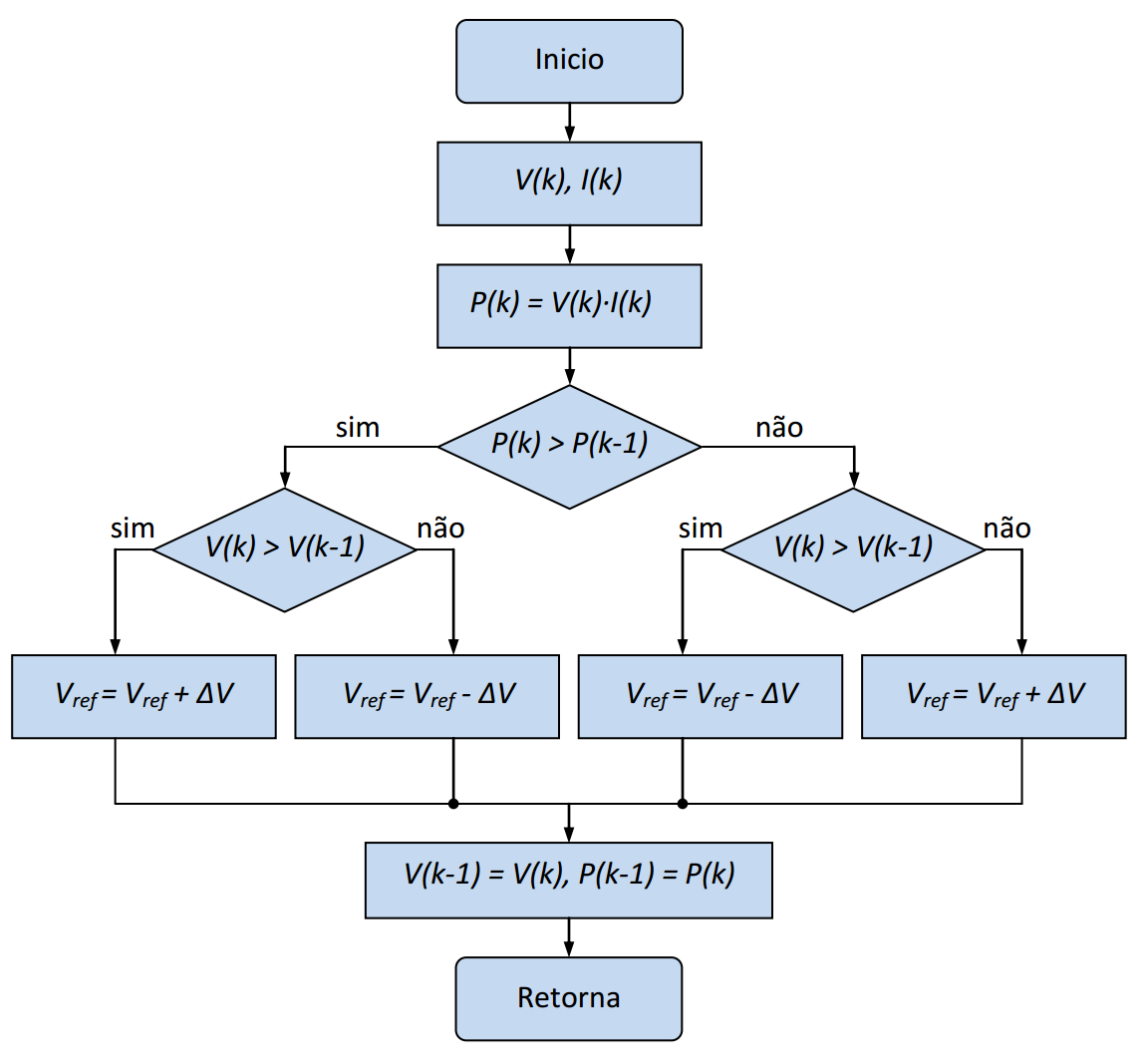

Figura 2.13 - Algoritmo MPPT por P\&O (MOÇAMBIQUE, 2012).

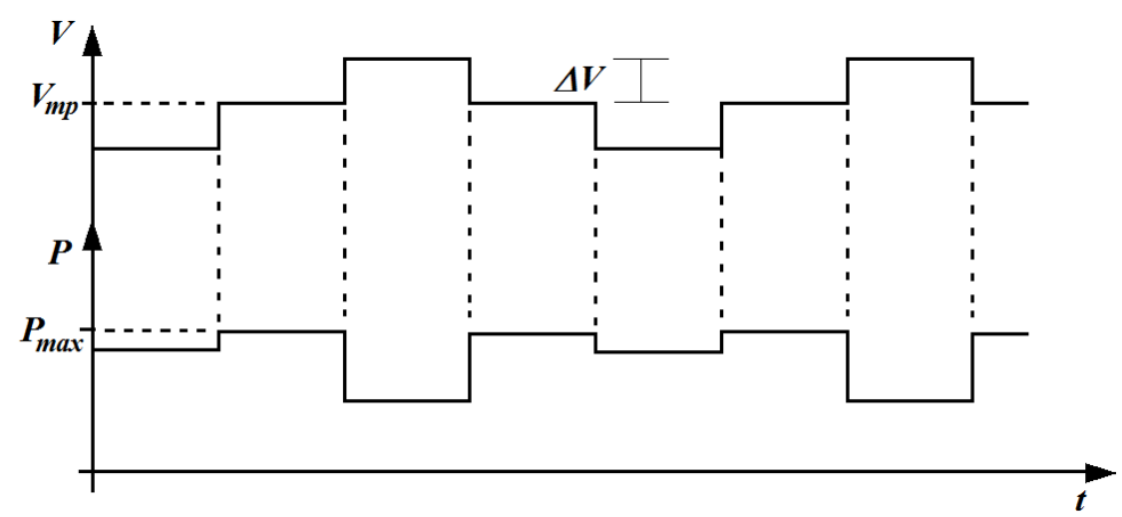

Figura 2.14 - Comportamento da tensão e da potência, durante o regime permanente utilizando algoritmo MPPT por P\&O com passo fixo.

\subsubsection{Conversor CC-CC bidirecional}

Para o sistema de gerenciamento de carga e descarga do banco de baterias, busca-se um conversor com a capacidade de se ter fluxo de potência em ambas direções, ou seja, com capacidade tanto de carregar quanto descarregar o banco de baterias. Na literatura são apresentadas algumas topologias de conversores CC-CC bidirecionais, isoladas e não isoladas, como:'Cuk bidirecional, 'Cuk isolado e o 
circuito em dupla ponte completa isolada (Dual Full-bridge) mostrados nas Figura 2.15 e Figura 2.16, respectivamente (MIURA, KAGA, et al., 2010; ABOULNAGA e EMADI, 2004).
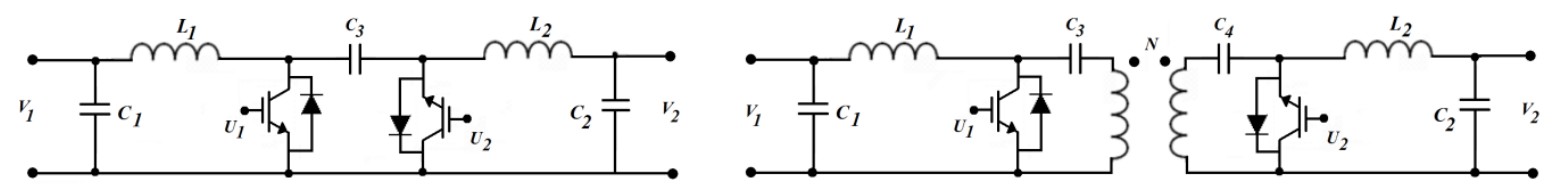

Figura 2.15 - 'Cuk Bidirecional e 'Cuk Bidirecional Isolado.

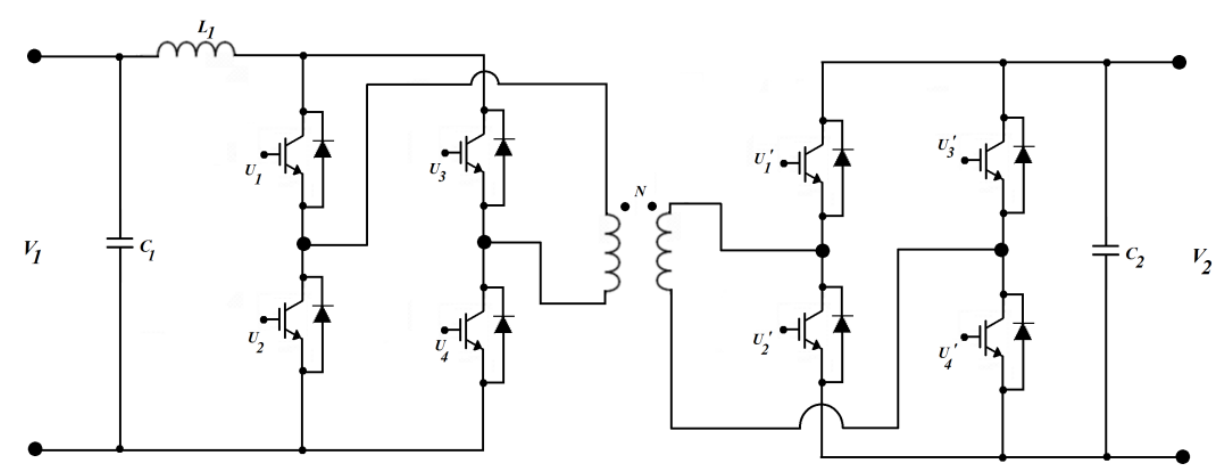

Figura 2.16 - Dual Full Bridge.

Entretanto, estes conversores apresentam um número elevado de componentes armazenadores de energia como o 'Cuk ou elevado número de dispositivos semicondutores como no caso do conversor Dual Full-Bridge. Além disso, circuitos isolados não são indicados para sistemas de alta potência, pois elevam o custo, o volume e o peso do sistema, tornando esta opção inviável. Desta forma, o circuito ideal para aplicações de potência mais elevada deve conter número reduzido de semicondutores e poucos componentes armazenadores de energia. Tais imposições fazem do conversor Buck-Boost bidirecional uma solução adequada para ser aplicado em sistemas com potências elevadas (na ordem de dezenas ou centenas de kW), Figura 2.17. Neste circuito, o modo de operação depende do sentido para o qual a energia está fluindo, como pode ser visto na Figura 2.18, ou seja, o circuito entra no modo Boost quando a energia flui do lado de baixa tensão rumo ao lado de alta tensão e no modo Buck, quando a energia faz o caminho inverso (NORTHCOTT, FILIZADEH e CHEVREFILS, 2009). 


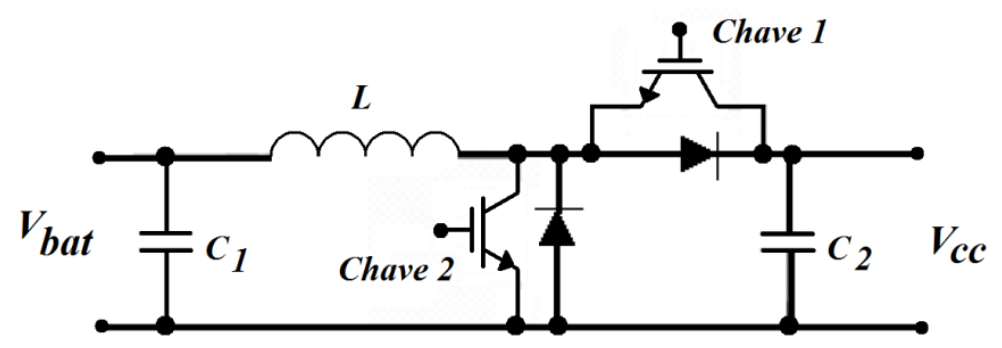

Figura 2.17- Conversor Buck-Boost bidirecional.
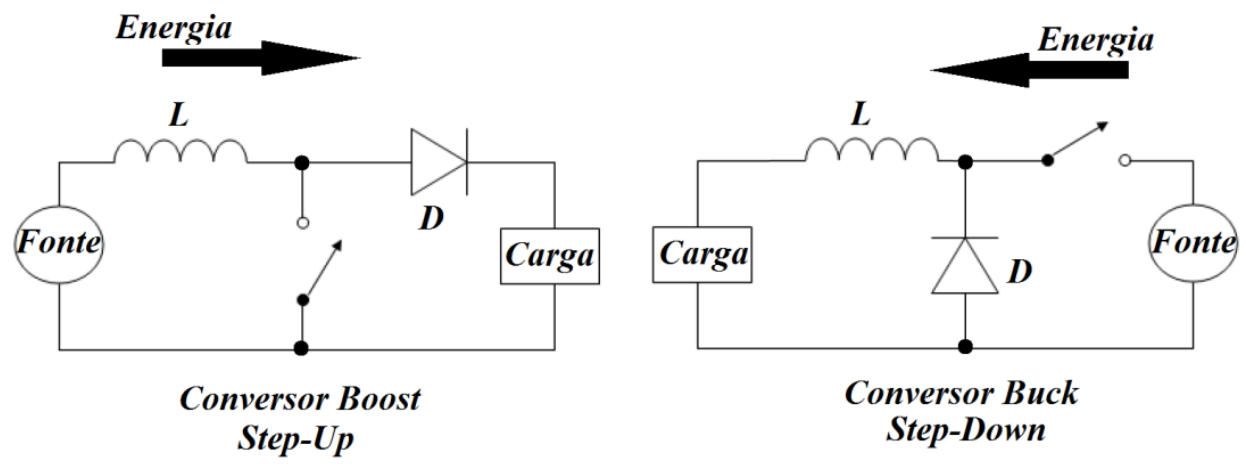

Figura 2.18 - Modos de operação.

No entanto, para que o circuito funcione adequadamente, é preciso que no modo Boost a chave 1 fique no estado de alta impedância enquanto a chave 2 recebe os pulsos do módulo PWM. Analogamente para o modo Buck, a chave 2 é que precisa ser colocada no modo de alta impedância e a modulação PWM aplicada a chave 1, Figura 2.19.

Para se obter uma representação matemática do comportamento do conversor eletrônico é adotado o seguinte procedimento: inicialmente o mesmo é modelado operando como um conversor Step-Up e depois como Step-Down.

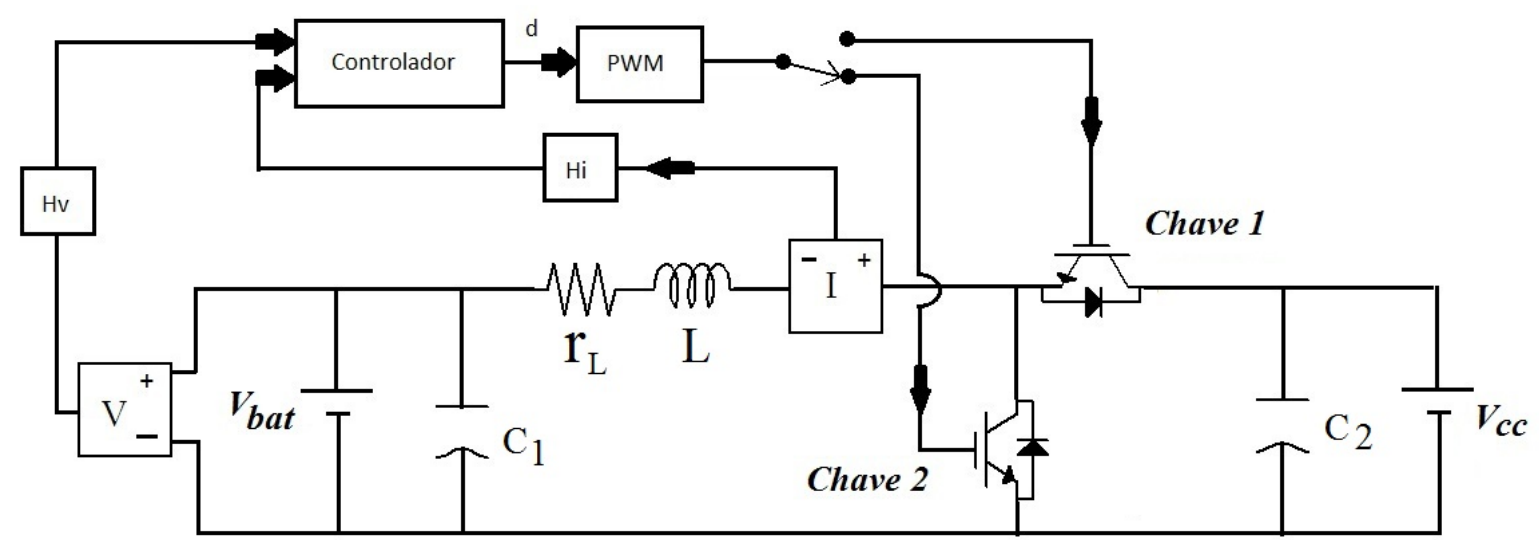

Figura 2.19 - Conversor Buck-Boost Bidirecional com controle. 


\subsubsection{Modelo do conversor no modo Boost (Step-Up)}

Para representar o sistema nas condições reais são consideradas as resistências parasitas na indutância $\left(r_{L}\right)$ e a resistência de condução das chaves $\left(r_{o n}\right)$.

Considerando o conversor operando no modo de condução contínua, o sistema apresenta dois estados para cada modo de funcionamento, que são apresentados nas Figuras 2.20, 2.21, 2.22 e 2.23. Aplicando a lei de Kirchhoff das tensões ao conversor para ambas as situações, são obtidas as seguintes equações de estado representadas na forma matricial (ERICKSON e MAKSIMOVIC, 2000).

Modo Boost - Chave fechada

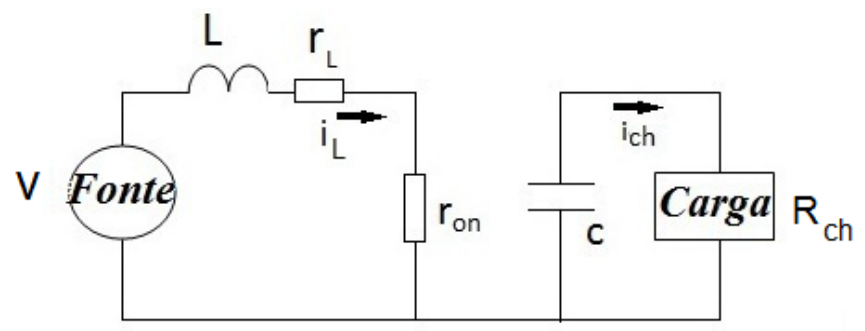

Figura 2.20 - Boost chave fechada.

$$
\begin{gathered}
\frac{d i_{L}}{d t}=\frac{V}{L}-\frac{\left(r_{o n}+r_{L}\right) i_{L}}{L} \\
\frac{d V_{C}}{d t}=-\frac{V_{C}}{C R_{c h}} \\
y=i_{L}
\end{gathered}
$$

$\mathrm{Na}$ forma matricial, as equações (7), (8) e (9) podem ser escritas da forma $\dot{x}=A_{1} x+B_{1} u$, e $y=C_{1} x$ durante o intervalo que a chave se encontra fechada $d T_{s}$.

$$
\left[\begin{array}{c}
d i_{L} \\
d t \\
\frac{d V_{c}}{d t}
\end{array}\right]=\left[\begin{array}{cc}
-\frac{\left(r_{o n}+r_{L}\right)}{L} & 0 \\
0 & -\frac{1}{C R_{c h}}
\end{array}\right]\left[\begin{array}{c}
i_{L} \\
V_{c}
\end{array}\right]+\left[\begin{array}{c}
\frac{1}{L} \\
0
\end{array}\right] V
$$




$$
y=\left[\begin{array}{ll}
1 & 0
\end{array}\right]\left[\begin{array}{l}
i_{L} \\
V_{c}
\end{array}\right]
$$

Modo Boost - Chave aberta

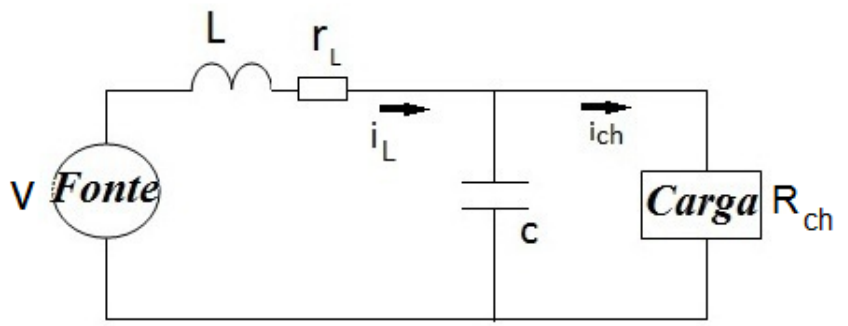

Figura 2.21 - Boost chave aberta

$$
\begin{gathered}
\frac{d i_{L}}{d t}=\frac{V}{L}-\frac{r_{L} i_{L}}{L}-\frac{V_{C}}{L} \\
\frac{d V_{C}}{d t}=\frac{i_{L}}{C}-\frac{V_{C}}{C R_{C h}} \\
y=i_{L}
\end{gathered}
$$

$\mathrm{Na}$ forma matricial, as equações (12), (13) e (14) podem ser escritas da forma $\dot{x}=A_{2} x+B_{2} u$ e $y=C_{2} x$ durante o intervalo $(1-d) T_{s}$.

$$
\begin{gathered}
{\left[\begin{array}{c}
\frac{d i_{L}}{d t} \\
\frac{d V_{c}}{d t}
\end{array}\right]=\left[\begin{array}{cc}
-\frac{r_{L}}{L} & -\frac{1}{L} \\
\frac{1}{C} & -\frac{1}{C R_{c h}}
\end{array}\right]\left[\begin{array}{l}
i_{L} \\
V_{c}
\end{array}\right]+\left[\begin{array}{l}
\frac{1}{L} \\
0
\end{array}\right] V} \\
y=\left[\begin{array}{ll}
1 & 0
\end{array}\right]\left[\begin{array}{l}
i_{L} \\
V_{c}
\end{array}\right]
\end{gathered}
$$

2.2.5 Modelo do conversor no modo Buck (Step-down)

Modo Buck - Chave fechada

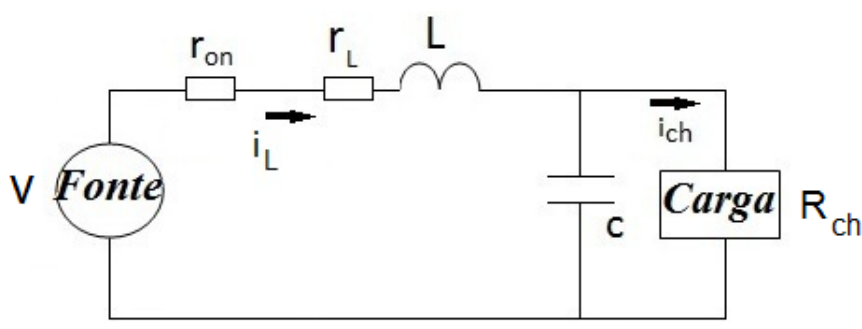

Figura 2.22 - Buck com chave fechada. 


$$
\begin{gathered}
\frac{d i_{L}}{d t}=\frac{V}{L}-\frac{\left(r_{o n}+r_{L}\right) i_{L}}{L}-\frac{V_{C}}{L} \\
\frac{d V_{C}}{d t}=\frac{i_{L}}{C}-\frac{V_{C}}{C R_{c h}} \\
y=i_{L}
\end{gathered}
$$

Semelhante ao que foi feito para (7), (8) e (9); (17), (18) e (19) podem, também, serem escritas da forma $\dot{x}=A_{1} x+B_{1} u$, e $y=C_{1} x$ durante o intervalo no qual a chave se encontra fechada $d T_{s}$.

$$
\begin{gathered}
{\left[\begin{array}{c}
\frac{d i_{L}}{d t} \\
\frac{d V_{C}}{d t}
\end{array}\right]=\left[\begin{array}{cc}
-\frac{\left(r_{o n}+r_{L}\right)}{L} & -\frac{1}{L} \\
\frac{1}{C} & -\frac{1}{C R_{c h}}
\end{array}\right]\left[\begin{array}{l}
i_{L} \\
V_{C}
\end{array}\right]+\left[\begin{array}{l}
\frac{1}{L} \\
0
\end{array}\right] V} \\
y=\left[\begin{array}{ll}
1 & 0
\end{array}\right]\left[\begin{array}{l}
i_{L} \\
V_{C}
\end{array}\right]
\end{gathered}
$$

\section{Modo Buck - Chave aberta}

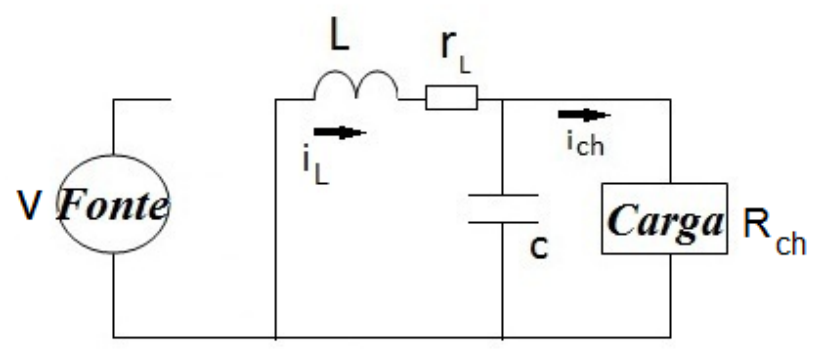

Figura 2.23 - Buck com chave aberta.

$$
\begin{gathered}
\frac{d i_{L}}{d t}=-\frac{r_{L} i_{L}}{L}-\frac{V_{C}}{L} \\
\frac{d V_{C}}{d t}=\frac{i_{L}}{C}-\frac{V_{C}}{C R_{C h}} \\
y=i_{L}
\end{gathered}
$$

Na forma matricial (22), (23) e (24) podem ser escritas como $\dot{x}=A_{2} x+B_{2} u$ e $y=C_{2} x$ durante o intervalo $(1-d) T_{s}$.

$$
\left[\begin{array}{l}
\frac{d i_{L}}{d t} \\
\frac{d V_{C}}{d t}
\end{array}\right]=\left[\begin{array}{cc}
-\frac{R_{L}}{L} & -\frac{1}{L} \\
\frac{1}{C} & -\frac{1}{C \cdot R_{C h}}
\end{array}\right]\left[\begin{array}{l}
i_{L} \\
V_{C}
\end{array}\right]+\left[\begin{array}{l}
0 \\
0
\end{array}\right] V
$$




$$
y=\left[\begin{array}{ll}
1 & 0
\end{array}\right]\left[\begin{array}{l}
i_{L} \\
V_{c}
\end{array}\right]
$$

\subsubsection{Modelo de pequenos sinais para os conversores}

Para obter uma representação de pequenos sinais em torno do ponto de operação dos conversores em um intervalo de chaveamento é preciso ponderar as matrizes de estado no tempo (ERICKSON e MAKSIMOVIC, 2000), conforme a equação a seguir:

$$
\begin{aligned}
& \dot{x}=\left[A_{1} d+A_{2}(1-d)\right] x+\left[B_{1} d+B_{2}(1-d)\right] V \\
& y=\left[C_{1} d+C_{2}(1-d)\right] x+\left[D_{1} d+D_{2}(1-d)\right] V
\end{aligned}
$$

Para o Boost:

$$
A_{1} \neq A_{2} ; B_{1}=B_{2} ; C_{1}=C_{2} ; D_{1}=D_{2}=0
$$

Para o Buck:

$$
A_{1} \neq A_{2} ; B_{1} \neq B_{2} ; C_{1}=C_{2} ; D_{1}=D_{2}=0
$$

Introduzindo uma pequena perturbação em (27) para separação das componentes $\mathrm{CC}$ e $\mathrm{CA}$, as variáveis se decompõem da seguinte forma:

$$
\begin{aligned}
\mathrm{x} & =\mathrm{X}+\hat{x} \\
\mathrm{i}_{L} & =I_{L}+\hat{\imath}_{L} \\
\mathrm{~d} & =\mathrm{D}+\hat{d}
\end{aligned}
$$

Em (28), o termo $X$ representa a parte contínua (valor médio) e o termo $\hat{x}$ a componente alternada do sinal (perturbações). Quando é desconsiderando perturbação no sinal de entrada tem-se uma representação da seguinte forma:

$$
\dot{\hat{x}}=A X+B V+A \hat{x}+\left[\left(A_{1}-A_{2}\right) X+\left(B_{1}-B_{2}\right) V\right] \hat{d}
$$

Onde

$$
A=A_{1} D+A_{2}(1-D) \text { e } B=B_{1} D+B_{2}(1-D)
$$


O comportamento em regime permanente pode ser obtido fazendo nulos os termos variáveis de (29):

$$
\begin{aligned}
& A X+B V=0 \\
& X=-A^{-1} B V
\end{aligned}
$$

Fazendo a equação (29) apenas para as componentes alternadas, ou seja, analisando o sistema oscilando em torno do ponto médio de funcionamento é encontrado:

$$
\dot{\hat{x}}=A \hat{x}+\left[\left(A_{1}-A_{2}\right) X+\left(B_{1}-B_{2}\right) V\right] \hat{d}
$$

Analogamente é possível usar o mesmo procedimento para a saída:

$$
\begin{gathered}
C=C_{1} D+C_{2}(1-D) \\
I_{L}=C X
\end{gathered}
$$

Inserindo as perturbações e utilizando apenas a parte alternada tem-se:

$$
\hat{\imath}_{L}=C \hat{x}+\left[\left(C_{1}-C_{2}\right) X\right] \hat{d}
$$

Para se obter a função de transferência é aplicada a transformada de Laplace nas equações (32) e (34), conforme é mostrado a seguir.

$$
\begin{gathered}
\hat{x}(s)=[s \mathrm{I}-A]^{-1}\left[\left(A_{1}-A_{2}\right) X+\left(B_{1}-B_{2}\right) V \hat{d}(s)\right. \\
\hat{\imath}_{L}(s)=C \hat{x}(s)+\left[\left(C_{1}-C_{2}\right) X\right] \hat{d}(s)
\end{gathered}
$$

Substituindo (35) em (36) tem-se:

$$
\begin{gathered}
G(s)=\frac{\hat{l}_{L}(s)}{\hat{d}(s)}=C[s \mathrm{I}-A]^{-1}\left[\left(A_{1}-A_{2}\right) X+\left(B_{1}-B_{2}\right) V\right]+\left(C_{1}-C_{2}\right) X \\
G(s)=\left(\frac{V}{K}\right) \frac{s\left(c R_{c h}^{2}(1-D)-c R_{c h} R_{o n}\right)+2 R_{c h}(1-D)-R_{o n}}{s^{2}\left(c L R_{c h}\right)+s\left(L+c R_{c h} R_{L}+c R_{c h} R_{o n} D\right)+K}
\end{gathered}
$$


Onde $K=R_{c h}+R_{L}+D^{2} R_{c h}-2 D R_{c h}+D R_{o n}$

Vale ressaltar que esta função de transferência representa apenas as variações em torno de um ponto médio de funcionamento, não sendo possível simular o funcionamento do circuito com esta planta. A principal funcionalidade deste modelo no domínio da frequência é fornecer informações necessárias ao projeto de controladores clássicos (ERICKSON e MAKSIMOVIC, 2000). O ponto médio em torno do qual a planta representa seu funcionamento é definido pelo valor da variável $X$, que corresponde aos valores médios de regime permanente das variáveis de estado, sendo o mesmo escrito em função das entradas CC, dos elementos do circuito e da largura de pulso média, como visto em (30) e (31).

\subsubsection{Projeto do controlador Fuzzy P+I}

Para o projeto dos ganhos do controlador fuzzy é tomado como base um controlador clássico $\mathrm{PI}$, que é projetado utilizando a função transferência $\mathrm{G}(\mathrm{s})$ da equação (38) da seção anterior, considerando os seguintes parâmetros escolhidos de forma a minimizar as oscilações de corrente na indutância e tensão no painel.

$$
\begin{gathered}
L=10 \mathrm{mH} \\
r_{L}=0,1 \Omega \\
r_{o n}=0,1 \Omega \\
c=1 \mathrm{mF} \\
f_{\text {chaveamento }}=10 \mathrm{kHz} \\
f_{\text {corte }}=400 \mathrm{~Hz} \\
R_{\text {carga }}=36 \Omega \\
V=36 \mathrm{~V} \\
D=0,7
\end{gathered}
$$

Os valores da resistência de carga $\left(R_{\text {carga }}\right)$, tensão de entrada $(V)$ e o ciclo de trabalho médio $(D)$, são escolhidos de modo a gerar um valor de regime permanente das variáveis de estado nos valores nominais, que são: 


$$
X=\left[\begin{array}{l}
I_{L} \\
V_{c}
\end{array}\right]=\left[\begin{array}{c}
4 \\
120
\end{array}\right]
$$

Ou seja, em regime permanente deseja-se $120 \mathrm{~V}$ no barramento CC com uma tensão de entrada de aproximadamente $36 \mathrm{~V}$ e uma corrente de descarga das baterias de no máximo $10 \%$ da capacidade das baterias, que é um pouco abaixo de 4 A.

Utilizando a ferramenta de sintonia Sisotool presente no MatLab® são obtidos os seguintes ganhos normalizados para o controlador PI.

$$
\begin{gathered}
G(s)=K_{p}+\frac{K_{i}}{s} \\
K_{i}=40 \text { e } K_{p}=0.2
\end{gathered}
$$

Na Figura 2.24 são mostrados os diagramas de Bode para a malha aberta de $\mathrm{G}$ (s) compensada e não compensada, enquanto que na Figura 2.25 tem-se 0 diagrama para a malha fechada compensado. Observa-se que o controlador PI reduz a frequência de corte do sistema de aproximadamente $2 \mathrm{kHz}$ para aproximadamente $400 \mathrm{~Hz}$, ou seja, abaixo de uma década da frequência de chaveamento utilizada (10 kHz), como recomendado em (MACHADO, 2005).

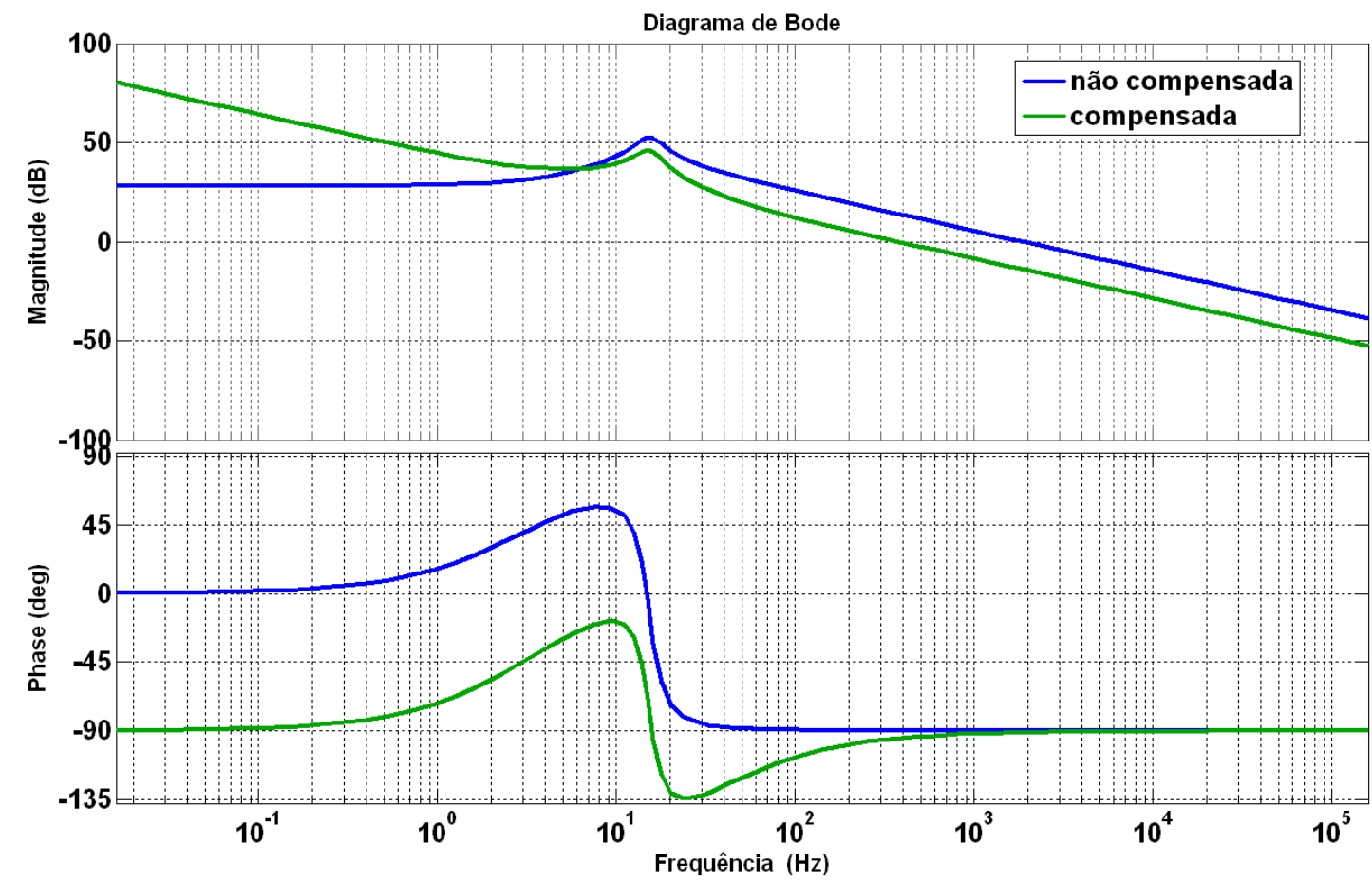

Figura 2.24- Diagrama de Bode em malha aberta para a planta $\mathrm{G}(\mathrm{s})$ Boost não compensada e compensada com controlador PI. 


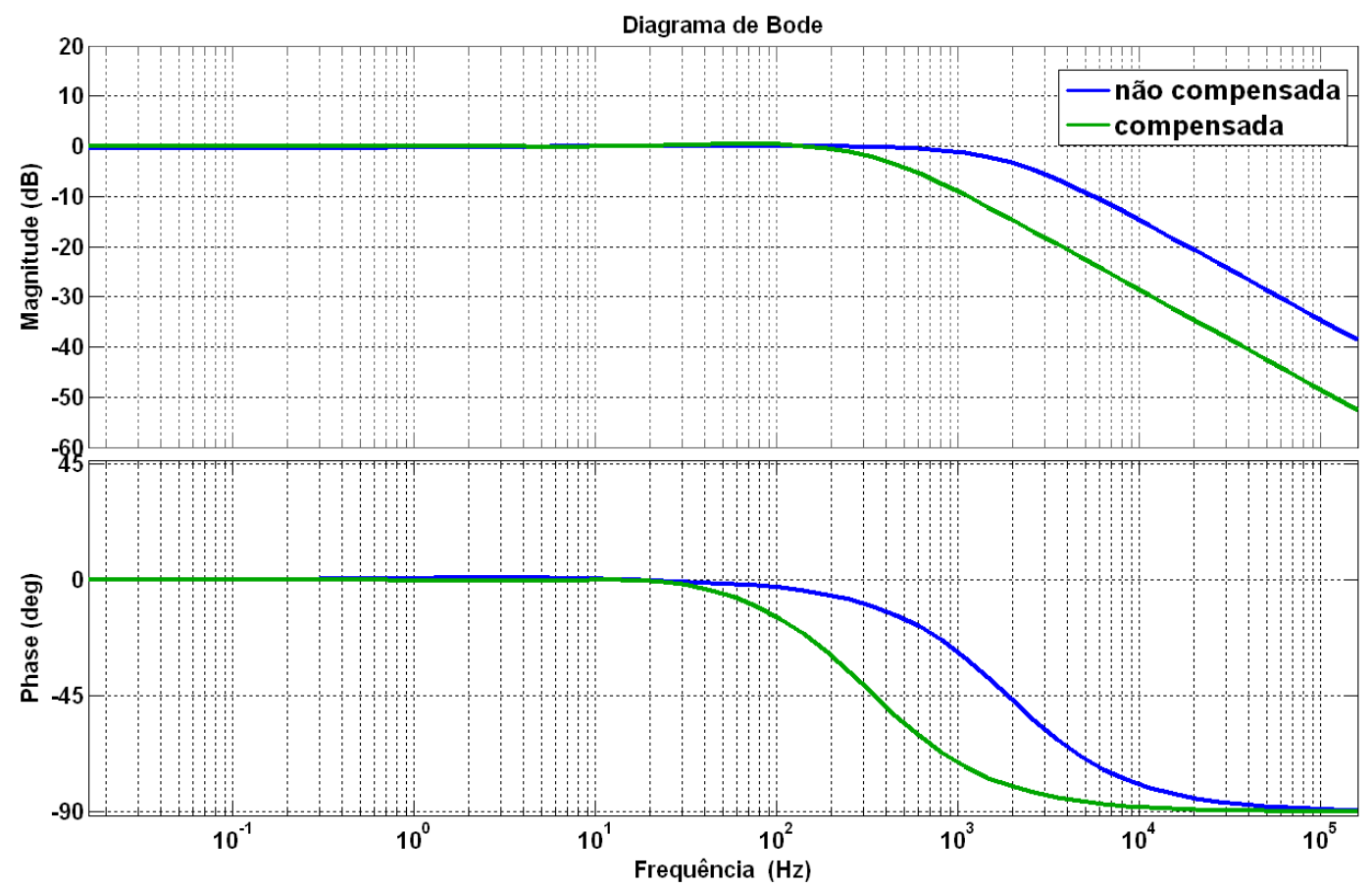

Figura 2.25 - Diagrama de Bode em malha fechada para planta G(s) Boost compensada e não compensada com controlador PI.

De posse do projeto do controlador clássico para um conversor Boost, o mesmo é usado como critério para a obtenção do ganho integral do controlador fuzzy $\mathrm{P}+\mathrm{l}$, proposto logo em seguida, dando dessa forma uma ideia dos valores a serem usados, uma vez que para este tipo de controlador não existe uma metodologia específica de sintonia.

Com o intuito de controlar a corrente de carga, descarga e a tensão nos terminais da bateria, é apresentada uma estratégia de controle de forma a se ter mínimo sobre sinal e mínimo erro em regime permanente. Entretanto, diferentemente do que ocorre em outros sistemas nos quais a planta e a variável a ser controlada pouco se alteram, o sistema de carga e descarga das baterias é um sistema dinâmico, variando sua planta à medida que o processo avança. Esta alteração na planta se dá devido à inversão do sentido do fluxo de energia do conversor bidirecional, que altera o circuito do conversor Boost para Buck, além da mudança da variável de controle que é alterada de corrente para tensão, durante a carga e descarga das baterias, caso o método de carga a dois níveis de tensão seja utilizando (seção 2.1.6).

Visto que a planta e a variável de controle do sistema se alteram durante 0 processo de carga e descarga da bateria, um controlador clássico dificilmente satisfaria os requisitos dinâmicos da planta (mínimo sobre sinal, tempo de resposta, 
etc), a menos que fosse usada uma estratégia chaveada, alterando o compensador para cada modo de operação. Desta forma, é proposto um controlador do tipo fuzzy $\mathrm{P}+\mathrm{l}$ para que este possa atuar em qualquer situação do conversor bidirecional, facilitando as ações de controle, operação e reduzindo a complexidade do controlador quando este é comparado ao controlador clássico chaveado. A Figura 2.26 mostra a estrutura do controlador fuzzy $\mathrm{P}+\mathrm{I}$, bem como, o sistema de carga e descarga das baterias a ser controlado.

Neste tipo de controlador, o bloco fuzzy funciona como um bloco proporcional, agindo sobre o erro de regime transitório, enquanto o bloco integral trabalha para zerar o erro de regime permanente, logo uma constante integral grande, reduz 0 tempo de estabilização aumentando o sobre sinal. Uma constante integral pequena reduz o sobre sinal, mas eleva o tempo de acomodação.

$\mathrm{Na}$ execução deste projeto o ganho integral é ajustado com o valor determinado pela metodologia clássica de sintonia do PI descrita no início desta seção. Já o cálculo da resposta fuzzy é substituído por uma tabela contendo as saídas correspondentes para cada entrada, dentro de um universo de discurso da entrada normalizada, logo a redução do número de entradas reduz, exponencialmente, o tamanho desta tabela, além disso, o aumento do número de entradas pode não se traduzir em aumento de eficiência.

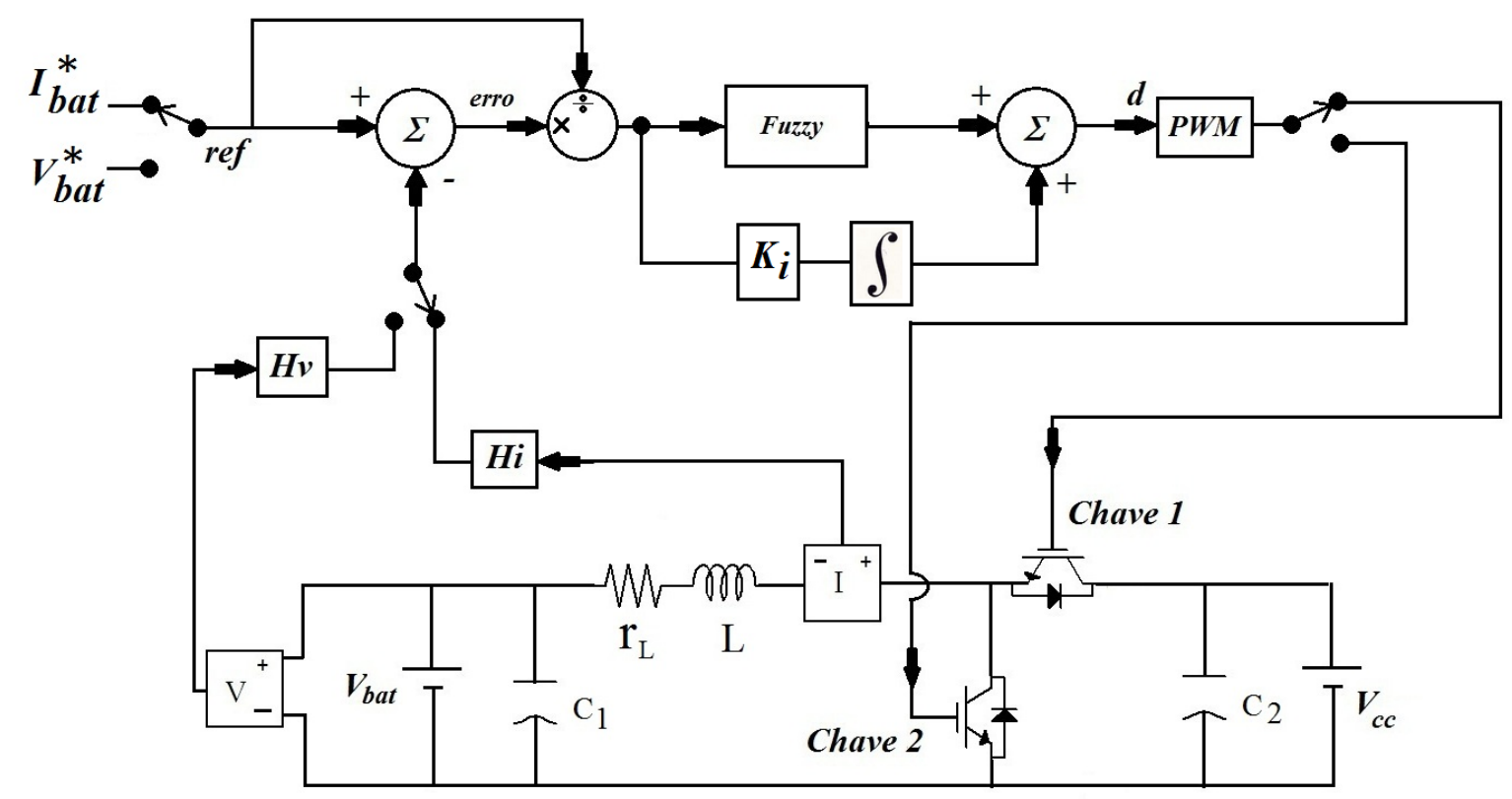

Figura 2.26 - Sistema de controle proposto fuzzy P+I. 
Na Figura 2.27, é apresentada uma superfície fuzzy com duas entradas, erro e derivada do erro, para o controle de um conversor Boost usado em (MOÇAMBIQUE, 2012). Nota-se que para diferentes valores de $\Delta e$ a saída em função do erro quase não se modifica, isso mostra que em determinadas situações o aumento da complexidade não se traduz em aumento da eficiência.

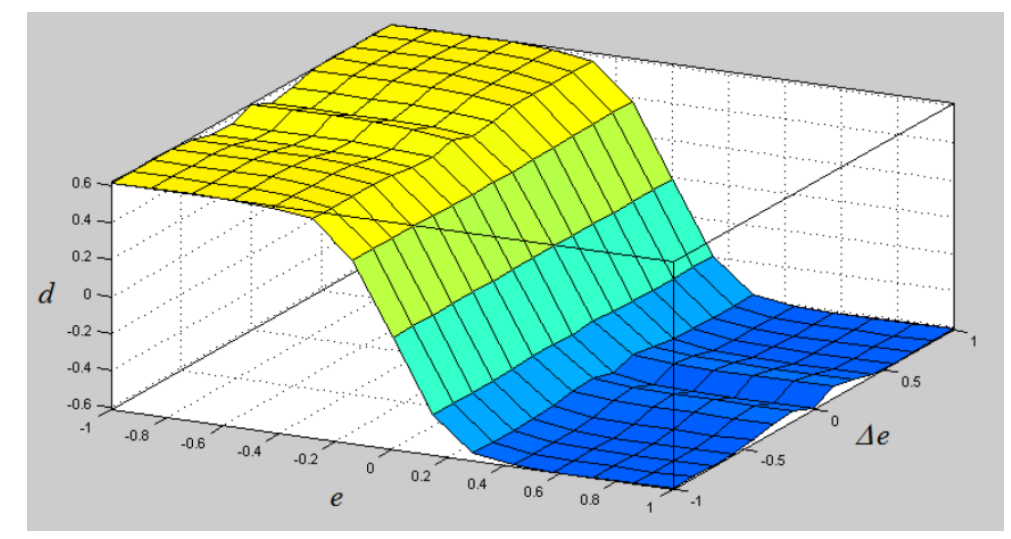

Figura 2.27 - Superfície fuzzy de um controlador fuzzy PD+l, contendo duas entradas (MOÇAMBIQUE, 2012).

Com o intuito de simplificar o sistema fuzzy, apenas o erro é utilizado como entrada, visto que para este tipo de aplicação a derivada do erro não acrescenta informações adicionais com o aumento da complexidade.

Calculando o erro, este é normalizado em função da referência, ou seja, um erro igual à referência equivale a $100 \%$ de erro ou igual a 1 . Isso é feito, pois o sistema altera a variável de controle durante o processo, assim esta normalização permite que o universo de discurso das entradas esteja sempre entre 0 e 1 , tornando o bloco fuzzy compatível com qualquer uma das entradas, tensão ou corrente.

Para gerar a superfície do sistema fuzzy são utilizadas apenas funções de pertinência triangulares devido à simplicidade e eficiência. Como operador de composição é utilizado o MAX-MIN, operador Mandani para implicação, MAX para agregação e o método do centroide para defuzzyficação.

A construção das regras que relaciona a entrada com a saída fuzzy é definida pelo conhecimento da dinâmica do sistema. Baseando-se neste conhecimento, a Tabela 2.4 é construída com o intuito de mostrar a base de regras para o controlador do conversor bidirecional. 
Tabela 2.4 - Regras do controlador fuzzy.

\begin{tabular}{|c|c|c|c|}
\hline $\begin{array}{c}\text { Erro } \\
\text { Positivo }\end{array}$ & $\begin{array}{c}\text { Saída } \\
\text { Positiva }\end{array}$ & $\begin{array}{c}\text { Erro } \\
\text { Negativo }\end{array}$ & $\begin{array}{c}\text { Saída } \\
\text { Negativa }\end{array}$ \\
\hline Baixo & Fraca & Baixo & Fraca \\
\hline Médio & Moderada & Médio & Moderada \\
\hline Alto & Forte & Alto & Forte \\
\hline
\end{tabular}

A Tabela 2.4 relaciona as funções de pertinência de entrada e saída, representadas pelas Figuras 2.28 e 2.29, que são ajustadas manualmente. Após defuzzificadas através do método do centroide que fornece a superfície da Figura 2.30 .

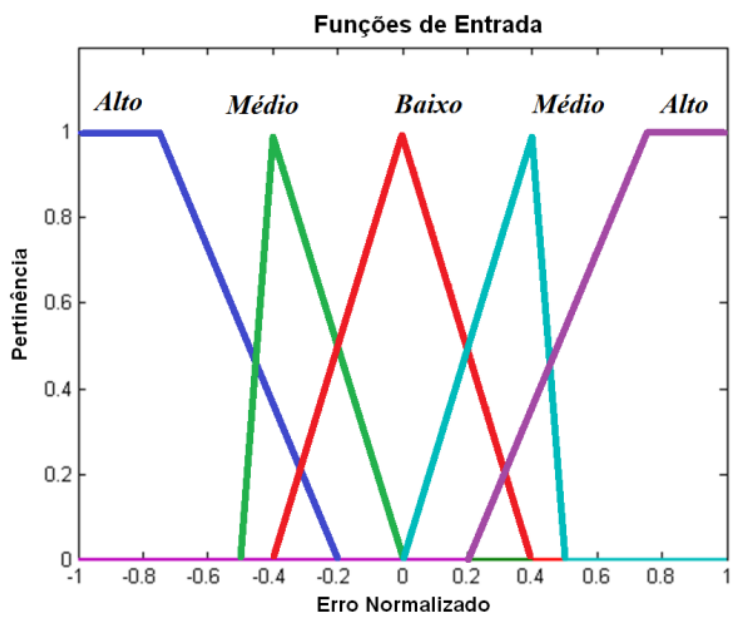

Figura 2.28 - Funções de pertinência de entrada ajustadas manualmente.

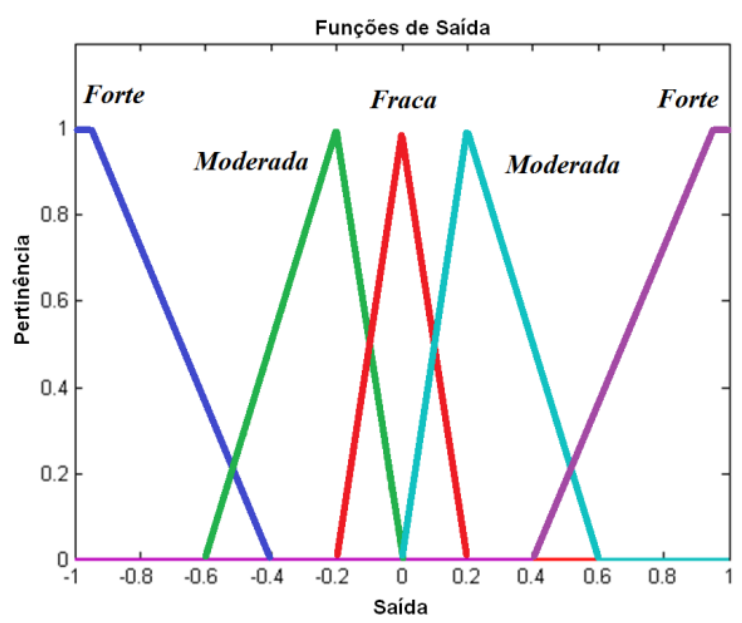

Figura 2.29 - Funções de pertinência de saída ajustadas manualmente. 


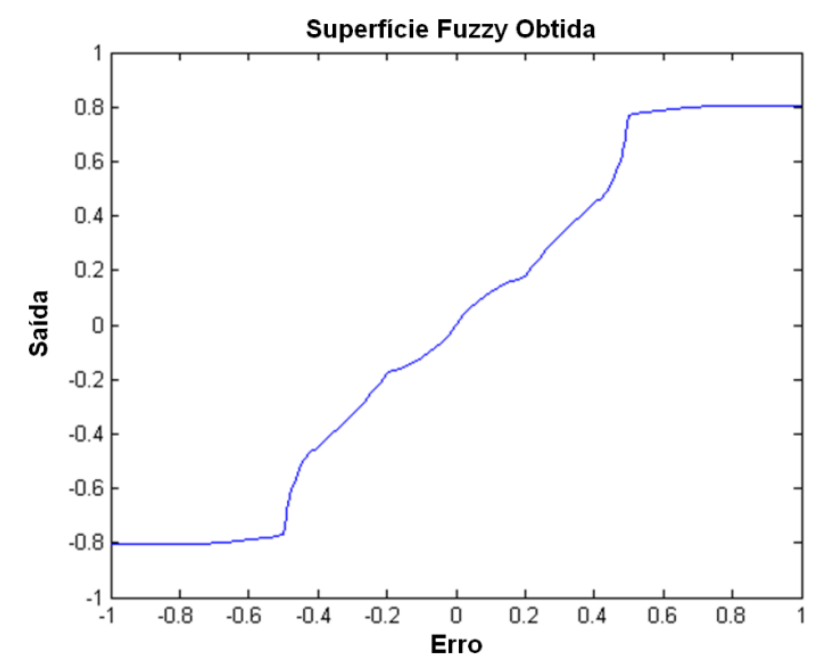

Figura 2.30 - Superfície fuzzy obtida pela defuzzyficação pelo método do centroide.

$\mathrm{Na}$ implementação do sistema fuzzy em hardware, a superfície da Figura 2.30 é inserida em forma de uma tabela, na qual cada entrada produzirá uma única saída. A inserção de uma tabela torna o cálculo da resposta fuzzy muito mais rápido em comparação com o cálculo pelo método fuzzy clássico, que envolve muitas operações com vetores e cálculos que exigem pesado processamento, como no caso do cálculo do centro de área. Vale ressaltar que assim como o método tabelado, o método fuzzy clássico depende, também, de valores discretos, pois suas funções de pertinência utilizadas no cálculo da resposta fuzzy são discretizadas. Assim, dependendo da discretização utilizada o método tabelado pode apresentar melhor resultado além de maior velocidade de processamento. Entretanto, caso o sistema fuzzy tenha mais de uma entrada, o método tabelado torna-se questionável devido à quantidade de dados que precisam ser armazenados.

\subsubsection{Modelo linearizado do painel fotovoltaico}

O sistema fotovoltaico é não linear e variante no tempo devido às características elétricas dos painéis fotovoltaicos que associados ao efeito do chaveamento, resultam em equações diferenciais complexas. No entanto, pode-se linearizar o modelo do painel em torno de determinados pontos de funcionamento (neste caso será em torno do ponto de máxima potência) considerando pequenas perturbações (MOÇAMBIQUE, 2012).

Abaixo se tem as tabelas 2.5, 2.6 e 2.7 que mostram as especificações de placa de um conjunto de 2 painéis Kyocera (KC130TM), os parâmetros ajustados 
para o modelo generalizado formado pelos dois painéis e os parâmetros do conversor elevador que é usado na busca do ponto de máxima potência.

Tabela 2.5 - Especificações elétricas do módulo solar KC130TM

\begin{tabular}{|c|l|l|l|}
\hline Símbolo & Parâmetro & Valor & Unidade \\
\hline$P_{M A X}$ & Potência Máxima & 260,1 & $\mathrm{~W}$ \\
\hline$V_{M P}$ & Tensão em $P_{M A X}$ & 35,2 & $\mathrm{~V}$ \\
\hline$I_{M P}$ & Corrente em $P_{M A X}$ & 7,39 & $\mathrm{~A}$ \\
\hline$V_{O C}$ & Tensão de circuito aberto & 43,8 & $\mathrm{~V}$ \\
\hline$I_{S C}$ & Corrente de curto circuito & 8,02 & $\mathrm{~A}$ \\
\hline$C_{V}$ & Coeficiente de temperatura de $V_{O C}$ & $-8.21 \times 10^{-2}$ & $\mathrm{~V} /{ }^{\circ} \mathrm{C}$ \\
\hline$C_{I}$ & Coeficiente de temperatura de $I_{S C}$ & $-3.18 \times 10^{-3}$ & $\mathrm{~A} /{ }^{\circ} \mathrm{C}$ \\
\hline & Tensão máxima do sistema & 600 & $\mathrm{~V}$ \\
\hline & & & \\
\hline
\end{tabular}

Tabela 2.6 - Parâmetros do modelo ajustado do conjunto fotovoltaico formado por dois módulos KC130TM conectados em série.

\begin{tabular}{|c|l|l|l|}
\hline Símbolo & \multicolumn{1}{|c|}{ Parâmetro } & \multicolumn{1}{|c|}{ Valor } & Unidade \\
\hline$I_{P V}$ & Corrente gerada pela luz & 8,0378 & $\mathrm{~A}$ \\
\hline$I_{O}$ & Corrente de saturação do diodo & 3,598 & $\mathrm{nA}$ \\
\hline$a$ & Fator de idealidade do diodo & 1,1 & \\
\hline$R_{p}$ & Resistência Shunt Equivalente & 176,27 & $\Omega$ \\
\hline$R_{S}$ & Resistência série equivalente & 0,180 & $\Omega$ \\
\hline
\end{tabular}

Tabela 2.7 - Parâmetros do conversor elevador de tensão.

\begin{tabular}{|c|l|l|l|}
\hline Símbolo & \multicolumn{1}{|c|}{ Parâmetro } & \multicolumn{1}{|c|}{ Valor } & Unidade \\
\hline$C$ & Capacitor de entrada & 1 & $\mathrm{mF}$ \\
\hline$L$ & Indutor & 5 & $\mathrm{mH}$ \\
\hline$R_{L}$ & Resistência série do indutor & 0,3 & $\Omega$ \\
\hline $\mathrm{D}$ & Razão cíclica nominal & 0,7 & \\
\hline$V_{c c}$ & Tensão nominal de saída & 120 & $\mathrm{~V}$ \\
\hline
\end{tabular}

Abaixo é apresentada a equação característica (5) que representa o modelo do painel fotovoltaico.

$$
I=I_{p v}-I_{0}\left[\exp \left(\frac{V+R_{S} I}{V_{t} a}\right)-1\right]-\frac{V+R_{S} I}{R_{p}}
$$

A linearização é feita em torno do ponto de máxima potência, que é o ponto de interesse, como mostrado na Figura 2.31. 


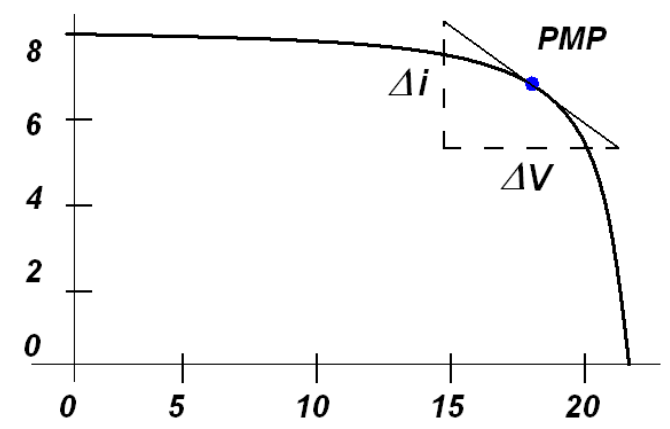

Figura 2.31 - Linearização em torno do ponto de máxima potência (PMP) para o módulo fotovoltaico KC130TM.

O modelo linear determinado pela reta tangente no PMP dado por (MOÇAMBIQUE, 2012; VILLALVA, 2010) pode ser escrito como:

$$
i=g\left(v-V_{M P}\right)+I_{M P}
$$

Tal que

$$
g=\frac{d i}{d v}=\frac{1}{r_{p v}} \approx \frac{\Delta i}{\Delta v}
$$

Onde $r_{p v}$ é a resistência dinâmica da célula que depende da irradiação e temperatura da célula e, portanto, possui comportamento variante no tempo (MOÇAMBIQUE, 2012). Utilizando a equação (40) determina-se o circuito equivalente nas vizinhanças do PMP como na Figura 2.32, sendo $R_{E Q}=-1 / \mathrm{g}$ e $V_{E Q}=V_{M P}-I_{M P} / g$, (VILLALVA, 2010).

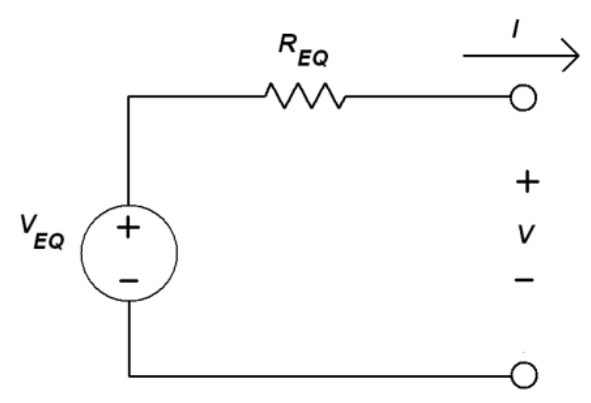

Figura 2.32 - Circuito linear equivalente no ponto de máxima potência.

Utilizando os parâmetros das tabelas 2.5 e 2.6, e com o painel linearizado no PMP, obtém-se $R_{E Q}=4,58 \Omega$ e $V_{E Q}=69,07 \mathrm{~V}$. 


\subsubsection{Modelo do conversor Boost acoplado ao modelo linearizado do painel}

Considerando o capacitor de saída, suficientemente, grande e a presença de um regulador de tensão no barramento $\mathrm{CC}$, tem-se o modelo linearizado do painel acoplado ao conversor elevador Boost e ao barramento CC, Figura 2.33.

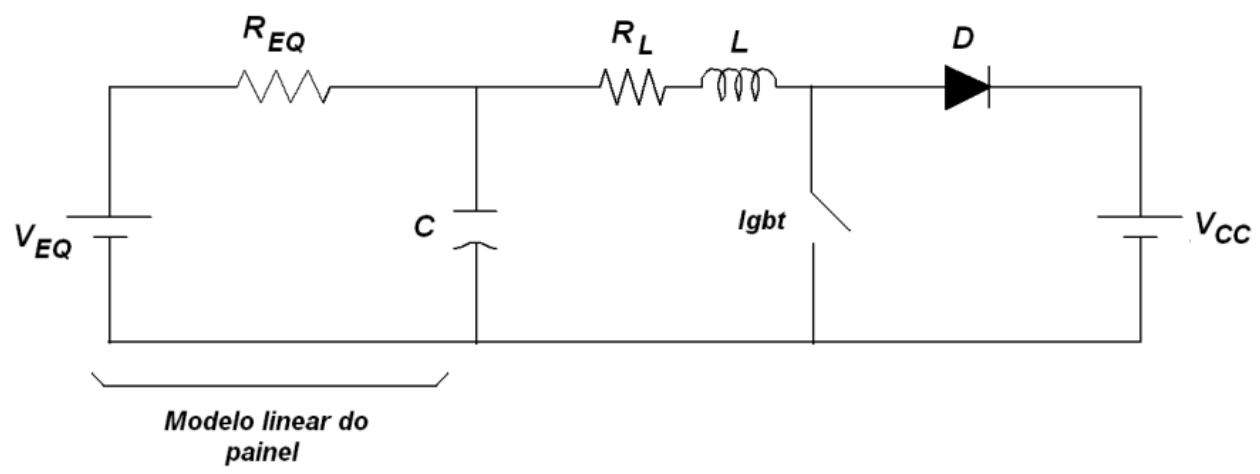

Figura 2.33 - Modelo do painel linearizado acoplado ao conversor Boost.

Para o projeto do controlador PI que é aplicado na busca do ponto de máxima potência, é utilizada a mesma metodologia para obtenção da função de transferência média aplicado no conversor Buck-Boost bidirecional, gerando as matrizes de estado e ponderando-as no tempo. Considerando o conversor operando no modo de condução contínua, o sistema apresenta dois estados que são apresentados nas Figuras 2.34, 2.35.

\section{Modelo com chave fechada}

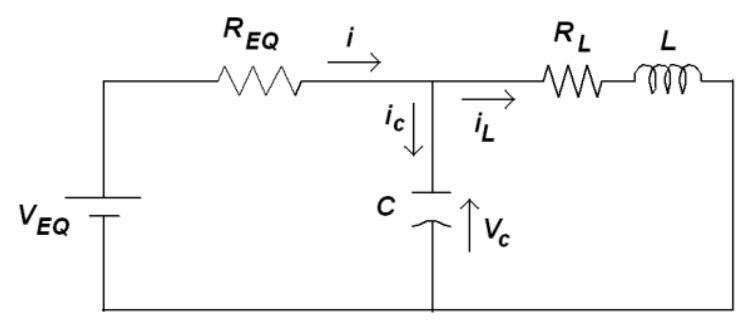

Figura 2.34- Modelo linearizado do painel acoplado ao Boost com chave ligada.

$$
\begin{gathered}
\frac{d i_{L}}{d t}=-\frac{R_{L} i_{L}}{L}+\frac{V_{c}}{L} \\
\frac{d V_{c}}{d t}=-\frac{i_{L}}{C}-\frac{V_{C}}{R_{e q} C}+\frac{V_{e q}}{R_{e q} C} \\
y=V_{c}
\end{gathered}
$$


$\mathrm{Na}$ forma matricial tem-se:

$$
\begin{gathered}
{\left[\begin{array}{c}
\frac{d i_{L}}{d t} \\
\frac{d V_{c}}{d t}
\end{array}\right]=\left[\begin{array}{cc}
-\frac{R_{L}}{L} & \frac{1}{L} \\
-\frac{1}{C} & -\frac{1}{R_{e q} C}
\end{array}\right]\left[\begin{array}{l}
i_{L} \\
V_{c}
\end{array}\right]+\left[\begin{array}{cc}
0 & 0 \\
0 & \frac{1}{R_{e q} C}
\end{array}\right]\left[\begin{array}{l}
V_{c c} \\
V_{e q}
\end{array}\right]} \\
y=\left[\begin{array}{ll}
0 & 1
\end{array}\right]\left[\begin{array}{l}
i_{L} \\
V_{c}
\end{array}\right]
\end{gathered}
$$

Modelo com chave aberta

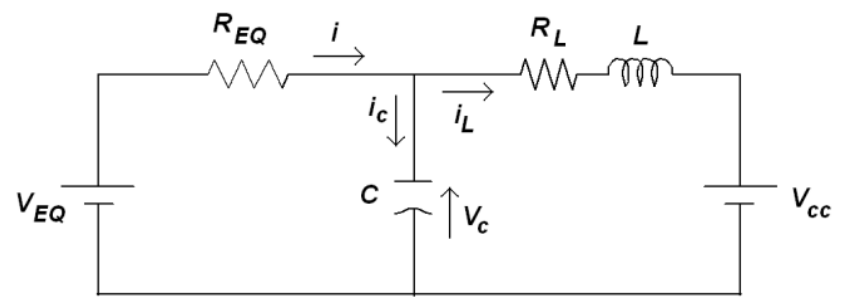

Figura 2.35- Modelo linearizado do painel acoplado ao Boost com chave desligada.

$$
\begin{gathered}
\frac{d i_{L}}{d t}=-\frac{R_{L} i_{L}}{L}+\frac{V_{c}}{L}-\frac{V_{c c}}{L} \\
\frac{d V_{c}}{d t}=-\frac{i_{L}}{C}-\frac{V_{c}}{R_{e q} C}+\frac{V_{e q}}{R_{e q} C} \\
y=V_{c}
\end{gathered}
$$

Na forma matricial tem-se

$$
\begin{gathered}
{\left[\begin{array}{l}
\frac{d i_{L}}{d t} \\
\frac{d V_{C}}{d t}
\end{array}\right]=\left[\begin{array}{cc}
-\frac{R_{L}}{L} & \frac{1}{L} \\
-\frac{1}{C} & -\frac{1}{R_{e q} C}
\end{array}\right]\left[\begin{array}{l}
i_{L} \\
V_{c}
\end{array}\right]+\left[\begin{array}{cc}
-\frac{1}{L} & 0 \\
0 & \frac{1}{R_{e q} C}
\end{array}\right]\left[\begin{array}{l}
V_{c c} \\
V_{e q}
\end{array}\right]} \\
y=\left[\begin{array}{ll}
0 & 1
\end{array}\right]\left[\begin{array}{l}
i_{L} \\
V_{c}
\end{array}\right]
\end{gathered}
$$

Utilizando a equação (37) e as matrizes (44), (45), (48) e (49) do modelo obtém-se a função de transferência $G(s)=\frac{\widehat{v_{c}}(s)}{\widehat{d}(s)}$ que é usada no projeto do controlador PI da tensão de saída do painel, além do diagrama de bode da planta do sistema, apresentado na Figura 2.36.

$$
G(s)=\frac{-R_{e q} V_{c c}}{s^{2} c L R_{e q}+s\left(L+c R_{e q} R_{L}\right)+R_{e q}+R_{L}}
$$




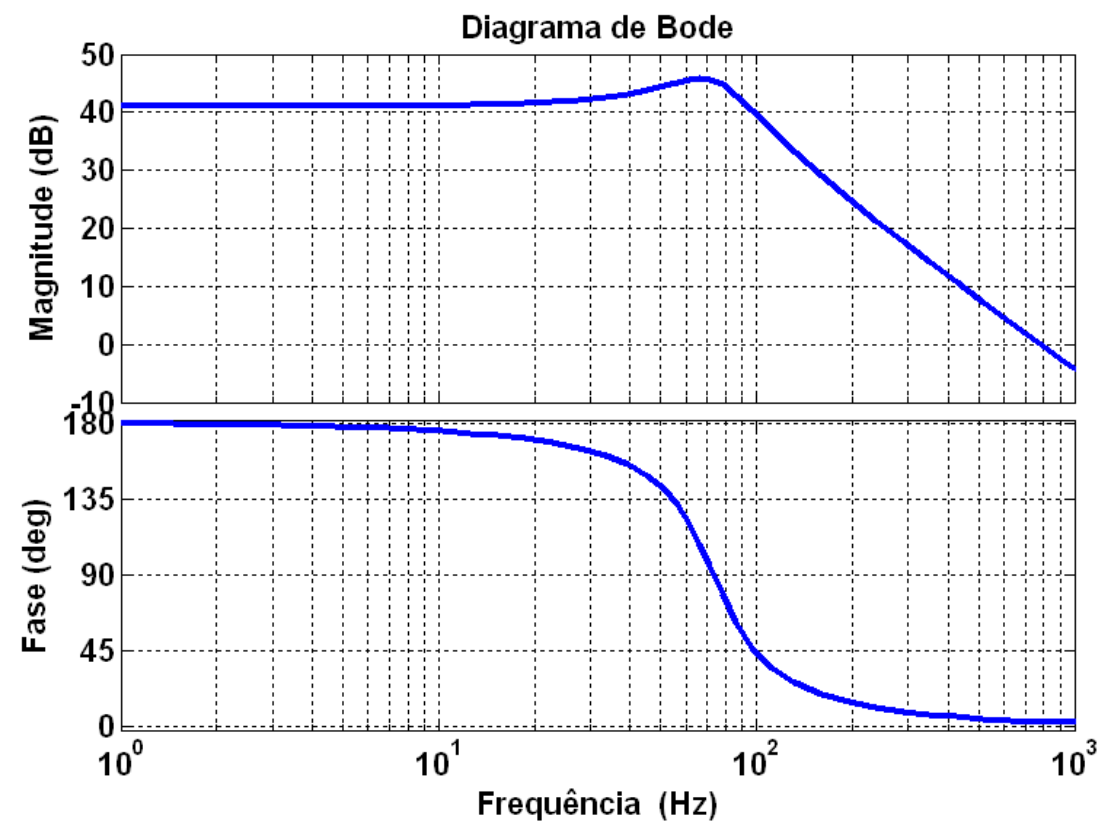

Figura 2.36 - Diagrama de Bode para o modelo linearizado do painel acoplado ao conversor Boost.

Utilizando o sisoTool do Matlab para sintonia do PI com uma largura de banda de $1000 \mathrm{~Hz}$ e $80^{\circ}$ de margem de fase, obtém-se os ganhos para o controle da tensão de saída do painel, Figura 2.37 .

$$
\begin{gathered}
G(s)=K_{p}+\frac{K_{i}}{s} \\
K_{p}=1,5 \\
K_{i}=50
\end{gathered}
$$

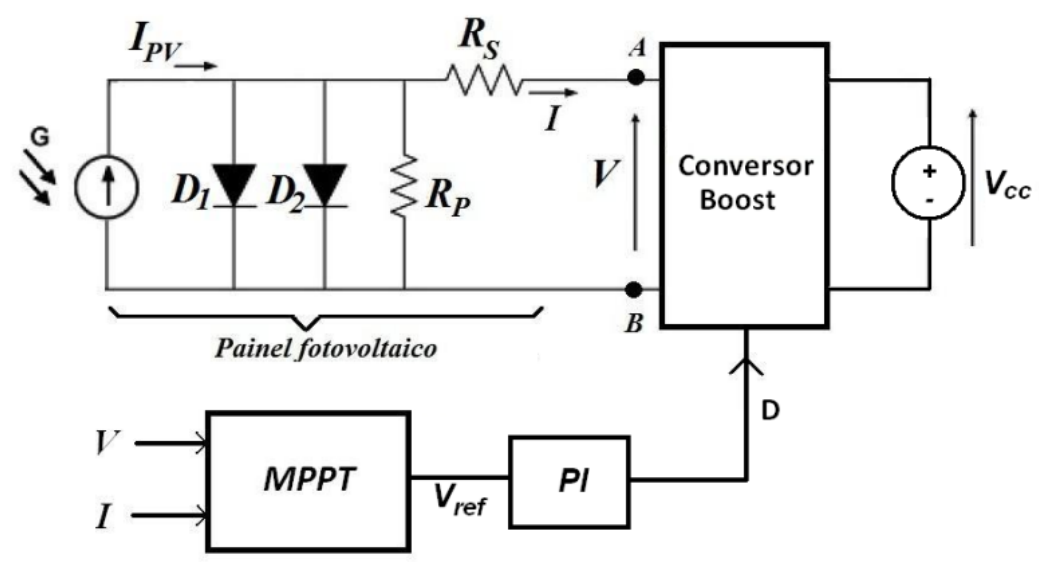

Figura 2.37 - Sistema de controle do painel fotovoltaico. 


\section{3- Sistema de injeção de potência na rede}

Nas simulações e na execução deste trabalho, o sistema de injeção de potência na rede elétrica é considerado como uma carga controlável cujo fluxo de potência drenado poderá ser controlado (Figura 2.38), uma vez que o interesse deste trabalho está na influência do controle do fluxo de potência sobre a tensão comum no barramento $\mathrm{CC}$ e não na geração de tensões sincronizadas e balanceadas com a rede. Este sistema garantirá a estabilização da tensão comum no barramento CC através do equilíbrio entre a potência gerada e potência consumida, estabelecido pela Equação (2).
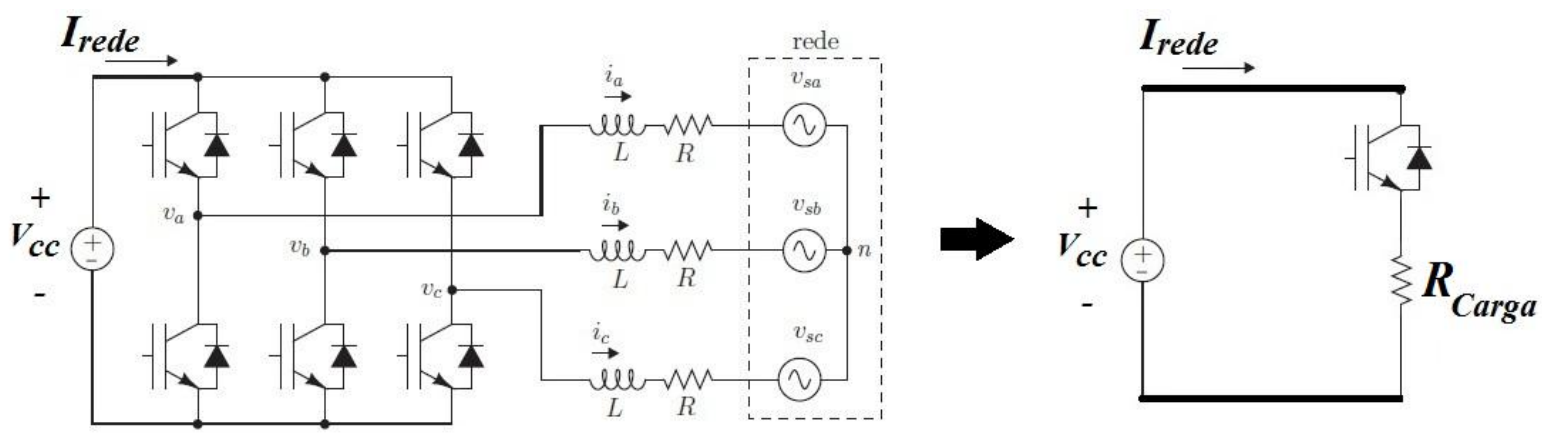

Figura 2.38 - sistema de injeção trifásico e equivalente.

A proximidade entre o sistema trifásico de injeção e a simplificação pode ser vista pela Figura 2.39, que mostra as formas de onda de corrente drenada para cada uma das topologias da Figura 2.38. Ambas as correntes tem uma característica pulsada na frequência do chaveamento, entretanto a corrente drenada pelo inversor trifásico possui outra componente pulsada com uma frequência de seis vezes a frequência fundamental gerada pelo inversor. Desta forma, quando se está simplificando o sistema de injeção baseado em um inversor trifásico de seis pulsos por uma carga controlada chaveada, do ponto de vista do barramento CC, está se eliminando a componente harmônica de sexta ordem da corrente drenada, fazendo com que esta simplificação seja válida para os fins desejados neste estudo. 

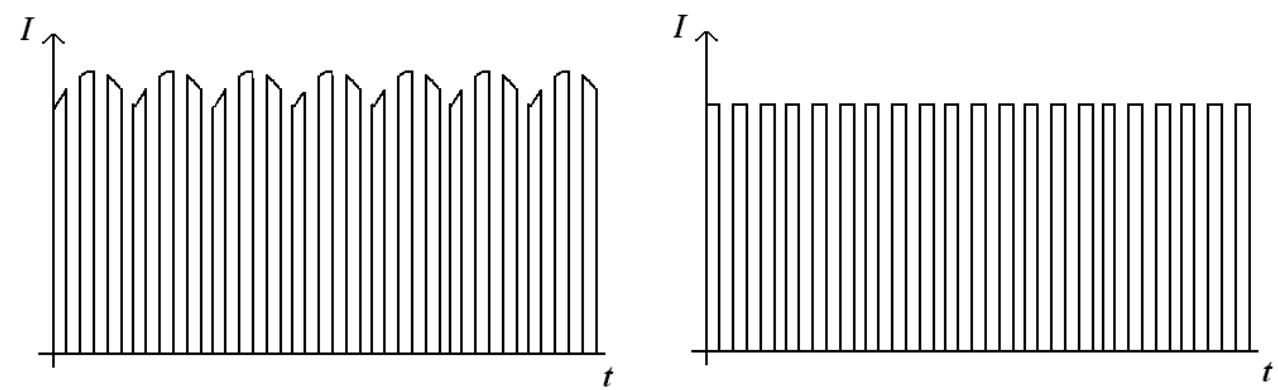

Figura 2.39 - Corrente drenada do barramento CC para um inversor trifásico e para o sistema simplificado considerado na Figura 2.38.

Para o controle da tensão do barramento CC é utilizada uma estrutura idêntica à estrutura para o controle do conversor bidirecional, definida na seção 2.3 com mínimas diferenças que são: a inversão de sinal na saída do compensador e o valor do ganho integral. A inversão na saída do compensador é necessária, pois a lógica de controle é invertida, ou seja, se o erro é positivo (tensão abaixo da referência) é preciso realizar uma ação de controle com uma atuação negativa (reduzir a potência drenada). Logo, a saída do compensador precisa ser invertida, como mostra a Figura 2.40. Por outro lado, o valor do ganho integral precisa ser ajustado de acordo com a dinâmica deste sistema, que é diferente da dinâmica do conversor bidirecional.

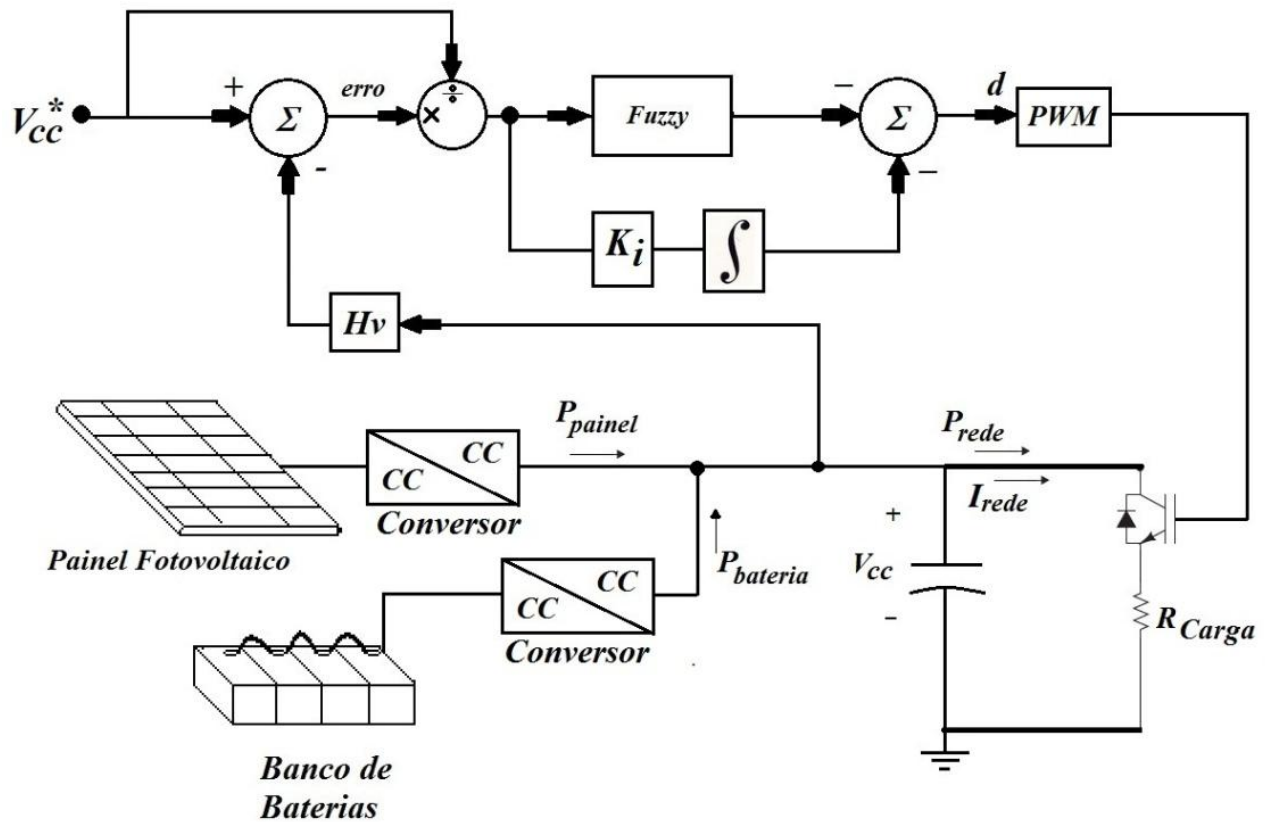

Figura 2.40- Sistema de controle fuzzy $\mathrm{P}+\mathrm{l}$, aplicado no controle da tensão do barramento CC. 


\section{4 - Considerações finais}

Neste capítulo é descrito o sistema de carga e descarga das baterias, no qual são mostradas as principais características das baterias de chumbo-ácido, os métodos de carga empregados, assim como o método a dois níveis de tensão que é utilizado na execução deste trabalho. Outro ponto importante discutido é o método de estimação do SOC interativo, que permitirá estimar durante o processo de carga ou descarga o estado de carga das baterias, facilitando a operação do sistema.

Para o controle da planta é preciso equilibrar a potência gerada à potência consumida para que a tensão comum do barramento CC se estabilize, uma vez que o algoritmo de busca da máxima potência dá uma característica de fonte de potência aos painéis.

Além disso, foram descritos os modelos em espaço de estado e a metodologia para obtenção das funções de transferências em torno de um ponto médio, que são usadas no projeto de controladores clássicos para o conversor bidirecional e painel fotovoltaico.

O projeto do controlador para o circuito bidirecional é desenvolvido usando um controlador do tipo fuzzy $\mathrm{P}+\mathrm{I}$ devido à necessidade de um controlador adaptado as alterações da planta. Já o bloco fuzzy é executado em hardware através de uma tabela, pois a metodologia clássica de cálculo da resposta fuzzy onera processamento e apresenta resultados semelhantes ao fuzzy tabelado.

O projeto do controlador PI para o conversor elevador responsável pela execução do MPPT é feito levando em consideração a linearização do modelo do painel em torno do ponto de máxima potência, assim é possível obter uma planta deste sistema e a sintonização do PI em questão.

É mostrada, também, a simplificação feita no modelo do sistema de injeção de energia na rede, uma vez que o interesse deste projeto é no efeito do controle do fluxo de potência e não na geração de tensões e correntes sincronizadas com a rede. Assim, um modelo mais simples facilita a simulação e o entendimento da dinâmica do sistema. 


\section{3-Estudo de casos}

Neste capítulo são mostradas as simulações envolvendo os modelos das baterias, painel fotovoltaico, algoritmo de busca MPPT e as metodologias de controle apresentadas no capítulo anterior que incluem simulações do sistema de estimação do SOC, controle de corrente da bateria, inversão de corrente do circuito bidirecional, controle da tensão no barramento $C C$ durante a inversão de corrente, controle da tensão no barramento CC durante queda da irradiação, além do comportamento do algoritmo de busca durante todas estas situações.

Todas as simulações são executadas levando em consideração a discretização realizada pelo processador que é utilizado na montagem do protótipo. Isso é feito para que a simulação seja o mais fiel possível ao sistema real evitando, portanto, fenômenos não previstos na execução do projeto.

\section{1 - Estimador de SOC.}

Para simular a estimação do SOC de uma bateria de chumbo-ácido é utilizado o modelo da bateria existente no Simulink (MatLab ${ }^{\mathrm{TM}}$ ) mostrado na Figura 3.1.

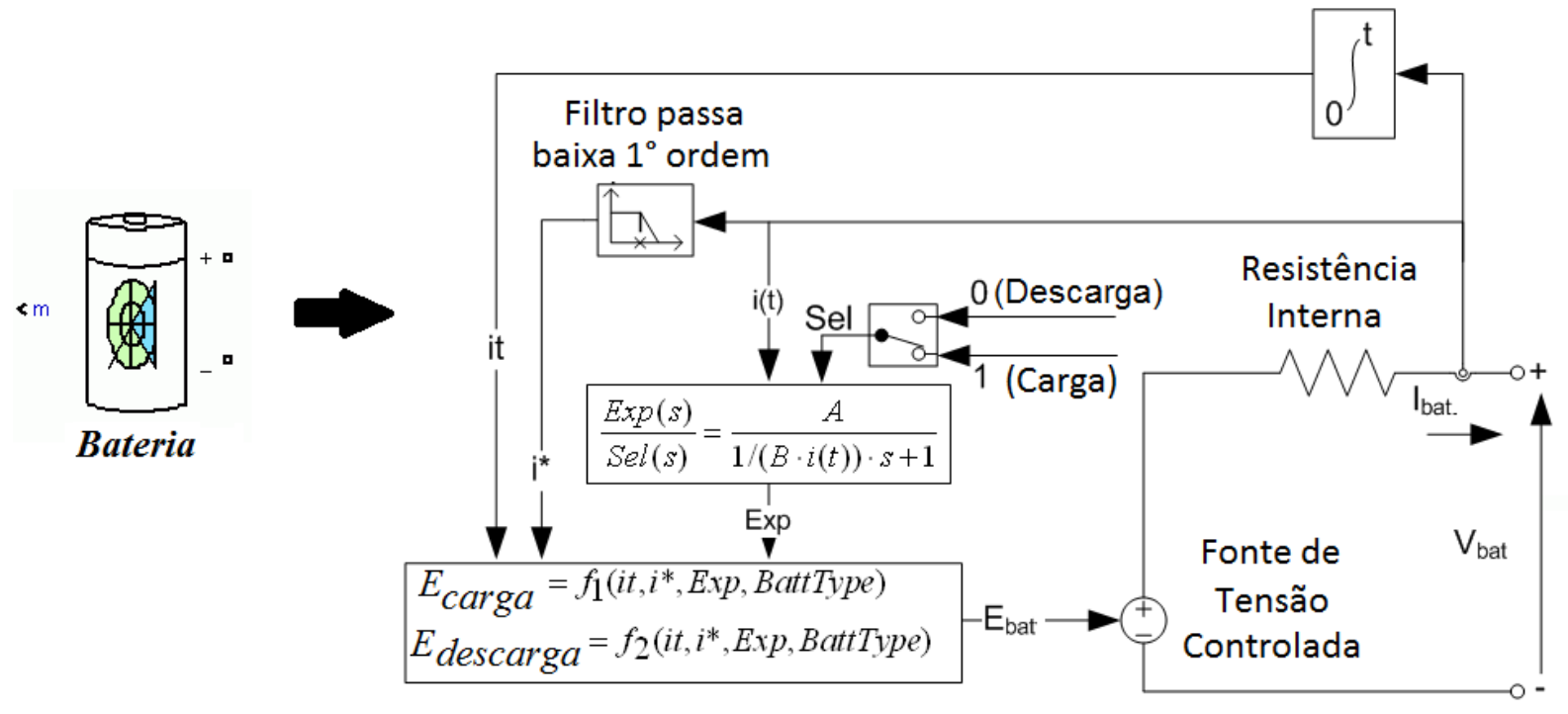

Figura 3.1 - Bloco da bateria e modelo. 
Este modelo leva em conta o comportamento não linear da tensão durante a carga ou descarga, além das perdas ôhmicas devido à resistência interna.

É criada uma forma de onda chaveada com uma frequência de $5 \mathrm{kHz}$ e através da equação (3) estima-se o SOC da bateria, comparando com o SOC que é fornecido pelo próprio bloco do Matlab. Na Figura 3.2, o primeiro gráfico representa a corrente injetada na bateria e a corrente amostrada pelo sistema de estimação. Note que é extraída apenas uma amostra por ciclo de chaveamento, para a determinação do valor médio da corrente de carga.

O segundo gráfico representa o SOC calculado pelo bloco da bateria (indicado no gráfico como SOC real) e o SOC estimado, cuja discrepância é decorrente do uso da equação (3) quando as perdas ôhmicas são negligenciadas. Vale ressaltar que a resolução da estimação está ligada ao estado inicial do $\mathrm{SOC}$ e de acordo com o que foi discutido na seção 2.1.5, depende da tensão de circuito aberto no instante anterior ao início da carga. Entretanto, para simular a estimação por integração de corrente foi considerado que o SOC inicial era conhecido na equação (3), ou seja, nesta simulação não estão inseridos os prováveis erros advindos da medição do estado inicial.

O terceiro gráfico apresenta o erro da estimação que é da ordem de $10^{-4} \%$, e se acumula devido ao fato das perdas serem negligenciadas, fazendo com que 0 sistema tenha de ser aferido com a tensão de circuito aberto a cada parada de manutenção, para eliminar os erros acumulados. Caso o erro se mantenha com uma taxa de crescimento constante, em aproximadamente $2 \mathrm{~h}$ e 30 min o erro acumulado chegaria a $5 \%$. 


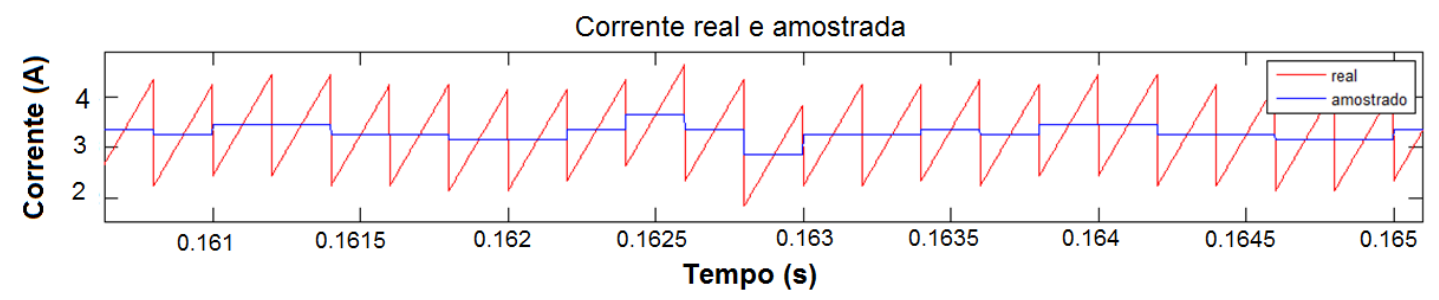

SOC real e estimado
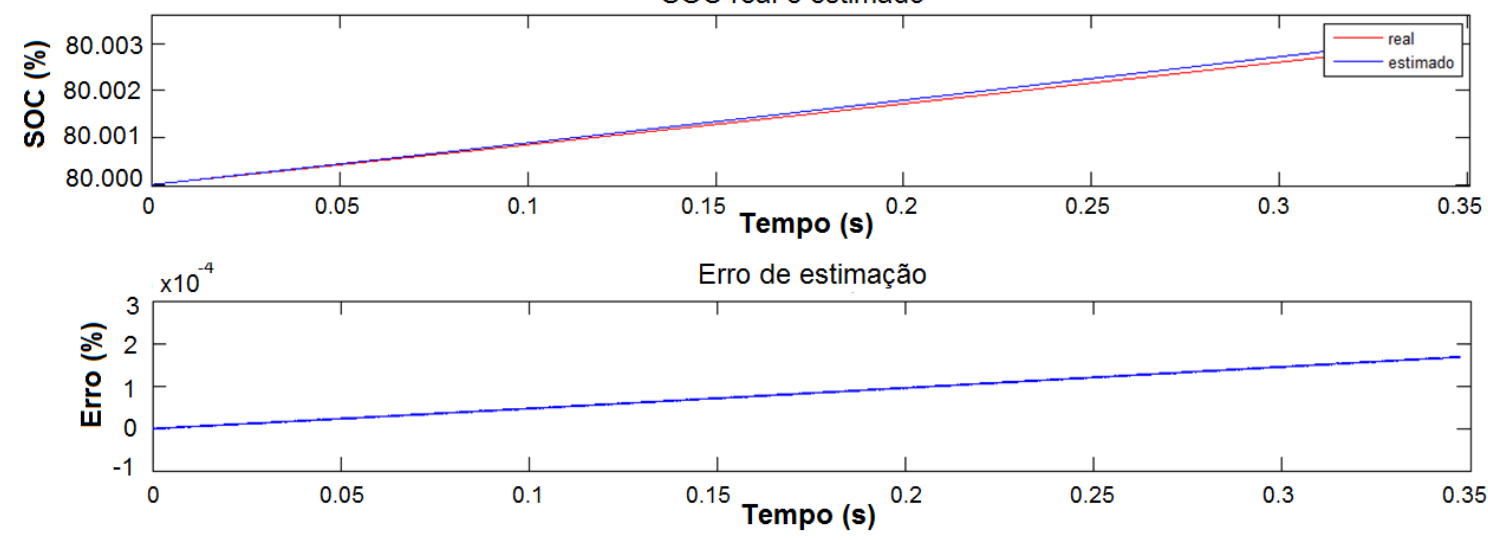

Figura 3.2- Corrente de entrada e corrente amostrada, SOC real e SOC estimado e Erro de estimação.

\section{2- Circuito bidirecional}

Para comprovar o funcionamento do circuito bidirecional e do controlador fuzzy $\mathrm{P}+\mathrm{l}$, é simulado um sistema utilizando duas fontes de energia que aceitam correntes reversas, sendo que do lado de alta tensão é utilizado uma fonte ideal com uma tensão de $120 \mathrm{~V}$, que é a tensão comum no barramento CC. No lado de baixa tensão, são utilizadas três baterias de $12 \mathrm{~V}$ conectadas em série formando um banco de 36 V. Na Figura 3.3 é mostrado o diagrama do circuito.

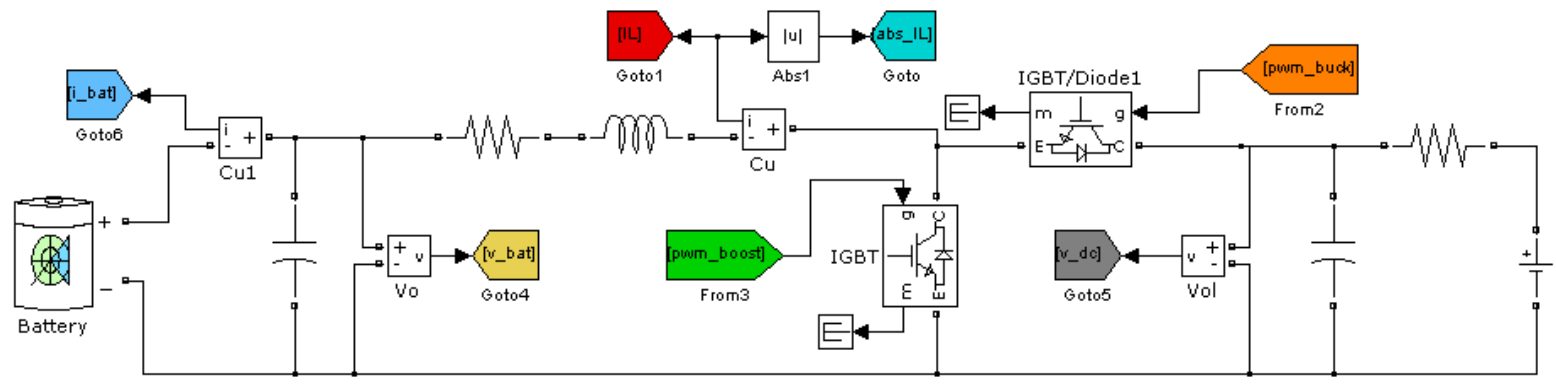

Figura 3.3 - Diagrama do circuito bidirecional, utilizando o controle fuzzy $\mathrm{P}+\mathrm{I}$ desenvolvido.

De acordo com (MOURA, 2011) não é recomendado uma corrente maior que $10 \%$ da capacidade da bateria, assim para uma bateria de 36 Ah não é 
recomendado uma corrente maior que 3,6 A, para carga ou descarga. Logo, para testar o desempenho do controlador em um caso extremo considerando uma bateria de 36 Ah, é utilizado uma referência de $4 \mathrm{~A}$ (Figura 3.4) que é um valor superior ao recomendado por (MOURA, 2011). Vale ressaltar que toda oscilação presente na corrente, em regime permanente, advém do chaveamento do conversor, assim estas oscilações podem ser reduzidas aumentando a frequência de chaveamento ou 0 indutor do conversor bidirecional.
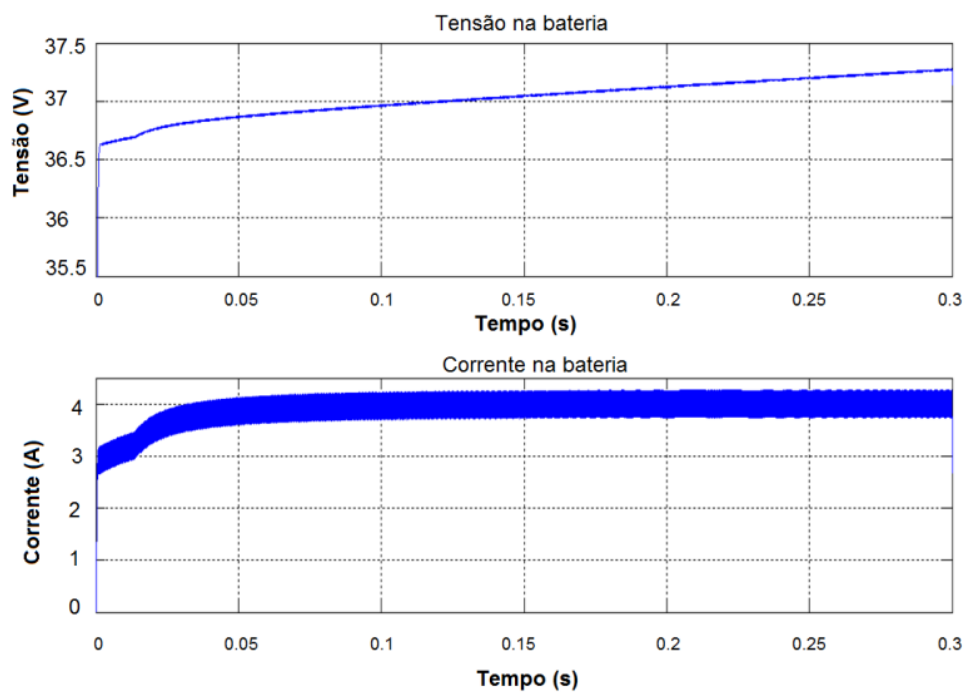

Figura 3.4 - Tensão e corrente da bateria durante a carga.

A Figura 3.5 mostra o sistema no modo de carga com uma inversão do sentido do fluxo de potência em $0,3 \mathrm{~s}$, ou seja, drenando potência da bateria a partir de 0,3 s. Durante a inversão nenhuma das chaves é acionada, pois o circuito aguarda o descarregamento da indutância, para então inverter o sentido da corrente, o que limita o tempo de inversão que é da ordem de $2 \mathrm{~ms}$. Assim que a corrente é zerada o circuito muda de Buck para Boost, fazendo a corrente fluir no sentido contrário (Figura 3.6). Nota-se que não há sobresinal durante todo o intervalo, mostrando a eficiência do controlador em gerenciar a operação do conversor em ambos os sentidos. 

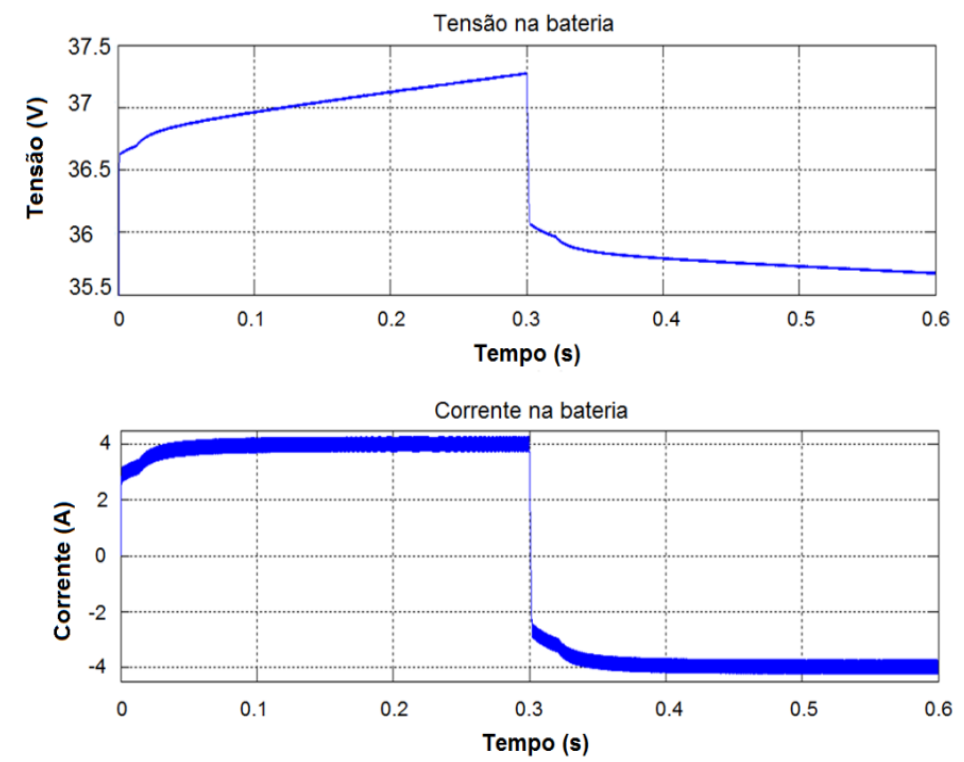

Figura 3.5 - Tensão e corrente da bateria quando a corrente é invertida em 0,3 s.

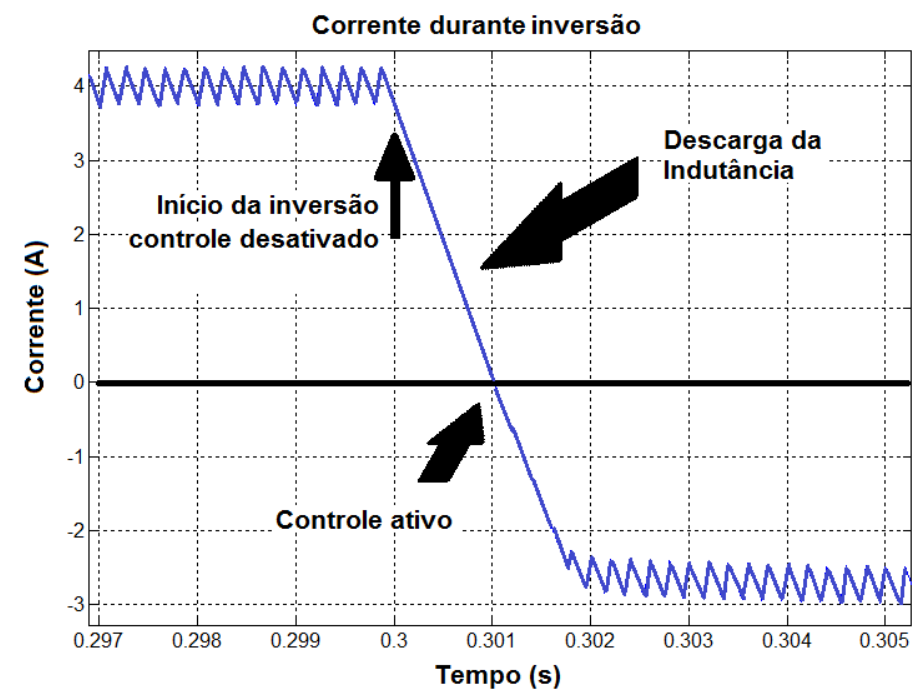

Figura 3.6 - Zoom sobre a inversão de corrente.

A Figura 3.7 mostra a mudança da variável de controle durante o processo de carga. No momento em que a tensão alcança um valor pré-estabelecido, a variável de controle é comutada e o sistema passa a controlar a tensão ao invés de controlar a corrente. Isso evita que os limites de tensão da bateria sejam ultrapassados.

Assim como descrito na seção 2.1.6, que mostra os métodos de carga, é possível perceber que a partir da ativação do controle da tensão a corrente tende a cair. Em $0,4 \mathrm{~s}$ o sentido de condução do circuito é invertido, logo o circuito não apresenta nenhuma limitação quanto à inversão do sentido de corrente, podendo ser 
invertido a qualquer momento, independentemente da variável controlada no momento da inversão.

A Figura 3.8 mostra o controlador PI projetado na seção 2.27 controlando tanto a tensão quanto a corrente do circuito bidirecional. Comparando o desempenho do controlador fuzzy $\mathrm{P}+\mathrm{I}$ ao controlador clássico, o PI apresenta uma resposta ao controle de corrente tão rápido quanto o fuzzy, entretanto na mudança de variável é que as diferenças são acentuadas e o fuzzy apresenta uma estabilização mais rápida de tensão, que é sentida na corrente mais suave.
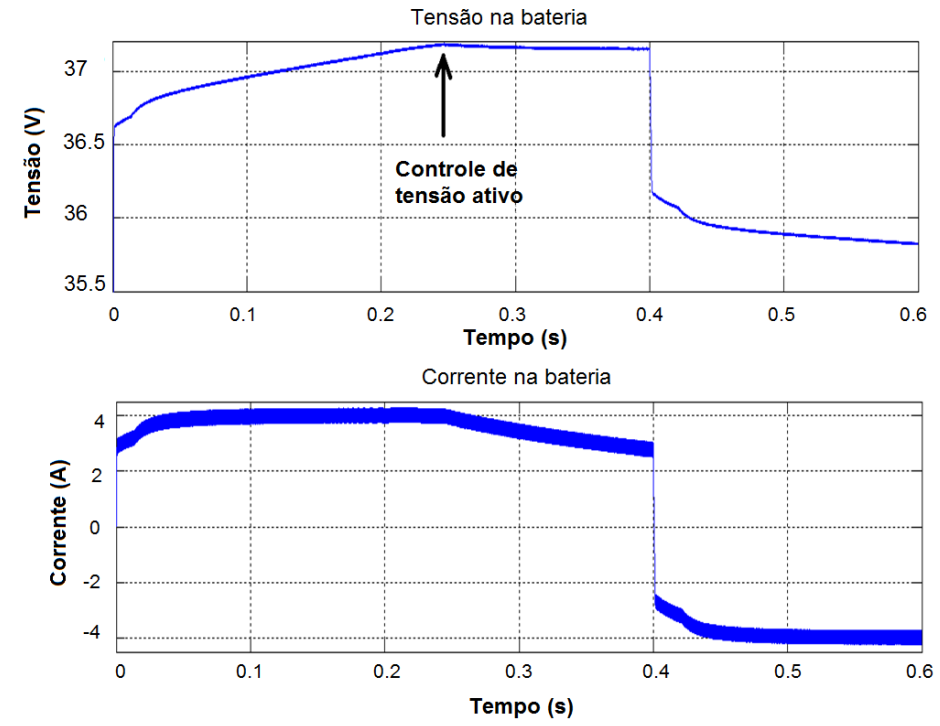

Figura 3.7 - Mudança da variável de controle e inversão do sentido de condução do conversor bidirecional utilizando controlador fuzzy $\mathrm{P}+\mathrm{I}$.
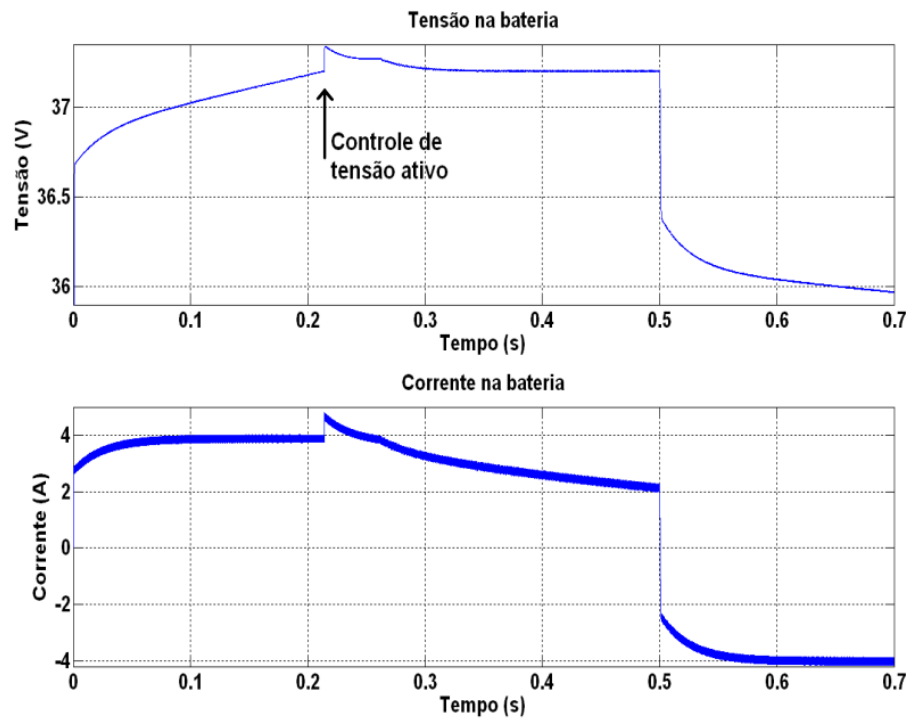

Figura 3.8 - Mudança de variável de controle utilizando o controle clássico PI. 


\section{3 - Sistema}

De posse do sistema de controle e do circuito bidirecional funcionando, é inserido o painel fotovoltaico e o modelo simplificado de injeção na rede, formando assim o sistema estudado nesta dissertação (Figura 3.9). Para o controle da tensão comum no barramento CC é utilizado o controle fuzzy mostrado na seção 2.4 com o intuito de avaliar o desempenho do sistema completo.

Nestas simulações, o sistema PV utiliza o algoritmo de busca do ponto de máximo MPPT e para mostrar o funcionamento durante a geração, a irradiação solar é mantida constante sobre os painéis, simulando um dia ensolarado.

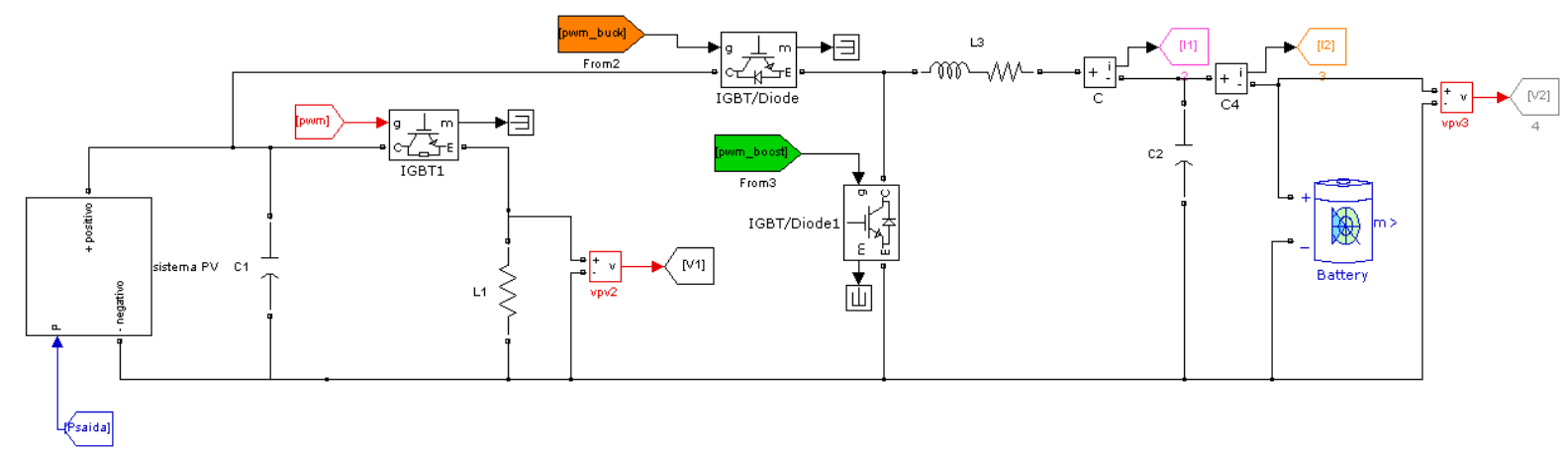

Figura 3.9 - Modelo do sistema completo.

A Figura 3.10 mostra a corrente de carga da bateria, com uma referência de 2 A. Nota-se que como no sistema ideal sem o painel da seção anterior, a corrente se estabiliza rapidamente, podendo ela ser invertida a qualquer momento, como acontece em 0,3 s. O pico de corrente negativo no inicio da simulação, advém do capacitor presente no barramento CC, pois este inicia descarregado e absorve corrente da bateria até que o painel tenha capacidade suficiente para alimentá-lo. 


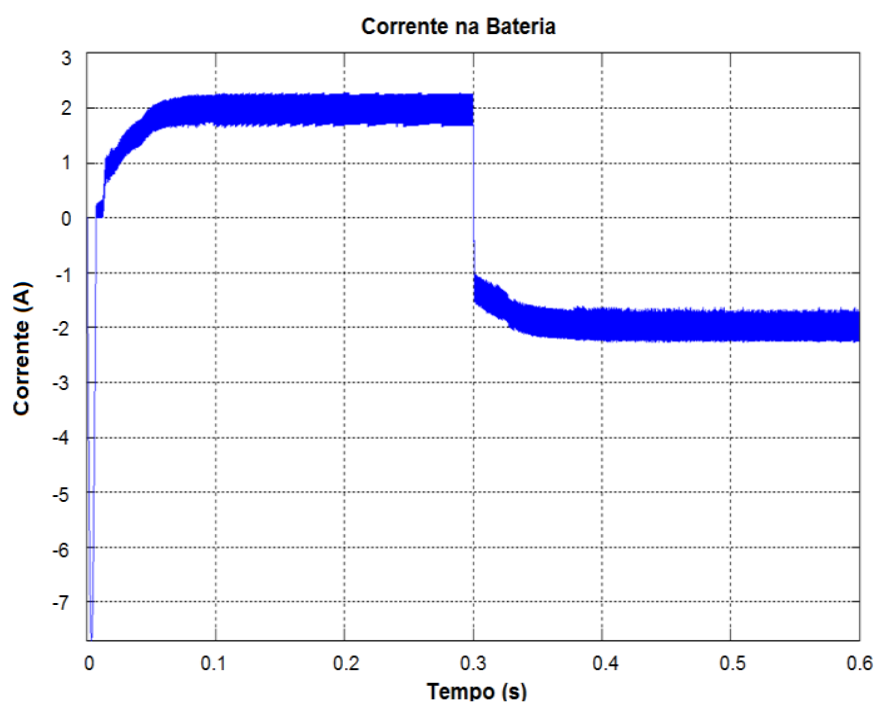

Figura 3.10- Corrente de carga da bateria, para uma referência de $2 \mathrm{~A}$ e em seguida uma inversão da corrente para -2 A em 0,3 s.

Na Figura 3.11 é mostrada a tensão $V_{c c}$ do barramento CC partindo do zero, com os painéis fotovoltaicos fora do ponto de máxima potência e a corrente que circula através das baterias não controladas. A partir do momento que o sistema sai de uma situação de repouso total para a operação em regime permanente, a tensão se estabiliza em menos de $0,1 \mathrm{~s}$, entretanto, a inversão da corrente da bateria em $0,3 \mathrm{~s}$ quebra o equilíbrio de potências, fazendo com que a potência drenada seja menor que a potência produzida, ocasionando um aumento de $V_{c c}$ como pode ser visto na Figura 3.11. Porém, este aumento é compensado em $0,2 \mathrm{~s}$ pelo sistema de controle, levando-o à estabilidade.

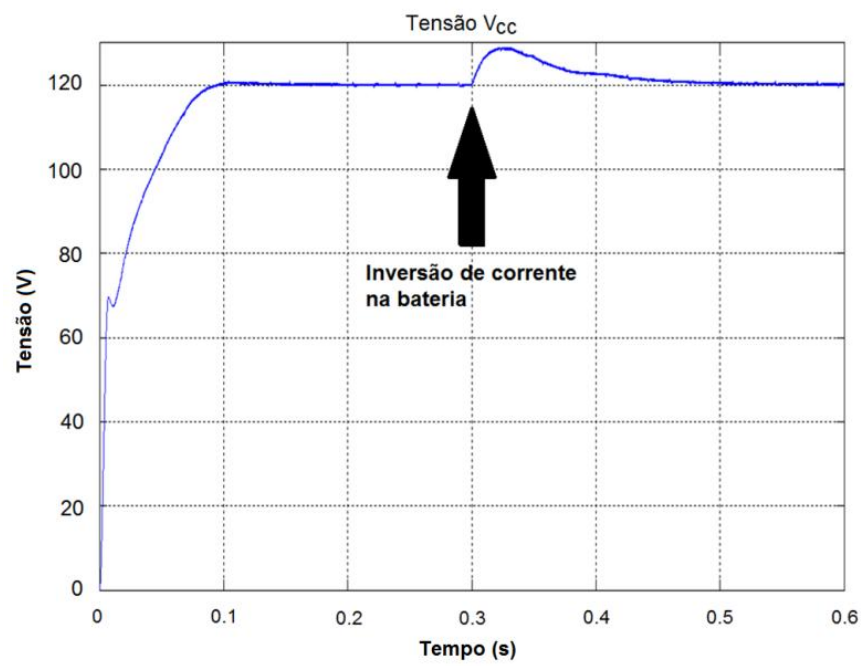

Figura 3.11 - Tensão comum no barramento CC ajustada em 120 V. Em 0,3 s a corrente na bateria é invertida. 
Por outro lado, na Figura 3.12 é mostrada a resposta do controlador de corrente quando a bateria é submetida à inversão no fluxo da corrente. Como previsto, o bloco fuzzy atua como um controlador proporcional durante os transitórios. Enquanto que o bloco integral atua no regime permanente, zerando o erro. A saída do controlador, que é a soma do fuzzy mais a saída do bloco integral, alcança o valor de referência em menos de $0,1 \mathrm{~s}$.
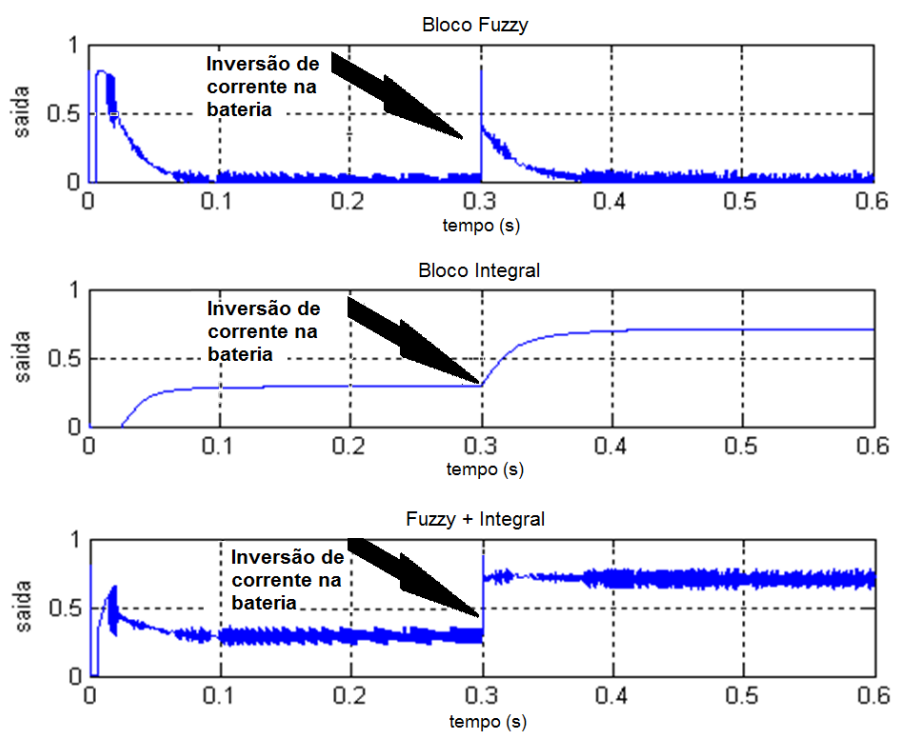

Figura 3.12 - Resposta do controlador de corrente na bateria com referência de $2 \mathrm{~A}$ e -2 A em 0,3 s.

Considerando a irradiação solar fixa, a tensão de máxima potência também deve permanecer fixa, entretanto com a utilização do MPPT com P\&O, o sistema tende a oscilar em torno do ponto de máxima potência devido ao método de busca, como foi apresentado na seção 2.2.2. A Figura 3.13 representa a tensão terminal do sistema PV em torno do ponto de máxima potência durante a inversão de corrente, é visto que mesmo durante a inversão (em $0,3 \mathrm{~s}$ ) a tensão terminal do painel se mantém em torno do ponto de máxima potência mesmo quando o fluxo de potência através da bateria é invertido. 


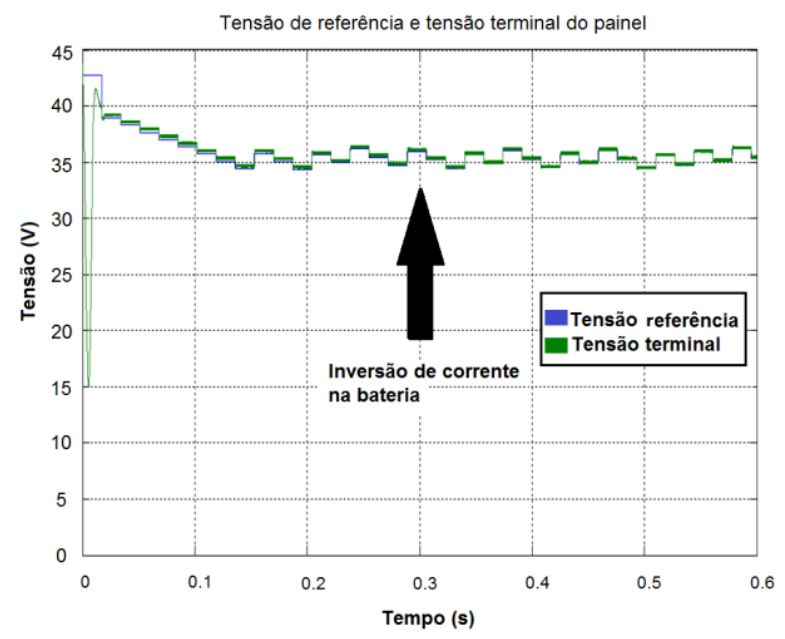

Figura 3.13 - Tensão de referência gerada pelo algoritmo MPPT e tensão terminal sistema PV.

Já na Figura 3.14 é mostrada a potência de referência do sistema PV produzida através da utilização do algoritmo MPPT, a potência de saída do PV e a potência total consumida pelo sistema. A diferença entre a potência de saída do PV e a potência consumida pode dar uma ideia do rendimento do conversor eletrônico, Figura 3.15. Ao ser analisado o rendimento do conversor, ficou constatado que 0 mesmo estava entre $80 \%$ e $90 \%$ o que é esperado para conversores sem comutação suave. A oscilação existente no rendimento em $0,3 \mathrm{~s}$ advém da inversão do sentido de condução do conversor bidirecional, que altera seu modo de funcionamento e, consequentemente, seu rendimento.

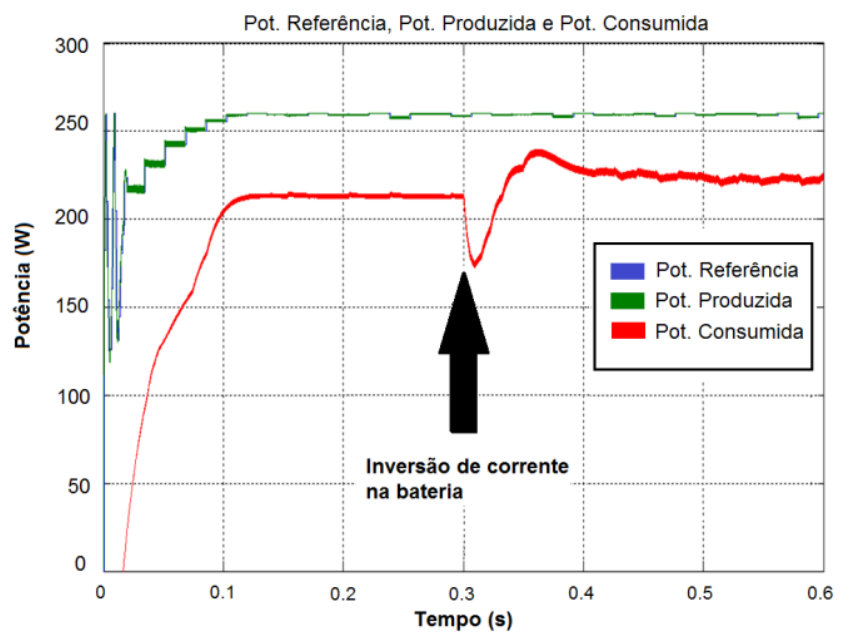

Figura 3.14-Potência de referência gerada pelo algoritmo MPPT, potência produzida pelos painéis e potência total consumida pelas baterias e pela rede. 


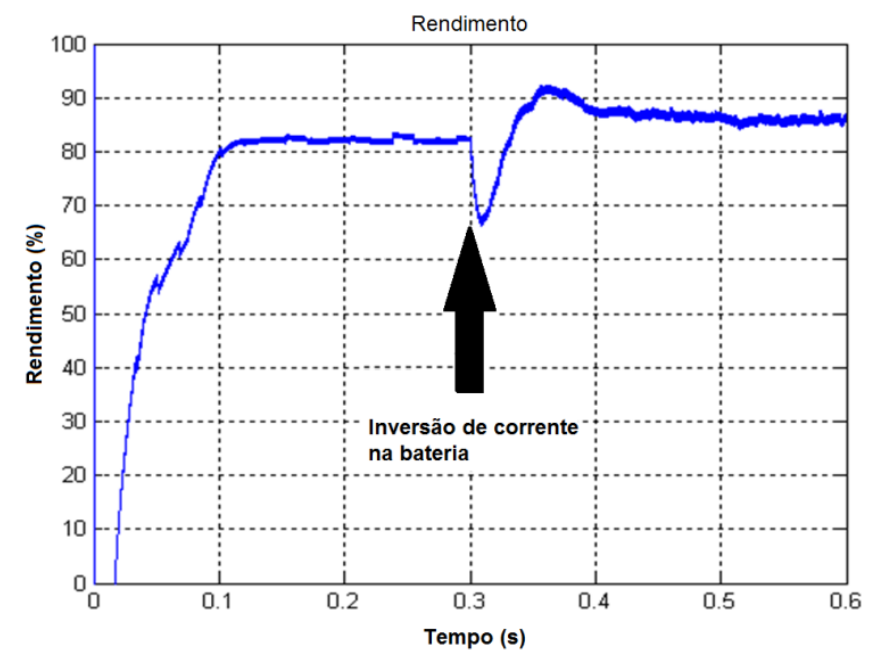

Figura 3.15 - Rendimento total do sistema.

\section{4-Sistema completo com alterações nas condições atmosféricas}

Nesta seção é utilizado o mesmo sistema da Figura 3.9, porém são impostas variações sobre irradiação solar. Estas variações simulam um dia muito nublado, cuja irradiação incidente sobre os painéis se altera bruscamente. Logo, é visto na Figura 3.16 que o sistema proposto mantém a corrente de carga das baterias constante enquanto regula a tensão no barramento CC (Figura 3.17).

Além disso, a corrente de carga das baterias é ajustada em $2 \mathrm{~A}$, quando a irradiação incidente sobre os painéis é reduzida de $1000 \mathrm{~W} / \mathrm{m}^{2}$ para $800 \mathrm{~W} / \mathrm{m}^{2}$, é observado que a corrente de carga não sofre nenhuma alteração visível, isto é devido ao controle da tensão do barramento $\mathrm{CC}$, pois como esta tensão quase não se altera (Figura 3.17), a perturbação não é suficiente para afetar a corrente, que é dependente da tensão comum no barramento CC. 


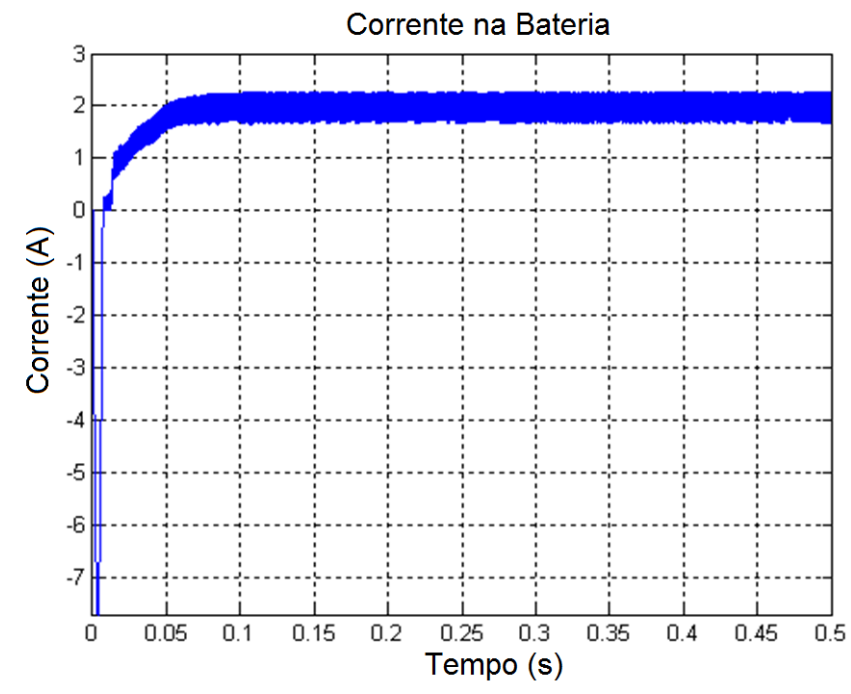

Figura 3.16 - Corrente de carga da bateria durante alteração da irradiação bruscamente em $0,3 \mathrm{~s}$.

No momento que a irradiação incidente sobre o painel é reduzida, a potência produzida por eles também se reduz, fazendo o balanço de potência seja quebrado por um consumo maior que a produção de energia. Logo a tensão sofre um afundamento, que é corrigido em aproximadamente em 0,2 s pelo sistema de controle da tensão no barramento CC (Figura 3.17) reduzindo a potência consumida, porém os painéis ainda possuem energia suficiente para suprir toda a demanda (bateria e rede).

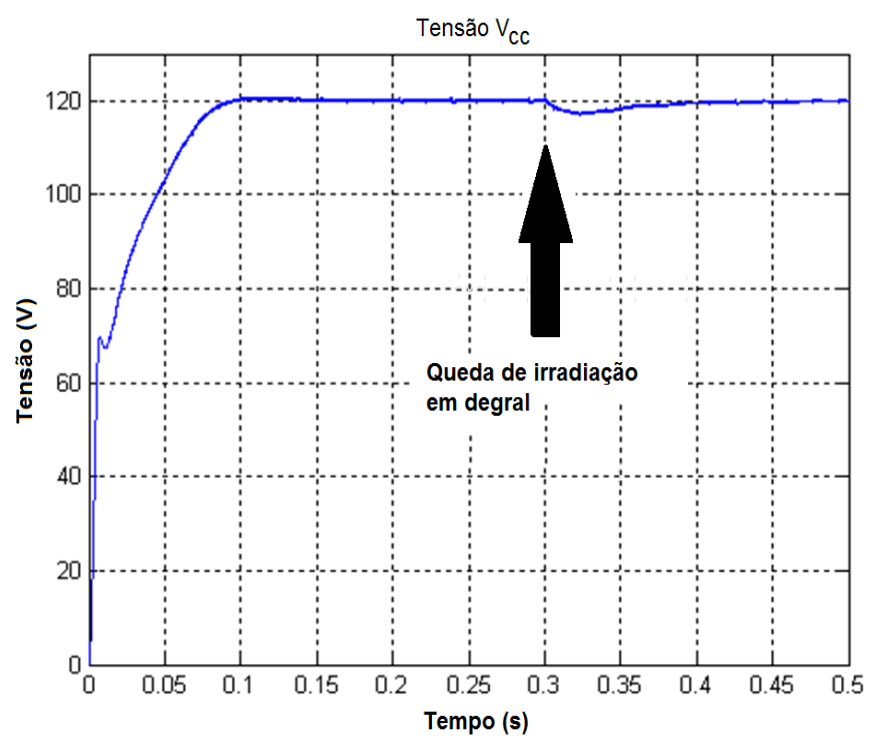

Figura 3.17 - Tensão comum do barramento CC durante alteração da irradiação bruscamente em $0,3 \mathrm{~s}$.

Mesmo após a queda da irradiação incidente, a tensão de máxima potência não sofre variações perceptíveis (Figura 3.18). Isto ocorre devido à proximidade da 
tensão de máxima potência dos painéis fotovoltaicos com $1000 \mathrm{~W} / \mathrm{m}^{2}$ e $800 \mathrm{~W} / \mathrm{m}^{2}$. Isto pode ser constatado pela Figura 2.11 da seção 2.2.1.

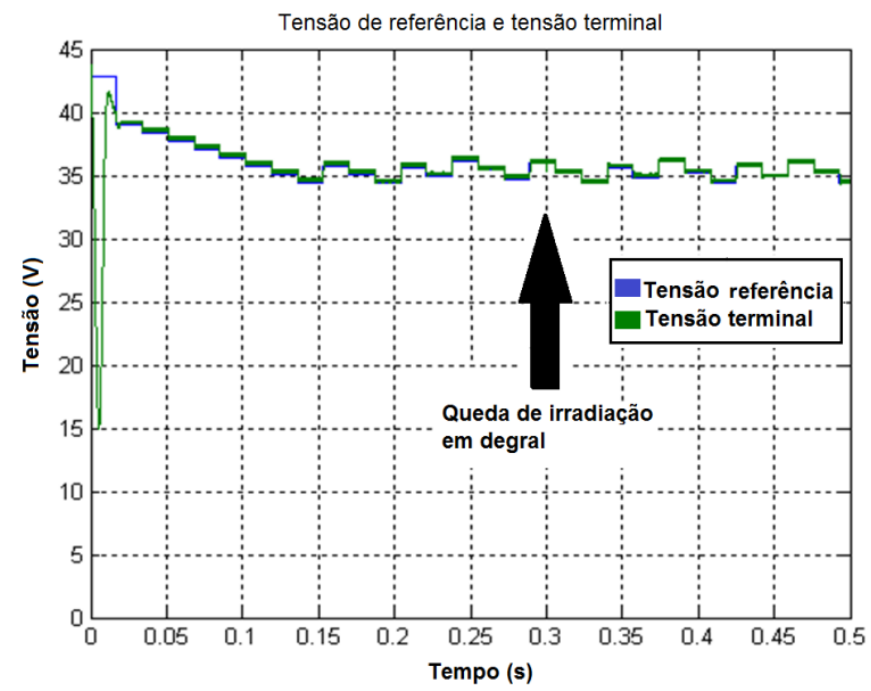

Figura 3.18 - Tensão de referência gerada pelo algoritmo MPPT e tensão nos terminais do PV durante alteração da irradiação bruscamente em 0,3 s.

No momento em que ocorre a transição abrupta de incidência solar, tanto a potência produzida pelos painéis quanto a potência que é entregue à rede são reduzidas (Figura 3.19). É visto que o consumo é ajustado pelo sistema de controle da tensão do barramento $C C$, que atua de forma a diminuir a potência consumida para recuperar o afundamento da tensão. A partir destas curvas, é calculado o rendimento do sistema que é mostrado na Figura 3.20, ficando entre $80 \%$ e $90 \%$ que é o esperado para este tipo de circuito, conforme já mencionado. O pico de rendimento em $0,3 \mathrm{~s}$ representa apenas um transitório e está relacionado com o consumo de potência do sistema que é maior que o produzido pelos painéis fotovoltaicos durante alguns instantes, Figura 3.19. 


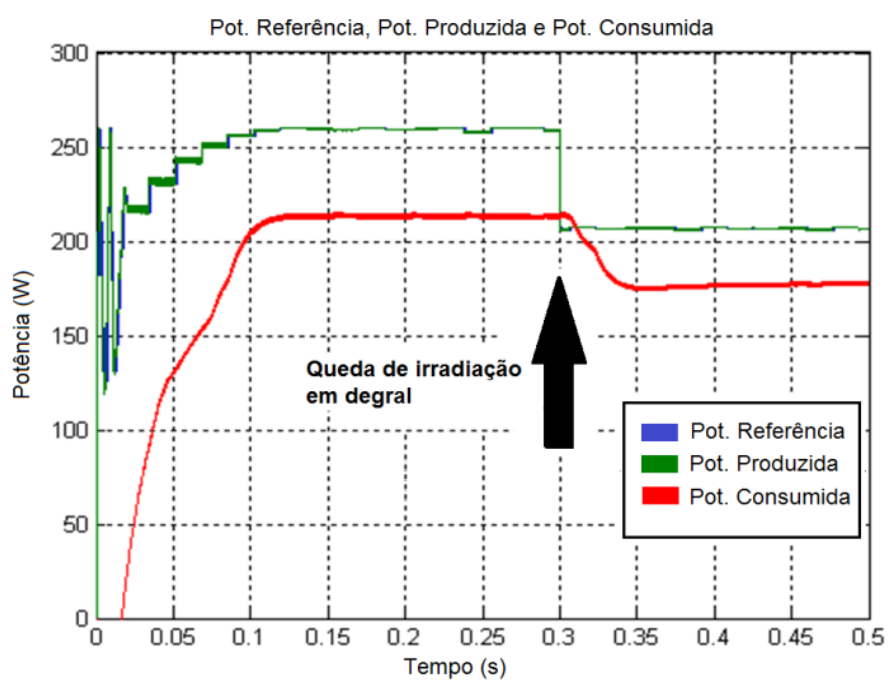

Figura 3.19-Potência de referência gerada pelo algoritmo MPPT, potência produzida pelos painéis e potência total consumida.

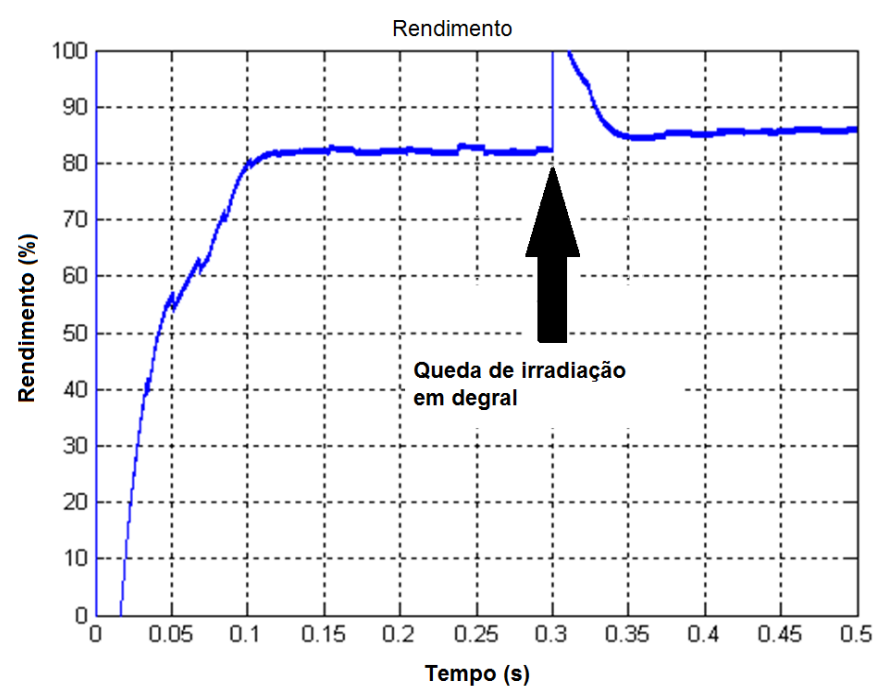

Figura 3.20 - Rendimento do sistema entre $80 \%$ e $90 \%$.

\section{5 -Sistema completo com variação contínua da irradiação solar}

$\mathrm{Na}$ seção anterior o conjunto de painéis fotovoltaicos é submetido a uma variação em degrau de irradiação solar o que proporcionou analisar a capacidade do controle e do dispositivo eletrônico em manter o sistema estável. Nesta seção, o mesmo é submetido a uma variação do tipo rampa de forma que se analisar o comportamento e a dinâmica do sistema durante a variação, além de verificar se o sistema é capaz de manter a corrente de carga da bateria e a tensão no barramento CC mesmo durante uma variação constante de irradiação. Assim, é criado um perfil 
de irradiação solar como da Figura 3.21, com a seguinte característica: um degrau em 0,2 s e uma variação linear até 0,5 s seguido da estabilização da irradiação.

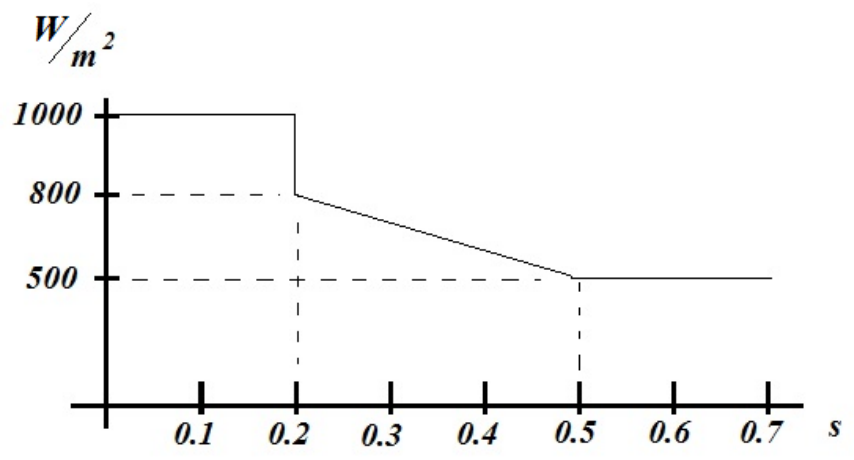

Figura 3.21 - Irradiação solar incidente sobre o painel.

Pela Figura 3.22, a corrente não é afetada pela variação da irradiação solar, mesmo sendo aplicado um degrau ou uma rampa na irradiação. Isto ocorre devido à baixa amplitude do afundamento da tensão comum no barramento $C C$, que pode ser visto na Figura 3.23.

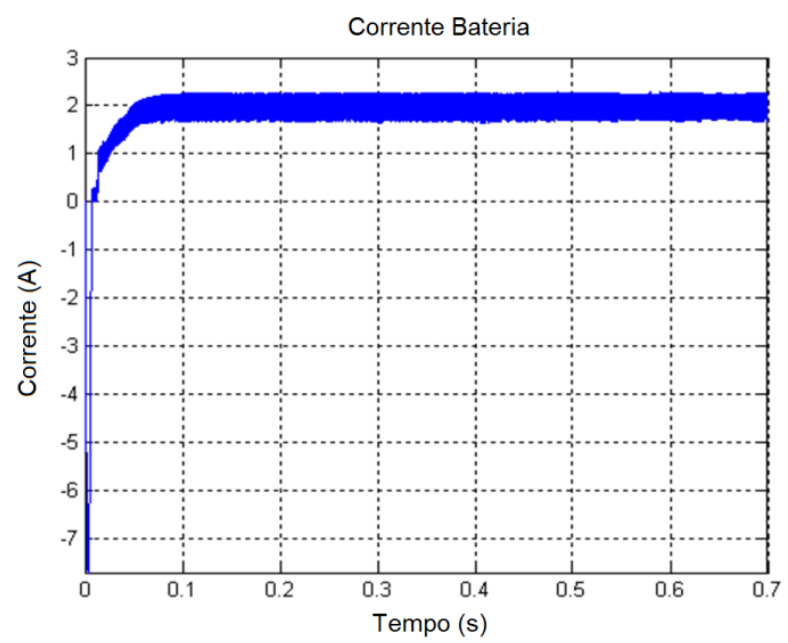

Figura 3.22-Corrente de carga da bateria durante alteração da irradiação.

Por outro lado, na Figura 3.23 é mostrado que a partir do momento em que a irradiação começa a ser reduzida em 0,2 s, a tensão sofre um afundamento que é constantemente compensado pelo sistema de controle da tensão do barramento CC. Entretanto, como a irradiação continua a cair, o processo de compensação continua ativo, pois o erro não é zerado, fazendo com que o sistema não seja capaz de uma estabilização completa, isso somente ocorre após a estabilização da irradiação em 0,5 s. Porém, mesmo que o sistema não zere o erro durante o transitório da 
irradiação, ele se manteve em torno de $5 \%$, mostrando a eficiência na regulagem da tensão do barramento CC mesmo durante transitórios.

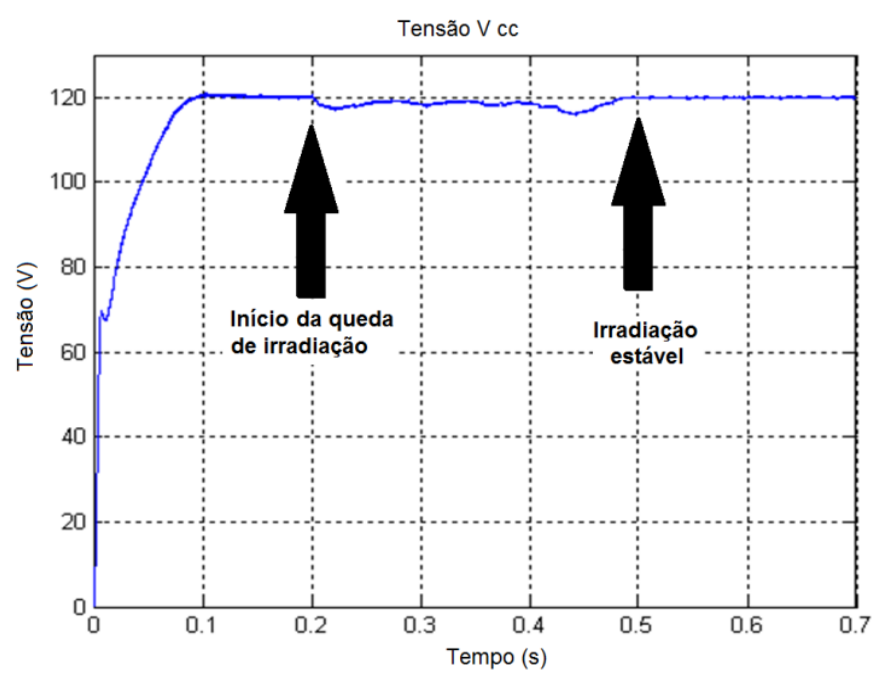

Figura 3.23 - Tensão no barramento CC com diminuição da irradiação em rampa.

Na Figura 3.24 é apresentada a tensão terminal do sistema PV, onde em 0,4 $\mathrm{s}$ ocorre um acréscimo e depois de transcorridos $0,1 \mathrm{~s}$ o sistema retorna a seu valor de máxima potência. Isto ocorre, pois o algoritmo de maximização (MPPT) trabalha sobre o princípio da perturbação e observação assim, a perturbação pode tomar a direção contrária ao ponto ótimo, retomando logo em seguida o caminho correto na busca do ponto de máxima potência, mostrando exatamente uma das fraquezas do algoritmo MPPT, que não apresenta bom desempenho em variações rápidas de irradiação.

Como no caso anterior, as tensões de máxima potência antes da redução da irradiação e depois da redução estão em torno dos $35 \mathrm{~V}$, pois a tensão de máxima potência se encontra numa região bem específica, com valores próximos, mesmo para irradiações diferentes. 


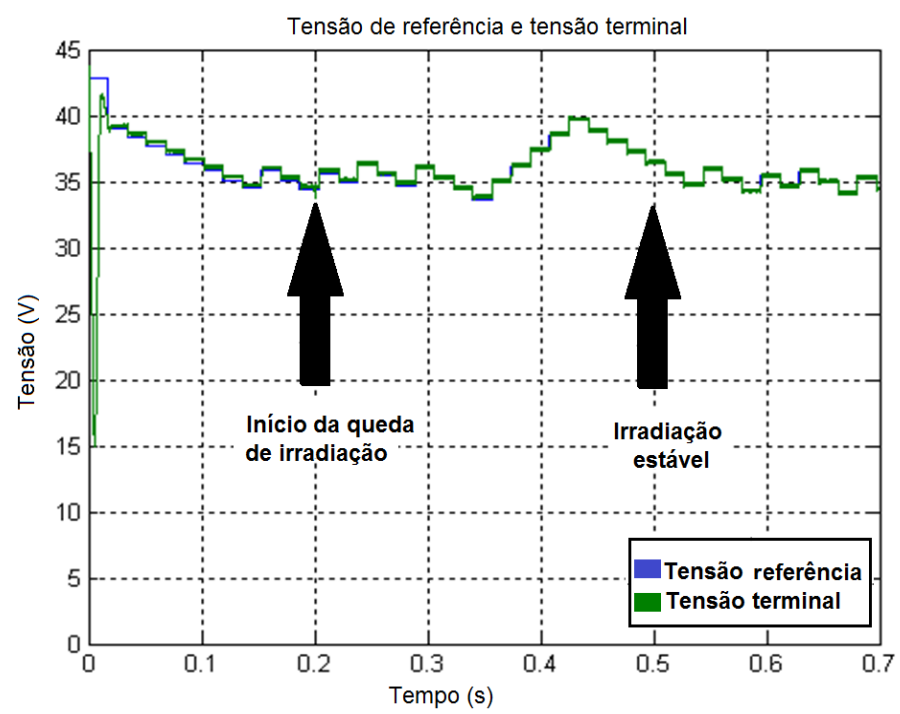

Figura 3.24- Tensão de referência gerada pelo algoritmo MPPT e tensão terminal do sistema PV durante a variação da irradiação.

Na sequência, é apresentada, na Figura 3.25, a potência de saída dos painéis e a potência total de saída do sistema. O sistema possui um perfil de potência de saída semelhante ao da Figura 3.21. Além disso, a potência consumida é ajustada pelo sistema de controle para garantir o balanço de potência. Observa-se que neste caso, após $0,5 \mathrm{~s}$, a tensão do barramento CC e a irradiação estão estáveis.

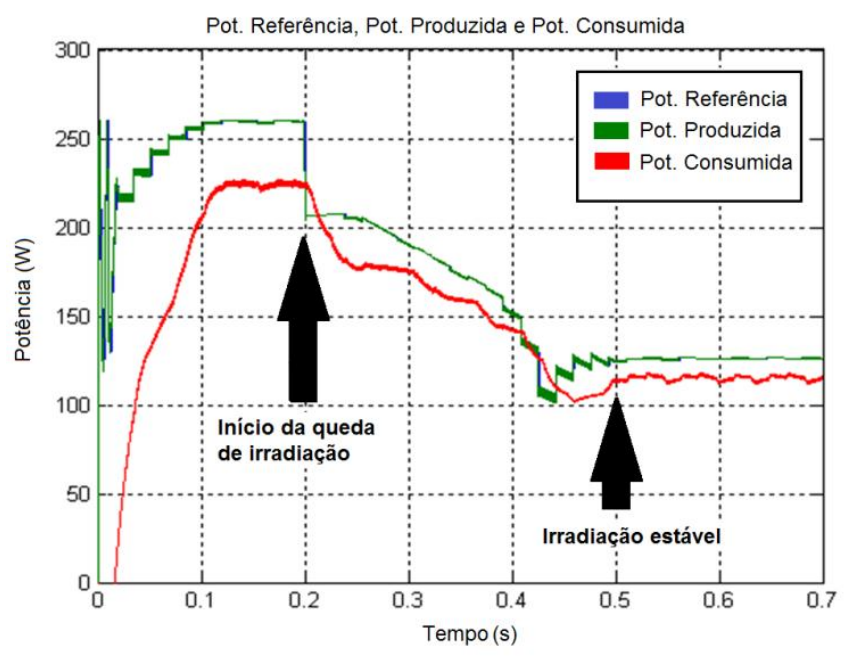

Figura 3.25-Potência de referência gerada pelo algoritmo MPPT, potência produzida pelos painéis e potência total consumida.

A Figura 3.26 mostra o rendimento do sistema, em torno de $90 \%$ em regime permanente. Isto se deve à redução da potência gerada, o que reduziu a corrente e alterou o ponto de operação dos conversores, reduzindo as perdas e aumentando o rendimento. Novamente, os picos de rendimento próximos a 100\% não representam 
o rendimento nestes instantes, e sim valores transitórios onde parte da potência reativa do capacitor do barramento CC é injetada no sistema.

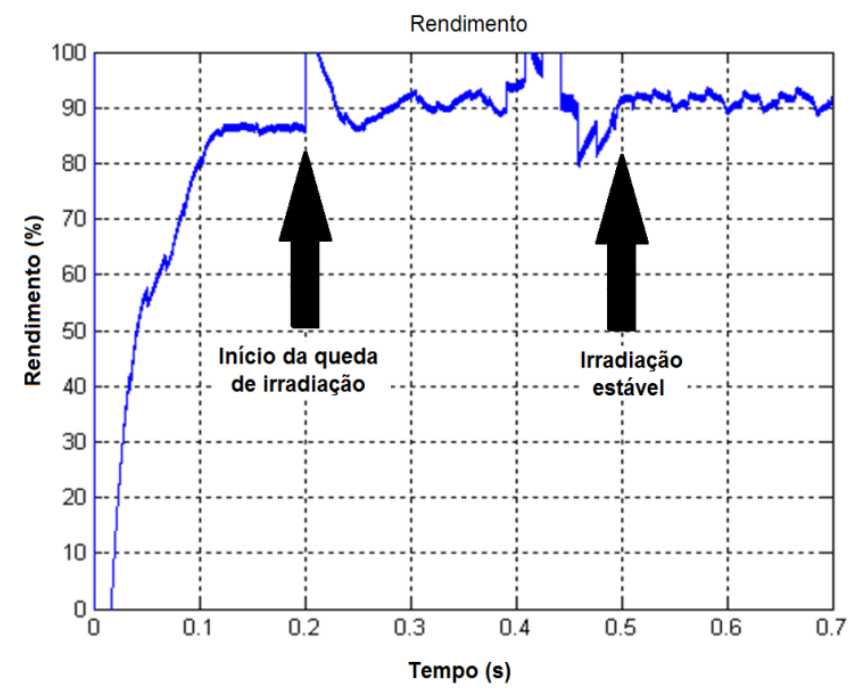

Figura 3.26-Rendimento do sistema.

\subsection{Considerações finais}

Neste capítulo, são apresentados os resultados das simulações realizadas no desenvolvimento deste projeto. Como previsto, o sistema de estimação do SOC deve ser aferido de tempos em tempos devido ao acúmulo de erro, além de que a resolução da estimação depende do estado inicial definido pela tensão de circuito aberto.

O sistema de controle fuzzy $\mathrm{P}+\mathrm{l}$ apresenta desempenho satisfatório, controlando a corrente em qualquer sentido no circuito bidirecional, convergindo em menos de 0,1 s sem a presença de sobre sinal, além de se conseguir mudar a variável de controle em qualquer instante sem alterar a estabilidade do sistema.

A corrente de carga não foi afetada por variações bruscas na irradiação solar, pois o sistema de controle da tensão comum no barramento CC foi eficiente, recuperando-se em menos de 0,2 s quando submetido a afundamentos e sobre tensões.

O rendimento dos conversores eletrônicos em regime permanente se manteve dentro dos limites esperados, entre $80 \%$ e $90 \%$, havendo um aumento da eficiência nos momentos nos quais a potência gerada pelos painéis é reduzida e quando ambos os conversores (conversor dos painéis e das baterias) estão no modo Boost (elevador de tensão). 


\section{4- Execução e resultados experimentais}

\section{1- Materiais utilizados}

Nesta seção são descritos os materiais e métodos utilizados na execução desta dissertação. A Figura 4.1 apresenta o diagrama do sistema com as diferentes etapas que farão parte do protótipo.

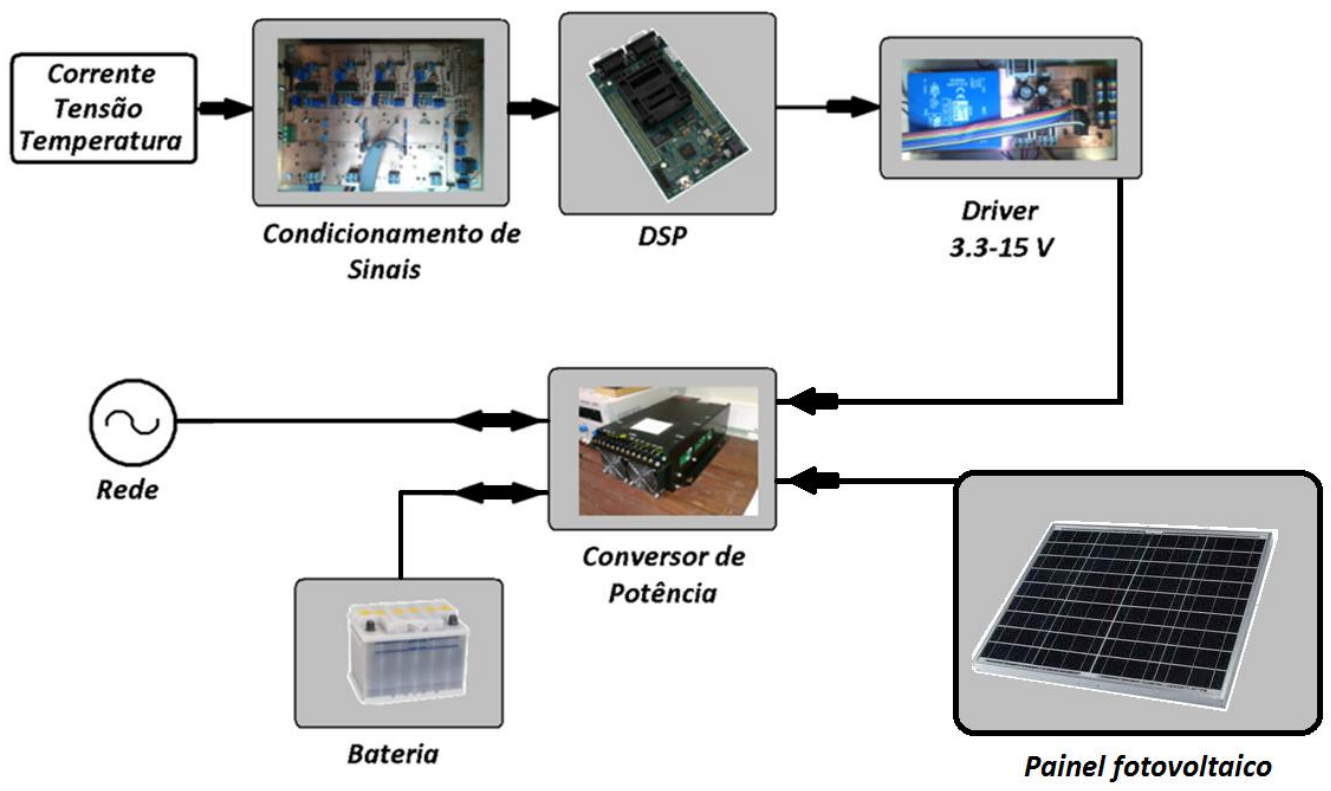

Figura 4.1- Diagrama do sistema.

Para a leitura e condicionamento dos sinais amostrados, é construída uma placa genérica de condicionamento sendo, na Figura 4.2, mostrado o diagrama deste circuito por canal. Esse circuito tem a função de condicionar os sinais amostrados de forma que possam ser lidos pelo DSP, além de limitar a tensão em um valor máximo, para que o processador não seja danificado em caso de sobre sinal. 


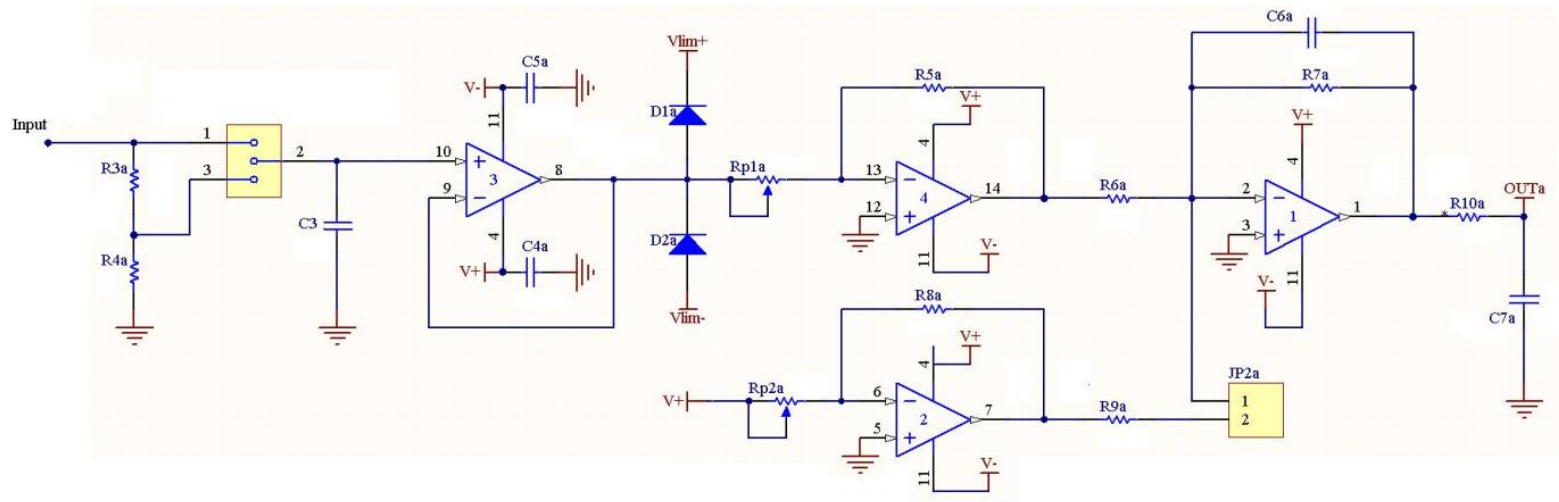

Figura 4.2-Diagrama da placa de condicionamento de sinais por canal.

Como unidade lógica e de processamento é utilizado uma placa da Spectrum Digital da Texas Instruments eZdsp TMS320F28335, Figura 4.3. O processador faz a leitura da corrente, tensão e temperatura na bateria, além da tensão no barramento CC. Depois de mensurar as variáveis, são executadas as rotinas de controle que permitirão comandar as chaves do conversor bidirecional e do sistema de injeção na rede regulando, desta forma, a carga das baterias, a tensão $V_{c c} \mathrm{e}$ calculando o SOC da bateria.

O bloco fuzzy é executado em forma de tabela, cuja superfície é gerada em um computador e seus valores inseridos na memória do processador. Esta metodologia é aplicada para tornar a execução mais simples e rápida.

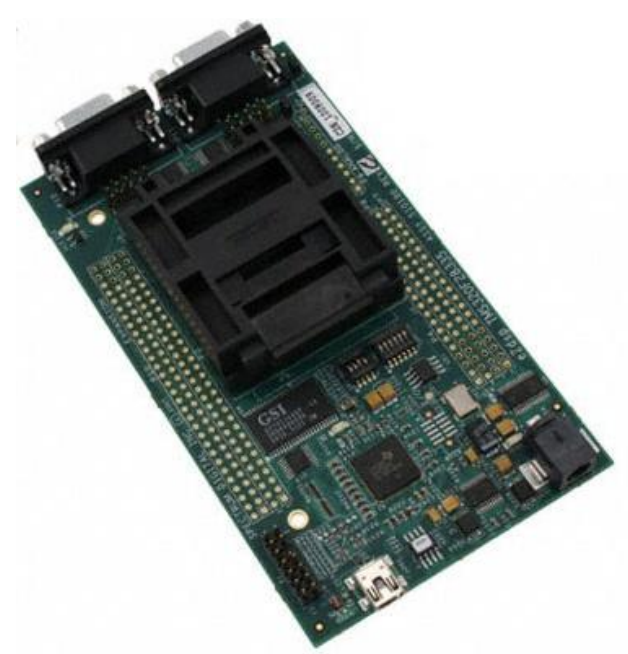

Figura 4.3 - DSP Texas instruments eZdsp TMS320F28335. 
Para a construção dos circuitos conversores e do sistema de injeção simplificado é utilizado um módulo conversor trifásico da Semikron (Modelo SKS 21F $\mathrm{B} 6 \mathrm{U}+\mathrm{E} 1 \mathrm{ClF}+\mathrm{B} 6 \mathrm{Cl} 12 \mathrm{~V} 12)$, Figura 4.4. Usando apenas um módulo é possível construir o conversor bidirecional e o sistema que simula a injeção na rede. Entretanto, para acionar o módulo, é necessário um PWM com uma tensão de $15 \mathrm{~V}$ (CC), porém o DSP fornece em seus terminais apenas 3,3 V. Para tal adequação de níveis de tensão, é utilizado um Driver com a função de alterar o nível de tensão do PWM gerado pelo DSP.

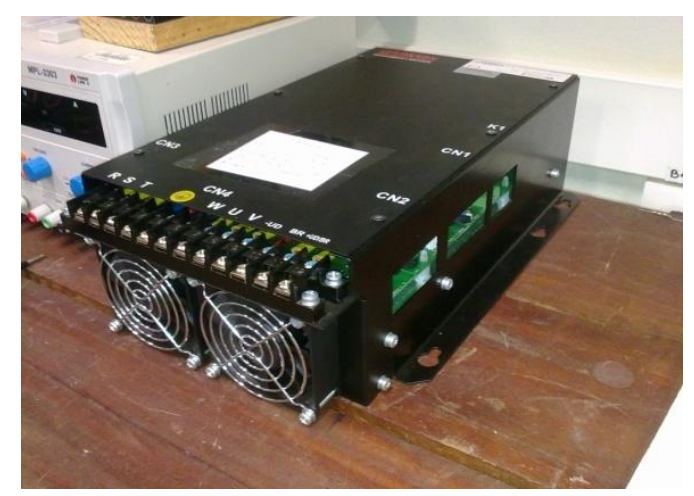

Figura 4.4- Módulo conversor Semikron Modelo SKS 21F B6U+E1CIF + B6Cl.

Como painel fotovoltaico é usada uma fonte emuladora de painéis Agilent Technologies (Modelo E4360A) de 550 W de potência máxima de saída, Figura 4.5. Para configurar a fonte como painel, basta ajustá-la com os seguintes parâmetros: Tensão de circuito aberto $\left(V_{o c}\right)$, tensão de máxima potência $\left(V_{m p}\right)$, corrente de curto circuito $\left(I_{s c}\right)$ e corrente de máxima potência $\left(I_{m p}\right)$, formando assim a curva característica da Figura 4.6.

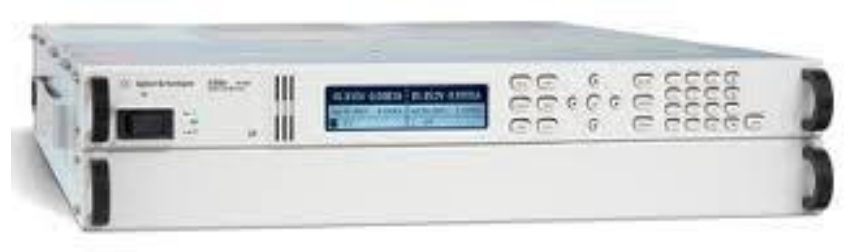

Figura 4.5 - Fonte emuladora de painéis Agilent. 


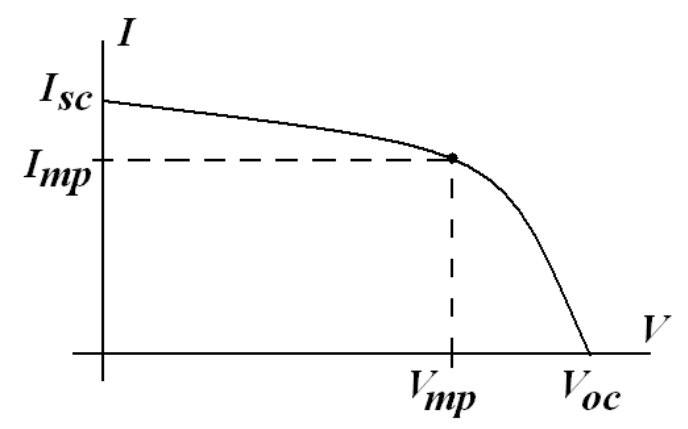

Figura 4.6 - Curva $\mathrm{V} \times \mathrm{I}$ a quatros parâmetros do emulador.

Foi usada a fonte no lugar dos painéis, pois com a fonte é possível ter controle total sobre os eventos, como redução e aumento da irradiação, mudança da tensão de máxima potência além de ser possível criar variações muito bruscas na energia gerada, testando o sistema no limite de seu desempenho e em casos extremos.

O banco de baterias foi montado utilizando três baterias Moura Clean (12MF36 de 12 V e 36 Ah, Figura 4.7), que são baterias próprias para sistemas estáticos, formando um banco de $36 \mathrm{~V}$ com uma capacidade de $36 \mathrm{Ah}$, totalizando 1296 Wh de energia máxima armazenada.

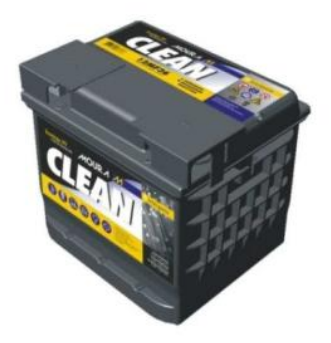

Figura 4.7 - Bateria Moura Clean para sistemas estáticos.

$\mathrm{Na}$ montagem do sistema, que pode ser representado pela Figura 4.8, foram usados os seguintes elementos passivos, escolhidos de forma a minimizar as oscilações de corrente e tensão.

$$
\begin{gathered}
L_{1}=10 \mathrm{mH} \\
C_{1}=940 \mu \mathrm{F} \\
L_{2}=5 \mathrm{mH} \\
C_{2}=1,410 \mathrm{mF} \\
C_{3}=1,360 \mathrm{mF}
\end{gathered}
$$




$$
\begin{gathered}
R_{\text {carga }}=40 \Omega \\
f_{\text {chaveamento }}=10 \mathrm{kHz}
\end{gathered}
$$

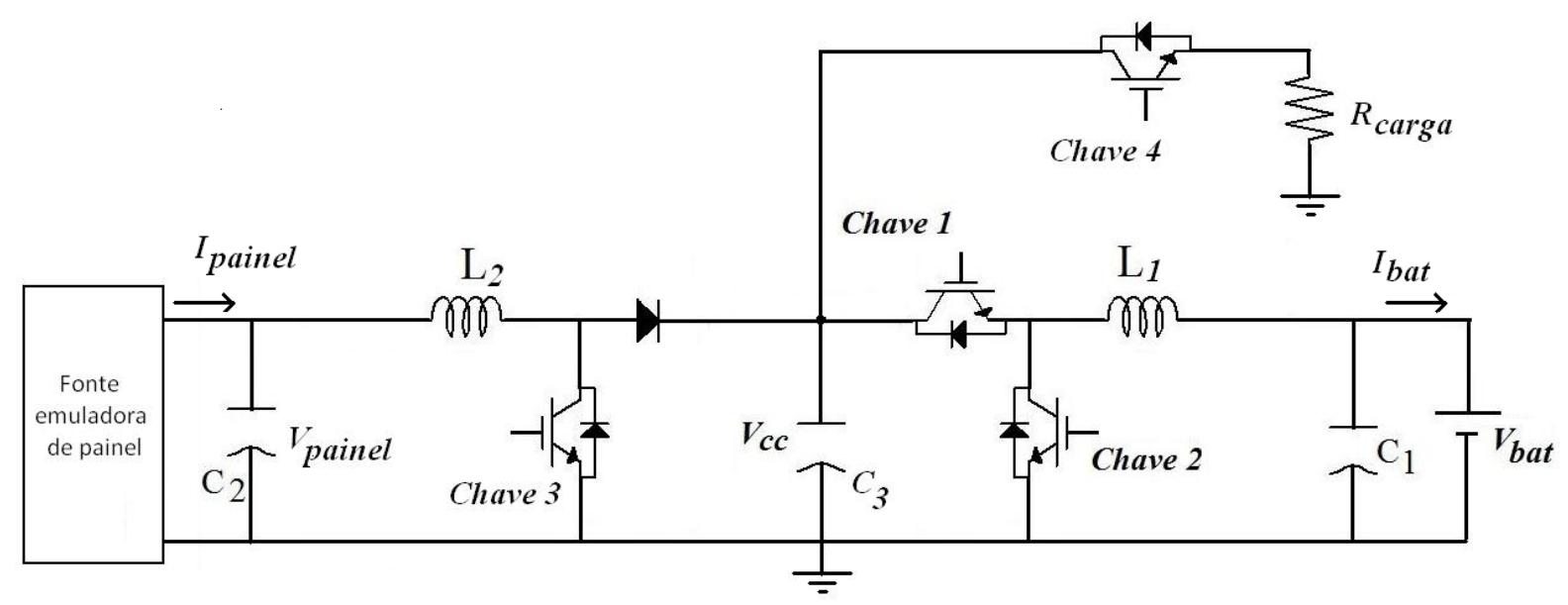

Figura 4.8 - Sistema construído.

A Figura 4.9 mostra uma foto do protótipo finalizado, destacando as partes que compõem o sistema que são: as baterias, os elementos passivos (capacitores e indutores), a placa de condicionamento, Driver de acionamento do conversor, DSP e a carga.

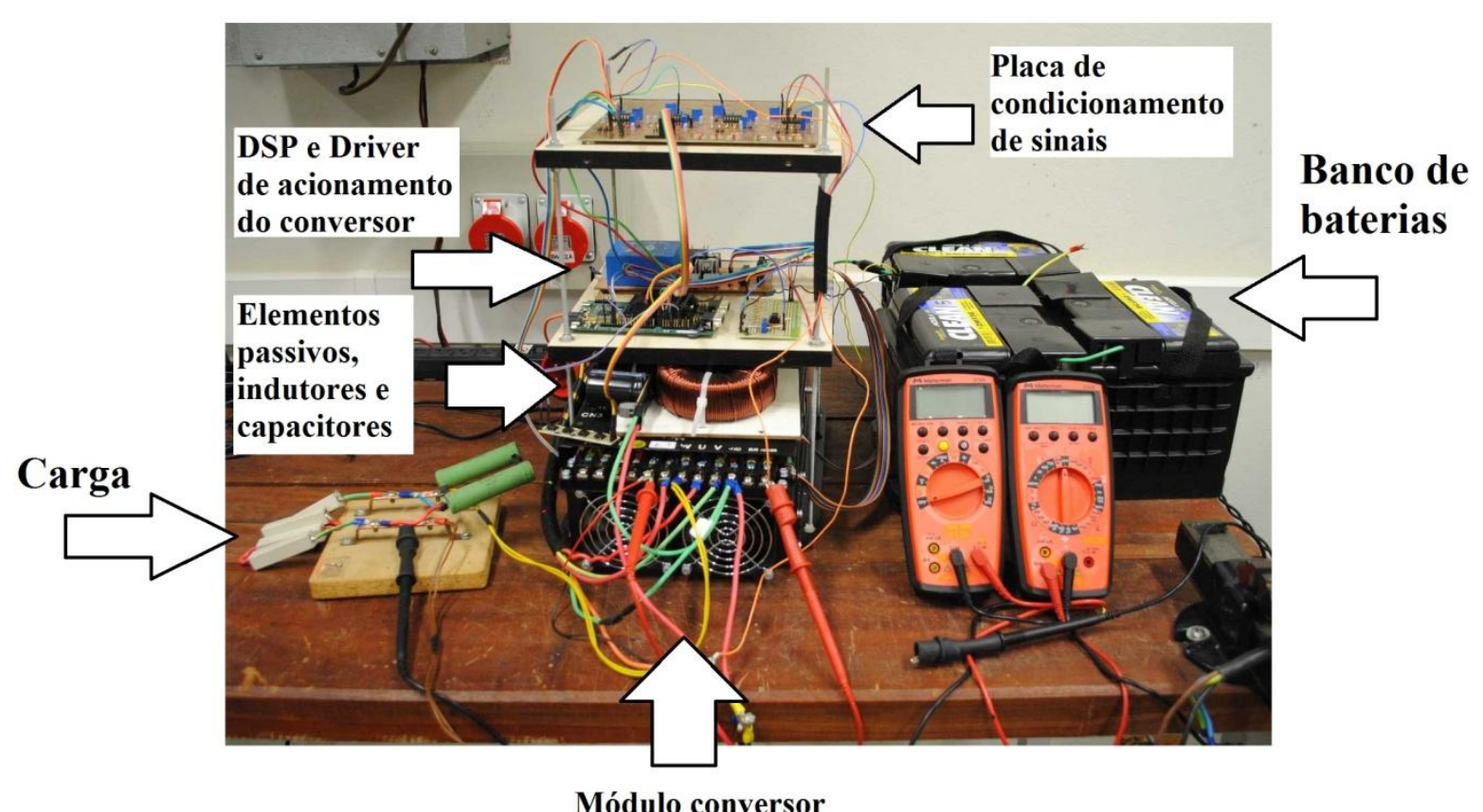

Figura 4.9 - Protótipo construído. 


\subsection{Resultados experimentais}

Para extração dos resultados foi usado um osciloscópio Tektronix (Modelo DPO 5054), Figura 4.10, de quatro canais. Sendo as variáveis medidas durante os experimentos: Tensão terminal dos painéis $\left(V_{\text {painel }}\right)$, corrente gerada pelos painéis $\left(I_{\text {painel }}\right)$, corrente das baterias $\left(I_{B a t}\right)$ e tensão no link CC $\left(V_{c c}\right)$, sendo a potência gerada pelos painéis $\left(P_{\text {painel }}\right)$ calculada pelo produto da tensão terminal do painel pela corrente gerada.

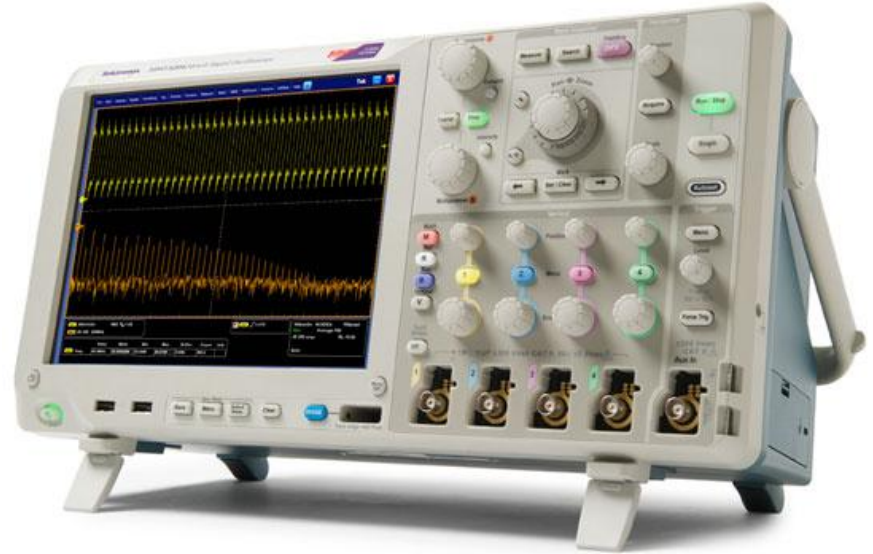

Figura 4.10 - Osciloscópio Tektronix usado para extração dos resultados.

Durante a construção do protótipo foi notada a presença de grande quantidade de ruído que é decorrente do processo de chaveamento dos conversores sobre as variáveis a serem controladas, principalmente, sobre a tensão da bateria. Desta forma, para que o sistema apresentasse um desempenho satisfatório, todos os ganhos utilizados no sistema de controle simulado sofreram ajustes finos. Outro artifício utilizado para a redução dos efeitos do ruído foi a utilização de uma média móvel para o calculo da tensão da bateria e para a potência extraída do painel, que são as variáveis que possuem resposta dinâmica lenta quando comparadas com o controle em corrente ou tensão das baterias, isto permitiu uma melhora no controle da bateria e na busca do ponto de máxima potência dos painéis fotovoltaicos.

A Figura 4.11 mostra a inicialização do sistema para os seguintes valores da curva de potência dos painéis: $V_{m p}=40 \mathrm{~V}, V_{o c}=48 \mathrm{~V}, I_{m p}=3 \mathrm{~A}, I_{s c}=3,1 \mathrm{~A}$. O tempo para cada passo do algoritmo MPPT P\&O foi ajustado em $1 \mathrm{~s}$ por passo (este valor foi escolhido para facilitar a visualização da execução) e a perturbação de 
tensão foi ajustada em $0,5 \mathrm{~V}$ por passo. Nota-se que o algoritmo de busca do ponto de máximo converge em menos de 10 interações do algoritmo MPPT.

$\mathrm{O}$ sistema controla a tensão $V_{c c}$ em $120 \mathrm{~V}$ com oscilações imperceptíveis, como também regula a corrente de carga da bateria de acordo com a energia gerada pelos painéis, como descrito pela Figura 4.12. Para ajustar a corrente de carga das baterias o sistema considera um rendimento de $80 \%$ para o caminho desde os painéis até as baterias, assim caso os painéis estejam gerando uma potência de $90 \mathrm{~W}$, o sistema usa como base $80 \%$ desta energia, ou seja, $72 \mathrm{~W}$, logo é utilizada uma corrente de $1 \mathrm{~A}$ para a carga das baterias. Apenas quando a potência gerada ultrapassar $105 \mathrm{~W}$ (84 W útil) a corrente passa a $2 \mathrm{~A}$. A Figura 4.12 foi gerada sabendo que para o banco de baterias, a máxima tensão recomendada é de $14 \mathrm{~V}$ por bateria (MOURA, 2011), ou seja, $42 \mathrm{~V}$ para o banco, multiplicando esta tensão máxima pelas correntes de carga, obtém-se o valor da potência máxima requerida pelo banco para cada corrente de carga.

A corrente máxima possível definida neste sistema foi de $4 \mathrm{~A}$ pois de acordo com (MOURA, 2011) não se recomenda ultrapassar $10 \%$ da capacidade da bateria em corrente, como este sistema utiliza baterias de $36 \mathrm{Ah}$, logo a máxima foi definida em 4 A, que é, ligeiramente, superior ao que é recomendado pelo fabricante $(11,1 \%$ da capacidade).

A consideração de rendimento $(80 \%)$ foi feita para que o sistema possa regular a corrente de carga em um valor que não absorva energia acima do que é produzido, pois nesta condição a tensão do barramento CC sofreria afundamentos, logo este artifício permite a estabilidade do sistema em condições irregulares de irradiação.

Pode-se notar este artifício em funcionamento no início da Figura 4.11, onde a corrente se inicia zerada, apenas quando a potência alcança o valor necessário o ajuste da corrente sobe para $1 \mathrm{~A}$, logo após um novo aumento da potência a corrente finalmente alcança o valor de $2 \mathrm{~A}$.

Toda a energia produzida que não é armazenado na bateria é enviada para a carga, que no sistema proposto seria enviada à rede elétrica e de acordo com o que foi discutido na seção 2.4 , o sistema de injeção de energia na rede foi omitido, sendo substituído por uma montagem que permitiu controlar a energia drenada do sistema, conforme a rede elétrica faria caso estivesse presente. 


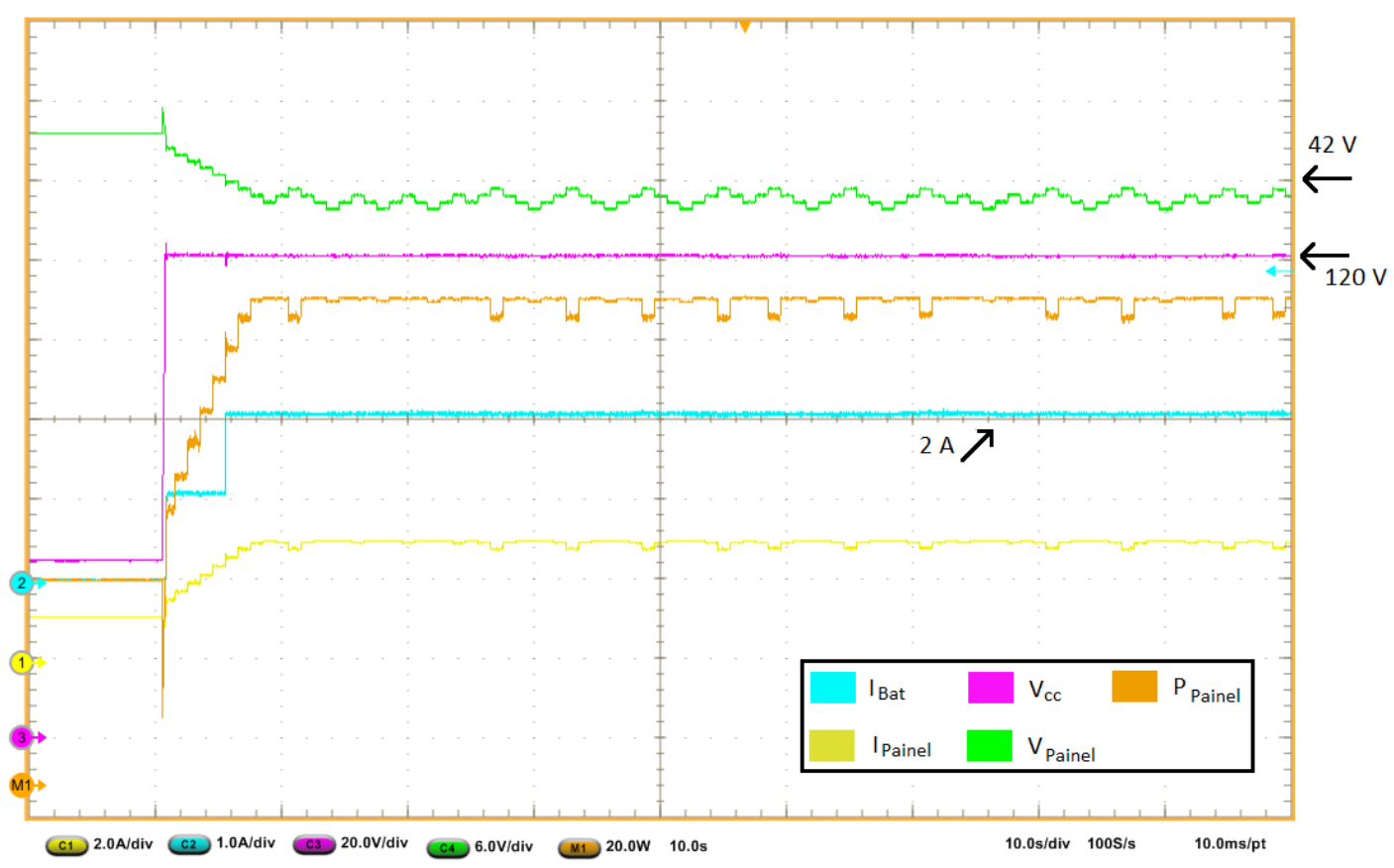

Figura 4.11 - Inicialização do sistema, onde a corrente de carga se ajusta a energia produzida, o ponto de máximo $\left(V_{m p}=40 \mathrm{~V}, I_{m p}=3 \mathrm{~A}\right)$ é alcançado em menos de 10 interações do MPPT e a tensão $V_{c c}$ se estabiliza em $120 \mathrm{~V}$.

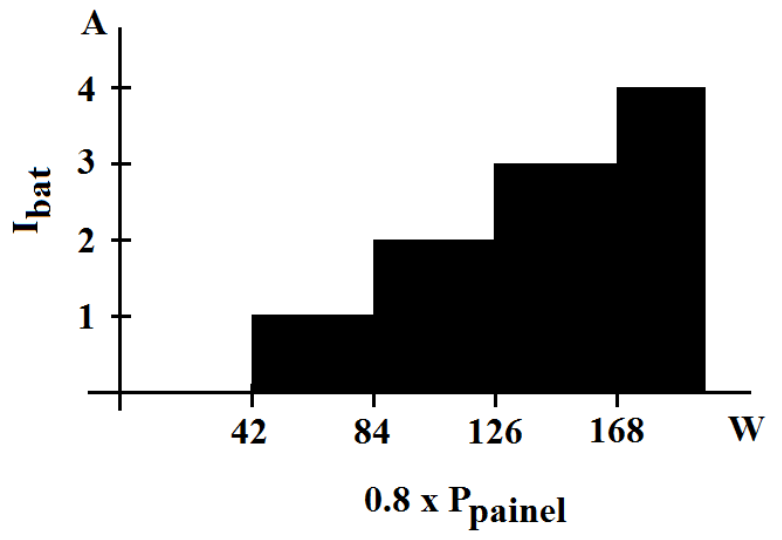

Figura 4.12 - Corrente de carga do banco de baterias em função da porção da energia gerada.

A Figura 4.13 é apresenta um zoom durante o regime permanente do sistema. Nota-se de maneira, bem clara, o funcionamento do algoritmo MPPT P\&O, cuja tensão do painel altera a direção da perturbação quando há um afundamento da potência produzida, fazendo com que o sistema oscile em torno do ponto de máxima potência, que foi ajustado para $V_{m p}=40 \mathrm{~V}, I_{m p}=3 \mathrm{~A}$. 


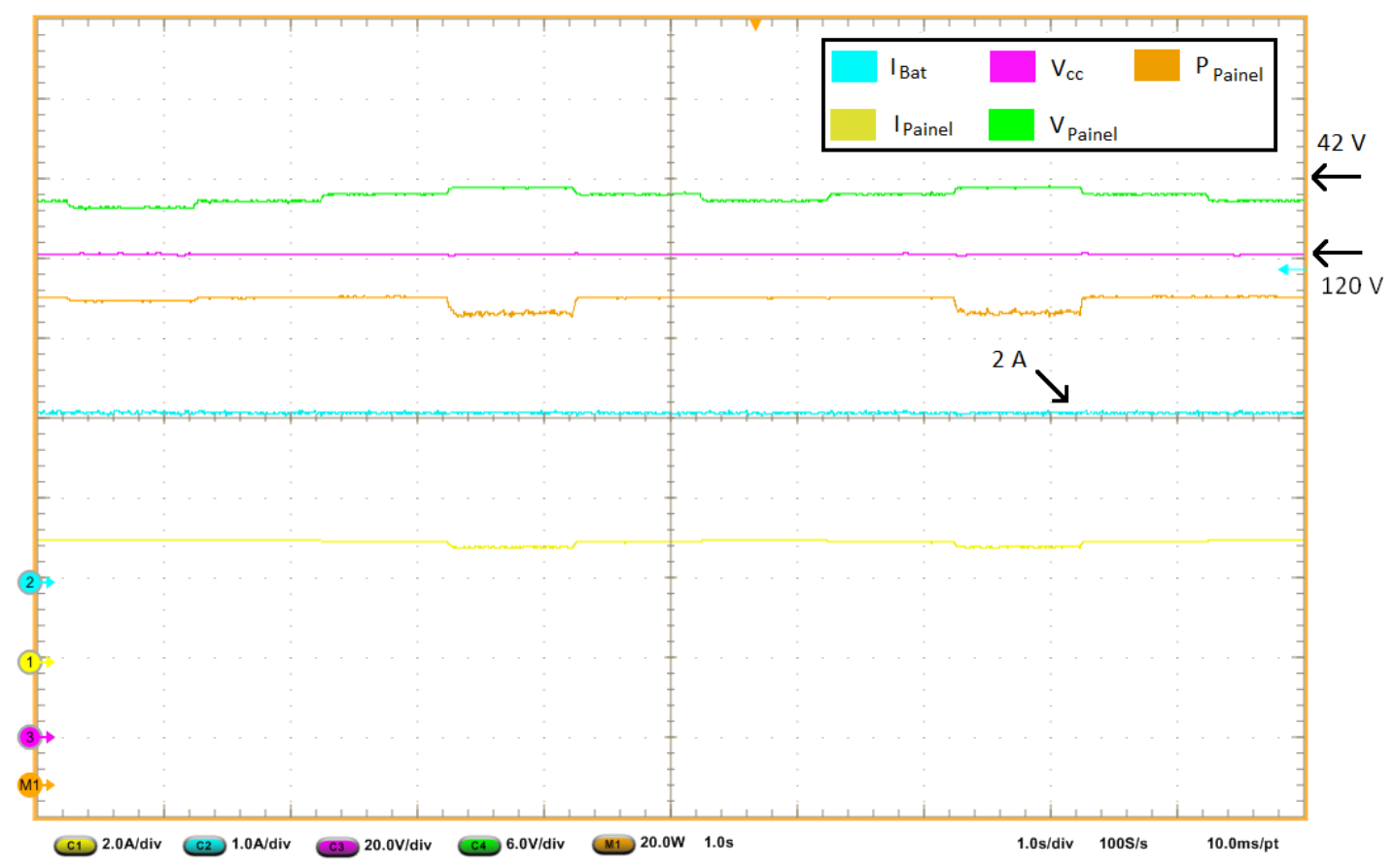

Figuras 4.13 - Zoom durante o regime permanente, $V_{m p}=40 \mathrm{~V}, I_{m p}=3 \mathrm{~A}$.

A Figura 4.14 mostra uma redução brusca da irradiação que reduz a potência gerada de cerca de $120 \mathrm{~W}$ para $100 \mathrm{~W}$. Para que o sistema não entre em colapso, a corrente de carga da bateria é reduzida, instantaneamente, após a redução da irradiação para $1 \mathrm{~A}$, adequando a potência consumida à potência gerada, de acordo com a Figura 4.12 já mencionada acima. Nota-se que após alguns instantes há um aumento da potência gerada para aproximadamente $140 \mathrm{~W}$, o que de acordo com o método utilizado gera uma corrente de carga de $2 \mathrm{~A}$.

Durante os transitórios de irradiação nota-se uma pequena perturbação na tensão $V_{c c}$ (da ordem de $4 \mathrm{~V}$ ) devido a alteração da corrente de carga das baterias, que quebra o balanço de potência por alguns instantes, mas este é logo reestabelecido fazendo com que a tensão $V_{c c}$ retorne para seu valor de ajuste, 120 V. Vale ressaltar que estas perturbações de irradiação são bruscas, não acontecendo normalmente nas aplicações práticas. Em uma situação real estas variações seriam progressivas e bem mais lentas, mas mesmo em um caso extremo o sistema de controle proposto é capaz de manter o balanço de potência. 


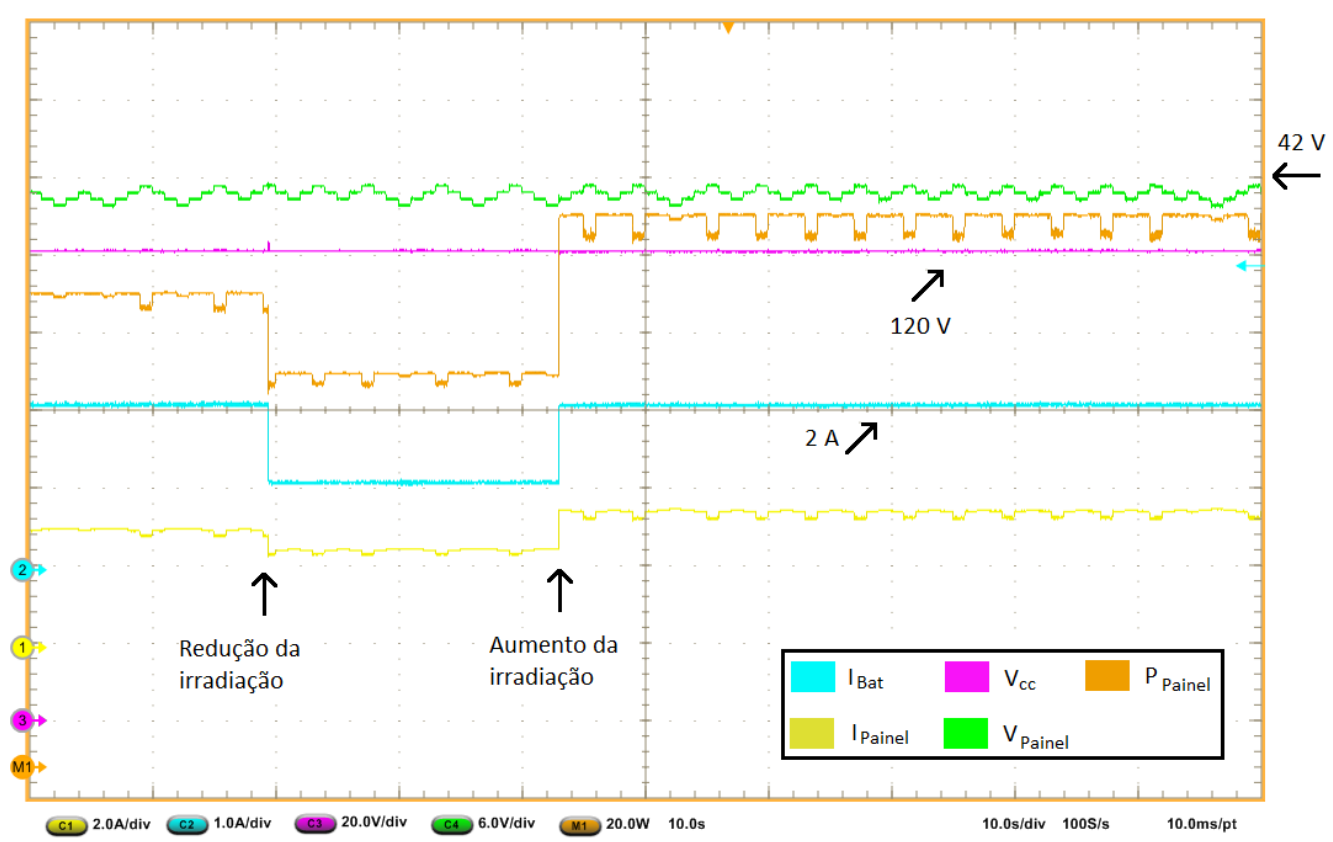

Figura 4.14 - Adequação do sistema durante uma redução da irradiação incidente, seguido de um aumento da irradiação, $V_{m p}=40 \mathrm{~V}$.

Na Figura 4.15 tem-se uma situação muito semelhante à situação anterior, entretanto neste caso a queda de irradiação é tão acentuada que a corrente de carga teve de ser anulada completamente, uma vez que a energia disponivel não era suficiente para inserir uma corrente constante nas baterias e para manter a tensão $V_{c c}$ em seu valor ajustado em $120 \mathrm{~V}$, assim para garantir uma tensão estável em $V_{c c}$ a corrente de carga é sacrificada. No instante em que a potência disponível é suficiente para manter uma corrente de carga, esta é restabelecida para um valor adequado. 


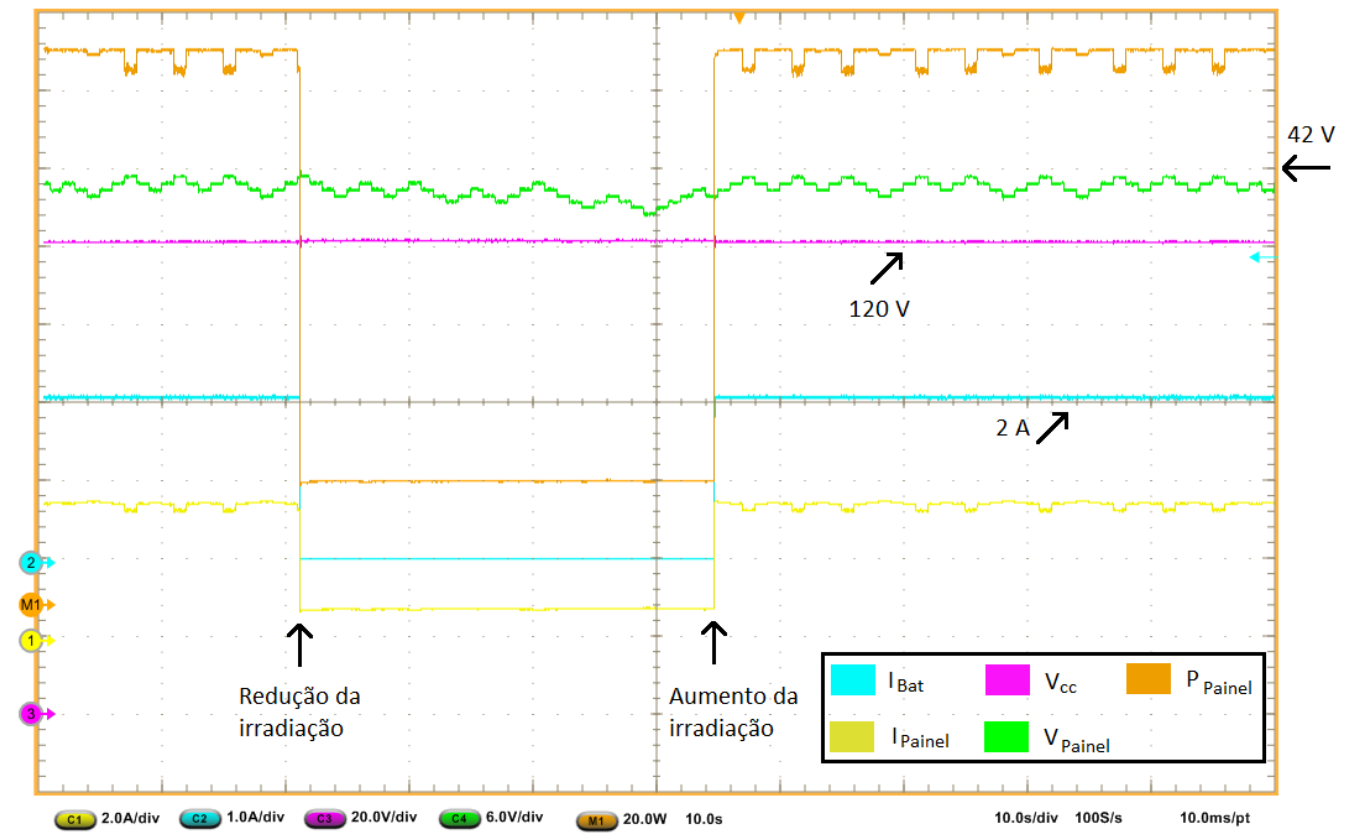

Figura 4.15 - Adequação do sistema durante uma queda de irradiação muito acentuada, seguido de uma recuperação, $V_{m p}=40 \mathrm{~V}$.

A Figura 4.16 mostra o funcionamento do sistema cuja operação é caracterizada pela desconexão dos painéis fotovoltaicos. Nesta situação, caso as baterias tenham energia suficiente, elas se encarregariam de suprir toda a demanda do sistema. Assim que detecta-se que a potência gerada é zero, instantaneamente, a corrente das baterias é invertida, mantendo o sistema operante com energia suficiente para manter a tensão $V_{c c}$ em $120 \mathrm{~V}$ e entregando toda essa energia a carga que representa a rede. Após a reconexão dos painéis e estabilização da energia entregue por eles, a corrente é novamente invertida, voltado à situação de carga.

Nota-se que durante todos os transitórios as mudanças são sentidas pela tensão $V_{c c}$ em forma de sobre sinal ou afundamentos, entretanto estes são de amplitude reduzida (máximo de $10 \mathrm{~V}$ durante a mudança da corrente de $-2 \mathrm{~A}$ para 2 A). 


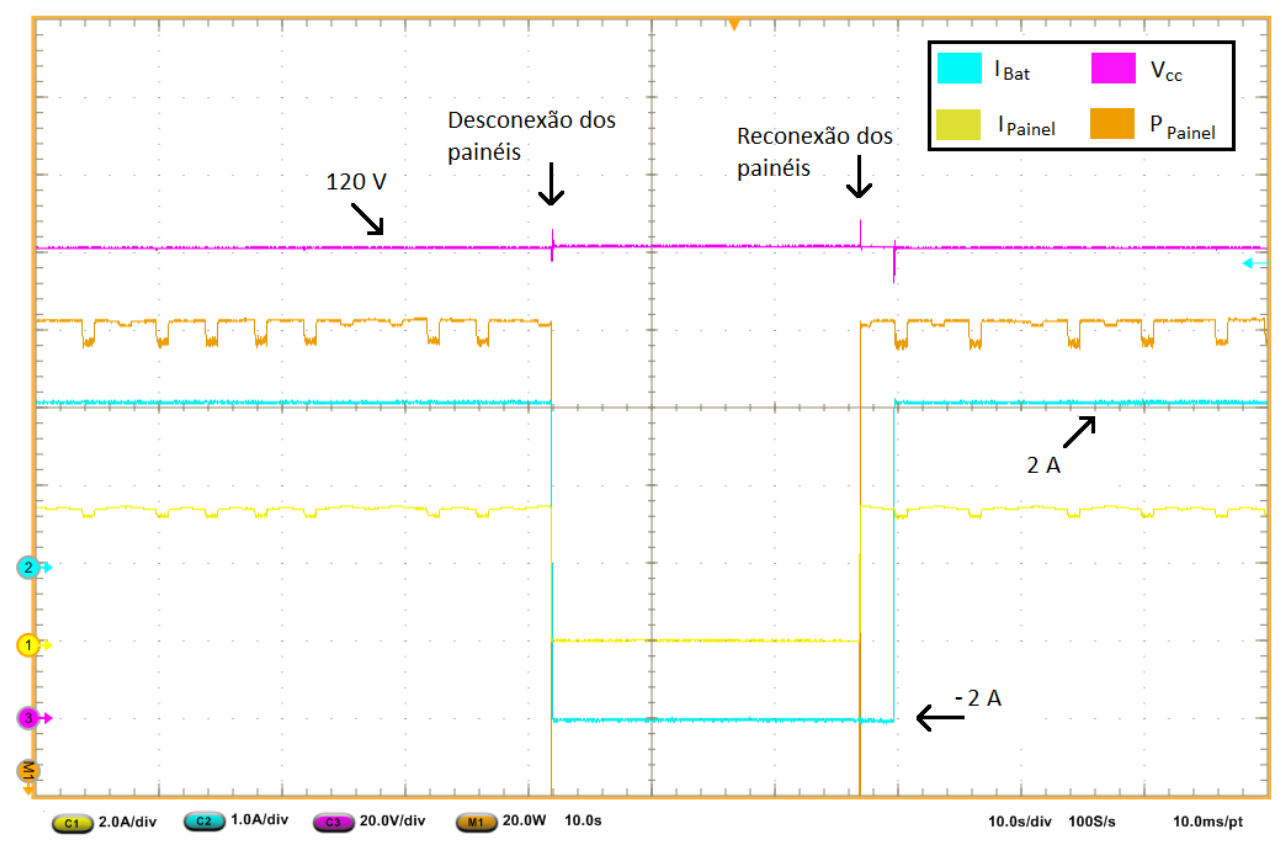

Figura 4.16 - Funcionamento do sistema em caso de desconexão dos painéis.

A Figura 4.17 representa o sistema durante uma redução da tensão de máxima potência de $40 \mathrm{~V}$ para $38 \mathrm{~V}$, mantendo a corrente de máxima potência em 3 A. Observa-se que as demais variáveis controladas do sistema, que são a corrente da bateria e a tensão $V_{c c}$ não são afetadas por essa variação, mantendo-se estáveis. A única consequência desta redução da tensão de máxima potência é a redução da potência máxima extraída, uma vez que ambas são diretamente proporcionais.

É importante mencionar que a redução da tensão de máxima potência pode ser entendida como um deslocamento para a esquerda da curva $\mathrm{V} \times \mathrm{I}$, que está associado ao aumento da temperatura das placas fotovoltaicas (VILLALVA, 2010) (Figura 4.18). Como na natureza variações bruscas de temperatura não ocorrem com facilidade, este efeito da variação de $V_{m p}$ ocorreria gradualmente e de maneira lenta, mostrando que o sistema se comporta de forma adequada em casos extremos. 


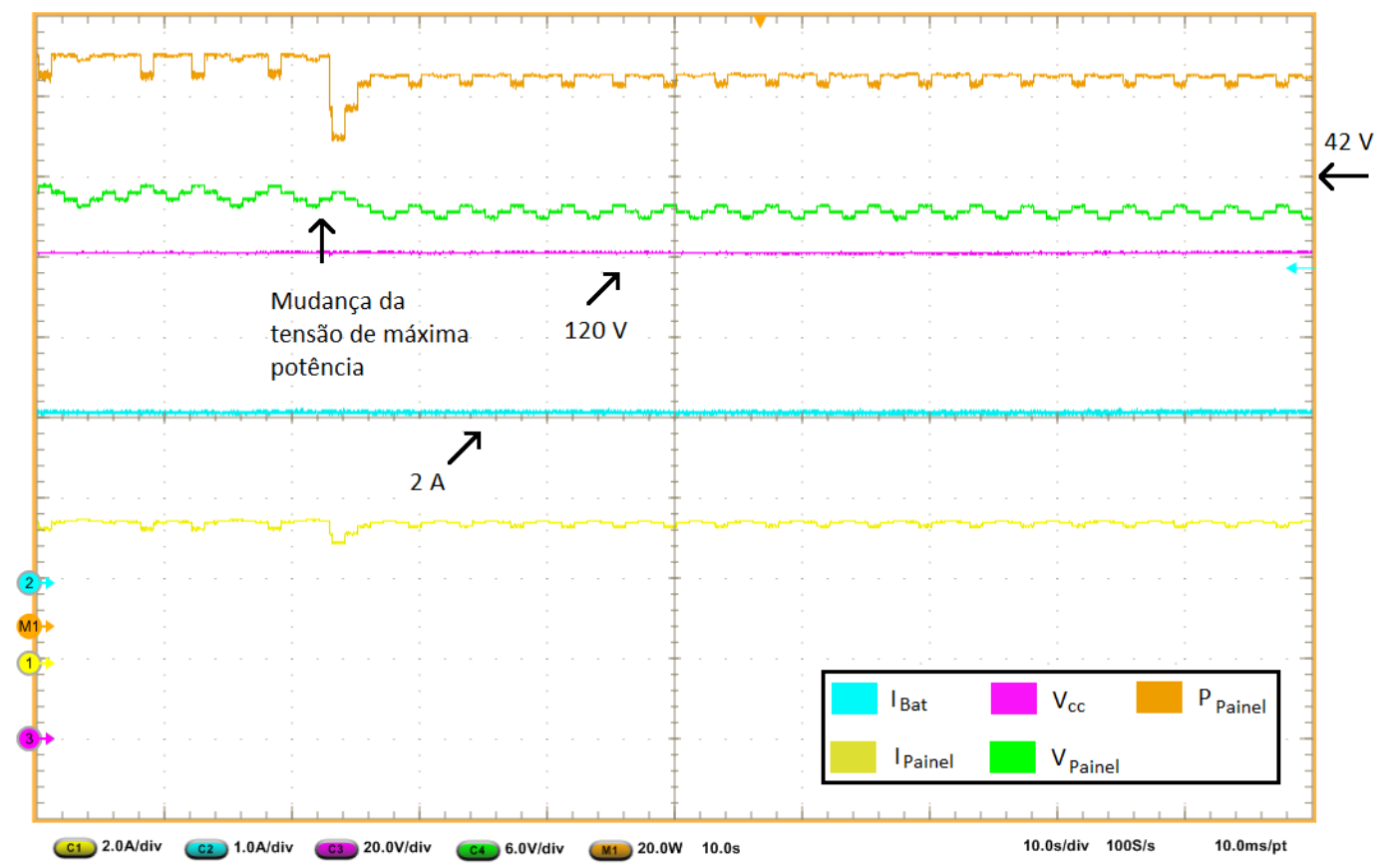

Figura 4.17 - Funcionamento durante redução da tensão de máxima potência de 40 $\mathrm{V}$ para $38 \mathrm{~V}$.

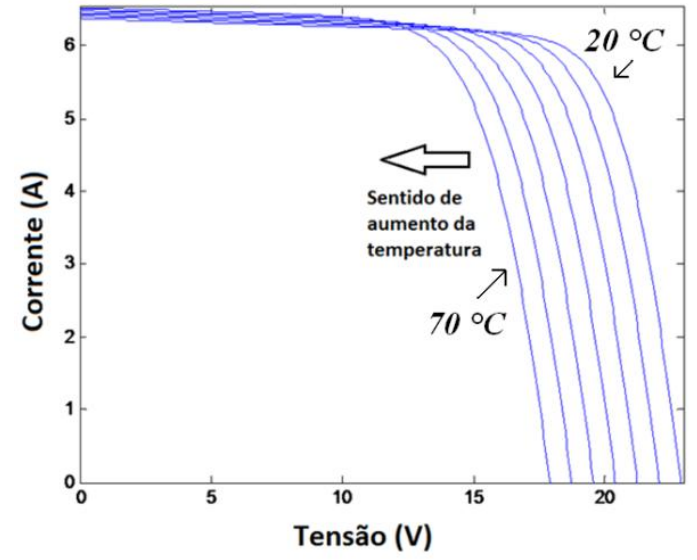

Figura 4.18 - Curva $V x$ I para um painel fotovoltaico com irradiação constante, variando a temperatura das placas.

A Figura 4.19 mostra uma situação semelhante ao caso anterior, entretanto agora a tensão de máxima potência sofre um aumento, de $38 \mathrm{~V}$ para $40 \mathrm{~V}$. Analogamente ao caso anterior, o aumento da tensão da máxima potência equivale a um deslocamento para a direita da curva $\mathrm{V} x \mathrm{I}$, que fisicamente representa uma redução da temperatura das placas fotovoltaicas.

Novamente, observa-se que a corrente de carga das baterias e a tensão $V_{c c}$ não são afetadas pela mudança da tensão de máxima potência, permanecendo estáveis. 


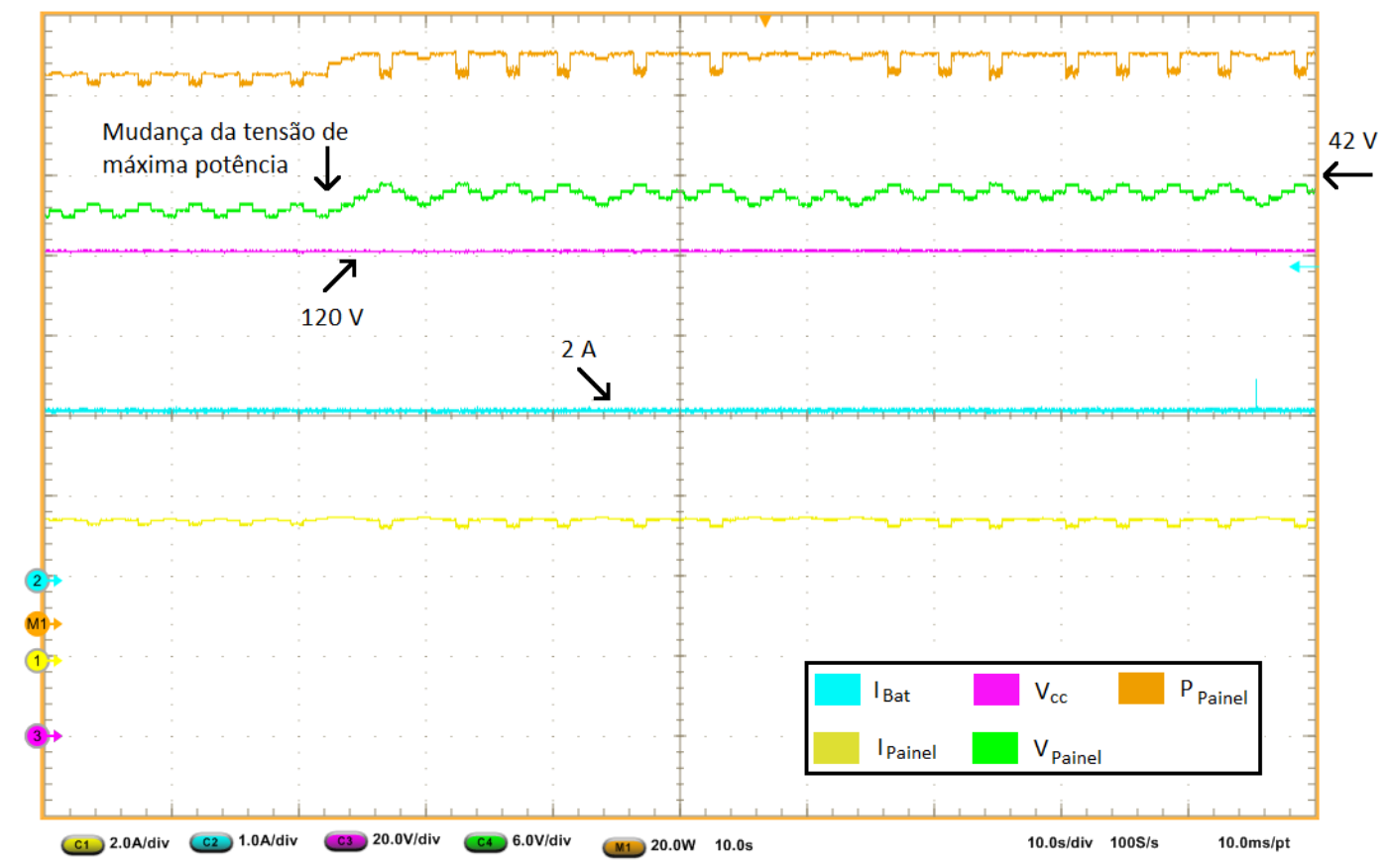

Figura 4.19 - Funcionamento durante uma elevação da tensão de máxima potência de 38 para $40 \mathrm{~V}$.

Já na Figura 4.20, é apresentado o sistema durante uma inversão da corrente na bateria, estando o sistema estável sem alterações de irradiação. Esta situação é equivalente a uma inversão de sentido devido ao início do horário de ponta, cuja necessidade energética entregue deve ser aumentada, logo o sistema de baterias deve fornecer energia ao barramento $\mathrm{CC}$ juntamente com os painéis. Após alguns instantes a demanda é reduzida, fazendo com que a bateria retorne à situação de carga.

Nota-se que durante a inversão de $2 \mathrm{~A}$ para -2 A é observado um sobre sinal na tensão $V_{c c}$ que é decorrente da quebra do balanço de potência por alguns instantes, de forma que a potência fornecida ao barramento CC torne-se maior do que a potência consumida pela carga. Na segunda inversão o balanço é, novamente, quebrado, entretanto agora existe um afundamento causado por um consumo elevado de potência. Em ambos os casos a amplitude da perturbação foi de no máximo $10 \mathrm{~V}(8,33 \%$ de variação sobre o valor ajustado de $120 \mathrm{~V})$, sendo, rapidamente, compensado (menos de $0,2 \mathrm{~s}$ ).

Um ponto a se destacar é que a variação da potência na carga durante as inversões de corrente da Figura 4.20 são da ordem de grandeza da potência gerada pelos painéis, como pode ser visto pela Figura 4.21, sendo que a potência entregue a carga triplicou. Durante a inversão de 2 A para -2 A, o sistema passa da situação 
(1) para a situação (2) da Figura 4.21 e passa da situação (2) para a situação (1) quando a inversão é de -2 A para 2 A é executada. Logo, durante estes transitórios, as variações são bruscas e mesmo nestas situações, o sistema de controle consegue manter a estabilidade da tensão $V_{c c}$, se adequando ao novo balanço das potências.

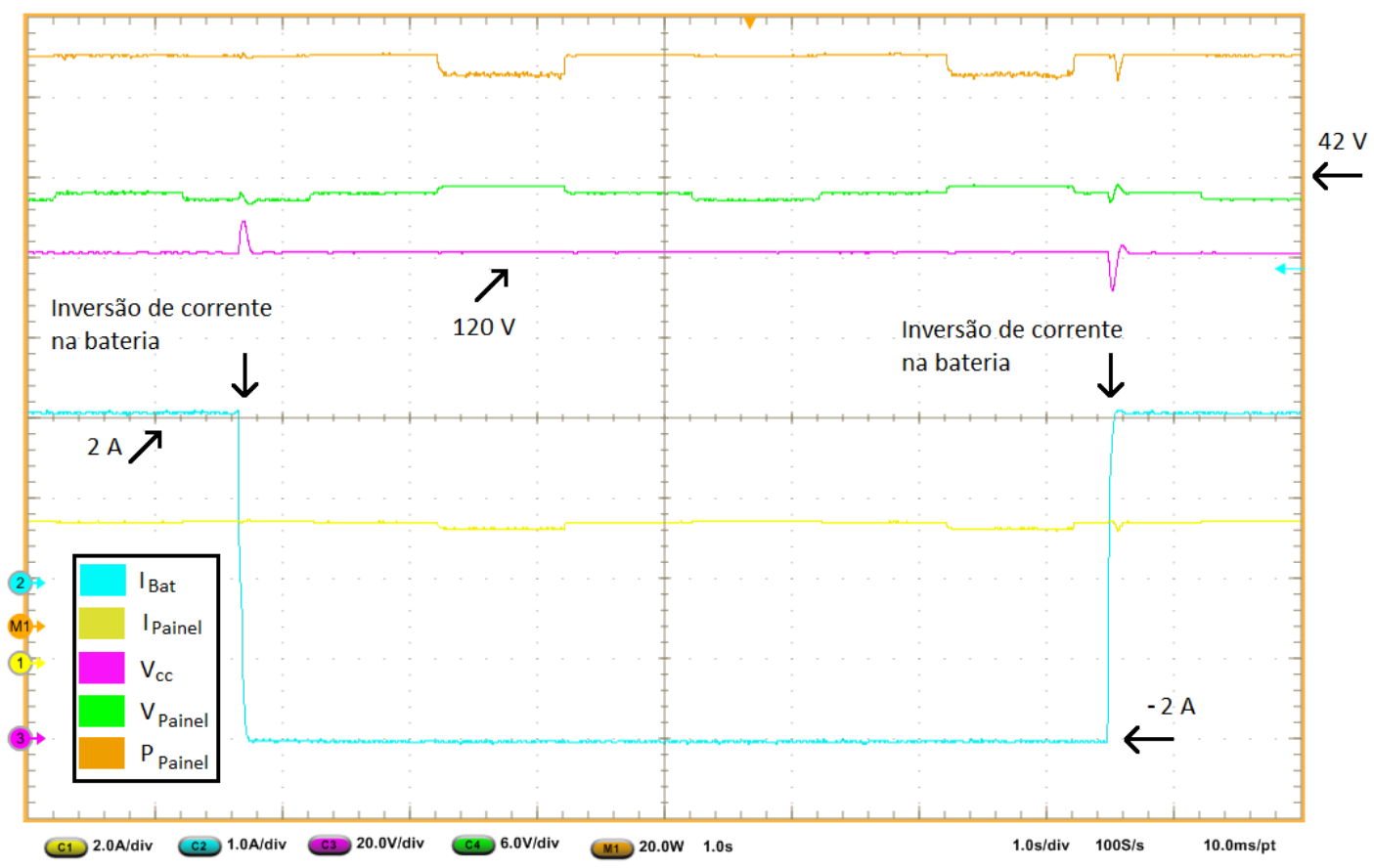

Figura 4.20 - Funcionamento do sistema durante inversão forçada da corrente, $V_{m p}=40 \mathrm{~V}, I_{m p}=3 \mathrm{~A}$.

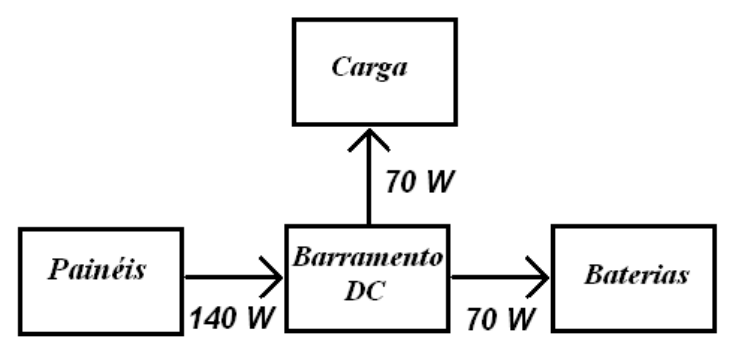

(1)

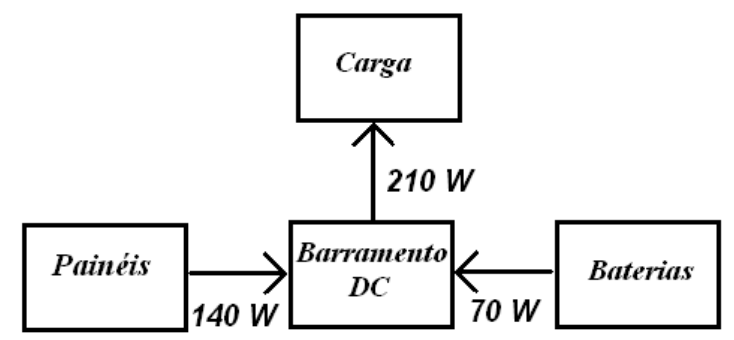

(2)

Figura 4.21 - Situações de carga durante inversão de corrente da Figura 4.20.

Nas Figuras 4.22, 4.23 tem-se os detalhes da inversão da corrente na bateria, entretanto pode-se observar que a corrente da bateria, Figura 4.23, pouco se assemelha a forma de onda da corrente na Figura 3.6 da seção 3.2, cujo conversor bidirecional foi apresentado, juntamente com as formas de onda de inversão de corrente. Esta diferença nas formas de onda é causada pelo ajuste dos ganhos do integrador e do proporcional fuzzy que foram necessários na execução do sistema 
embarcado, pois no sistema real o nível de ruído embutido nas medições demandou uma redução dos ganhos. Este ajuste dos ganhos calculados foi realizado de forma empírica até que o sinal controlado se mantivesse estável e com uma resposta rápida. A Figura 4.24 mostra o sistema simulado da seção 3.2 com os ganhos utilizados no sistema real. Nota-se que com os novos valores a Figura $4.23 \mathrm{se}$ aproxima muito do sistema simulado, comprovando a fidelidade do modelo.

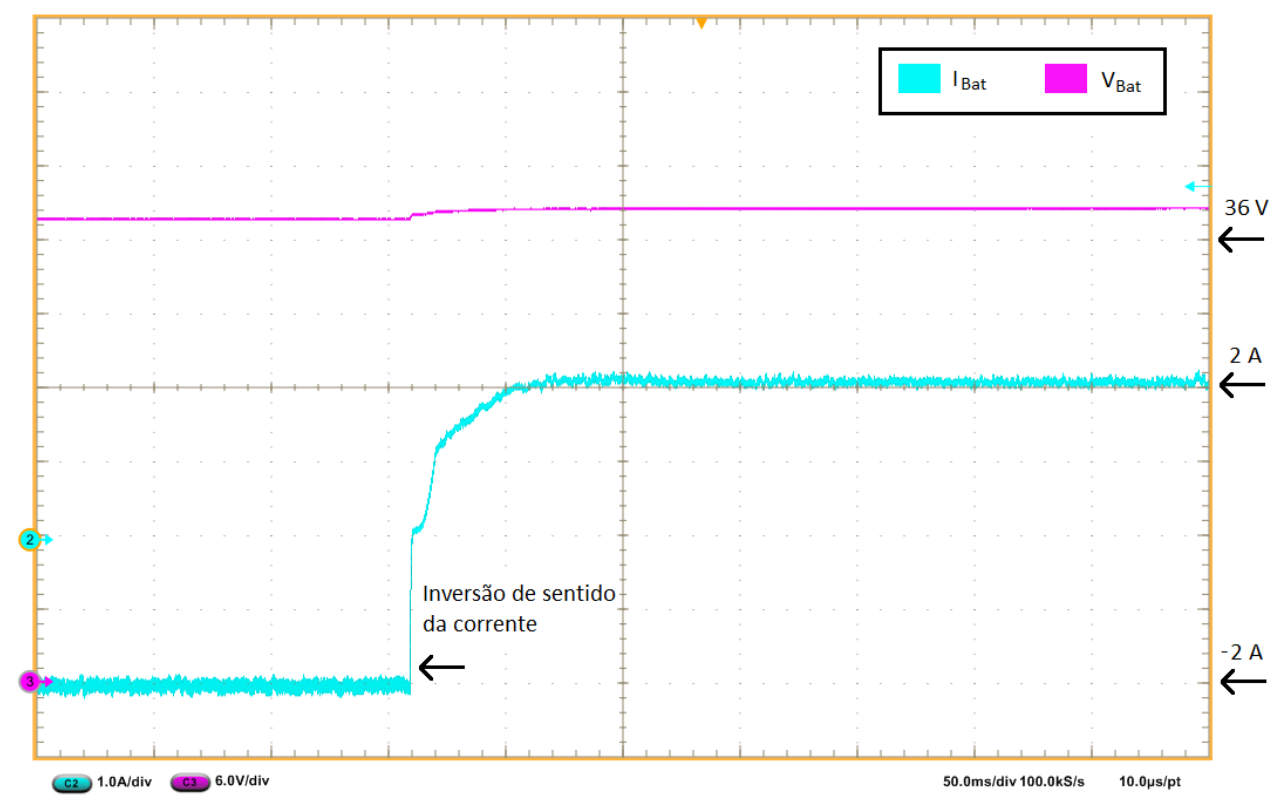

Figura 4.22 - Inversão de corrente na bateria de -2 A para 2 A.

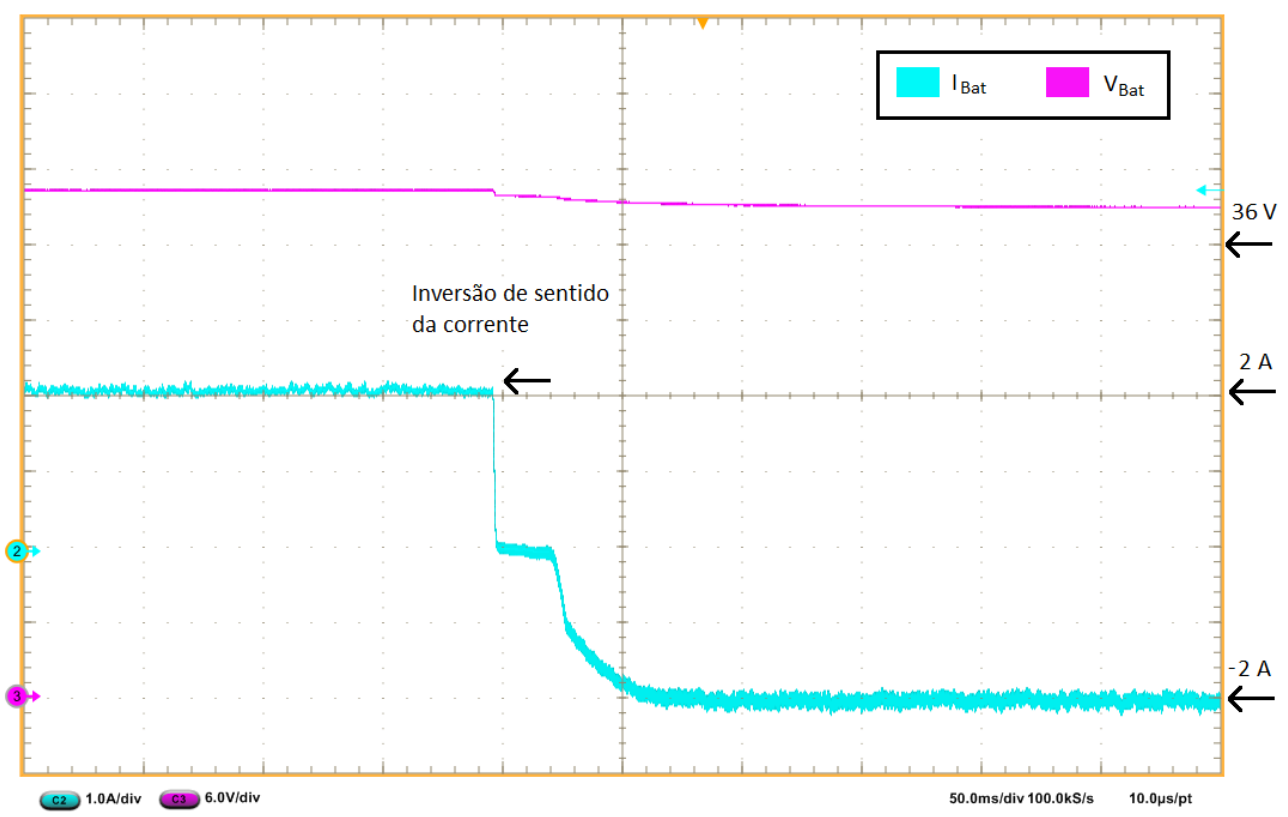

Figura 4.23 - Inversão de corrente na bateria de 2 A para -2 A. 


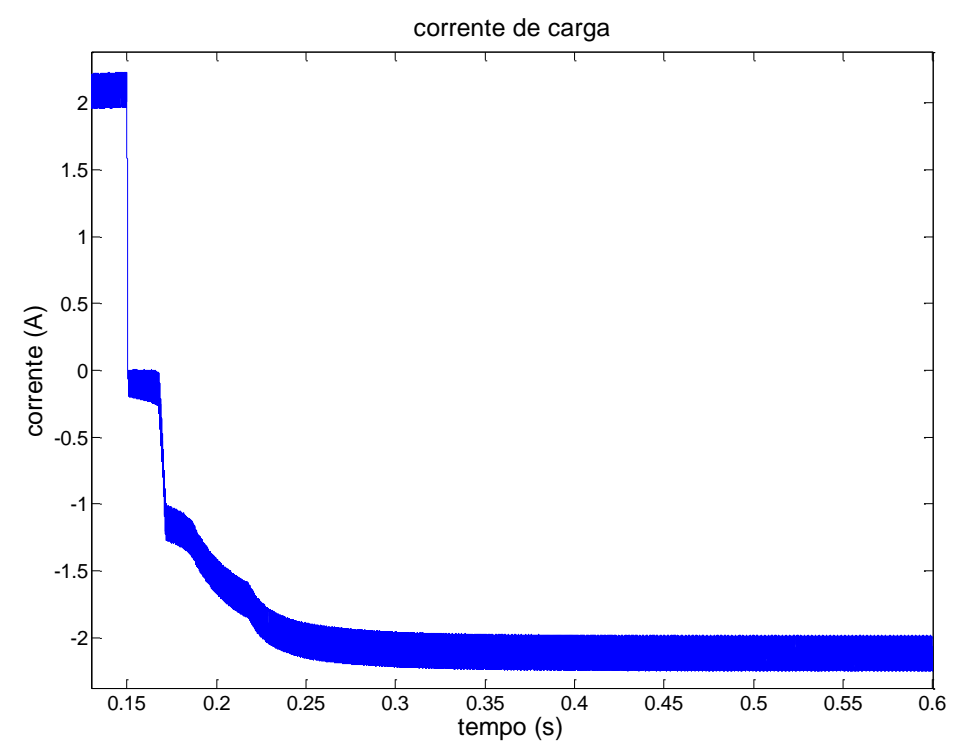

Figura 4.24 - Simulação do sistema de carga de baterias da seção 3.2 com os ganhos iguais aos do protótipo.

A Figura 4.25 mostra as variações sofridas pela tensão da bateria durante 0 processo de carga e descarga. Nota-se que há um aumento suave durante o processo de carga e uma diminuição durante a descarga.

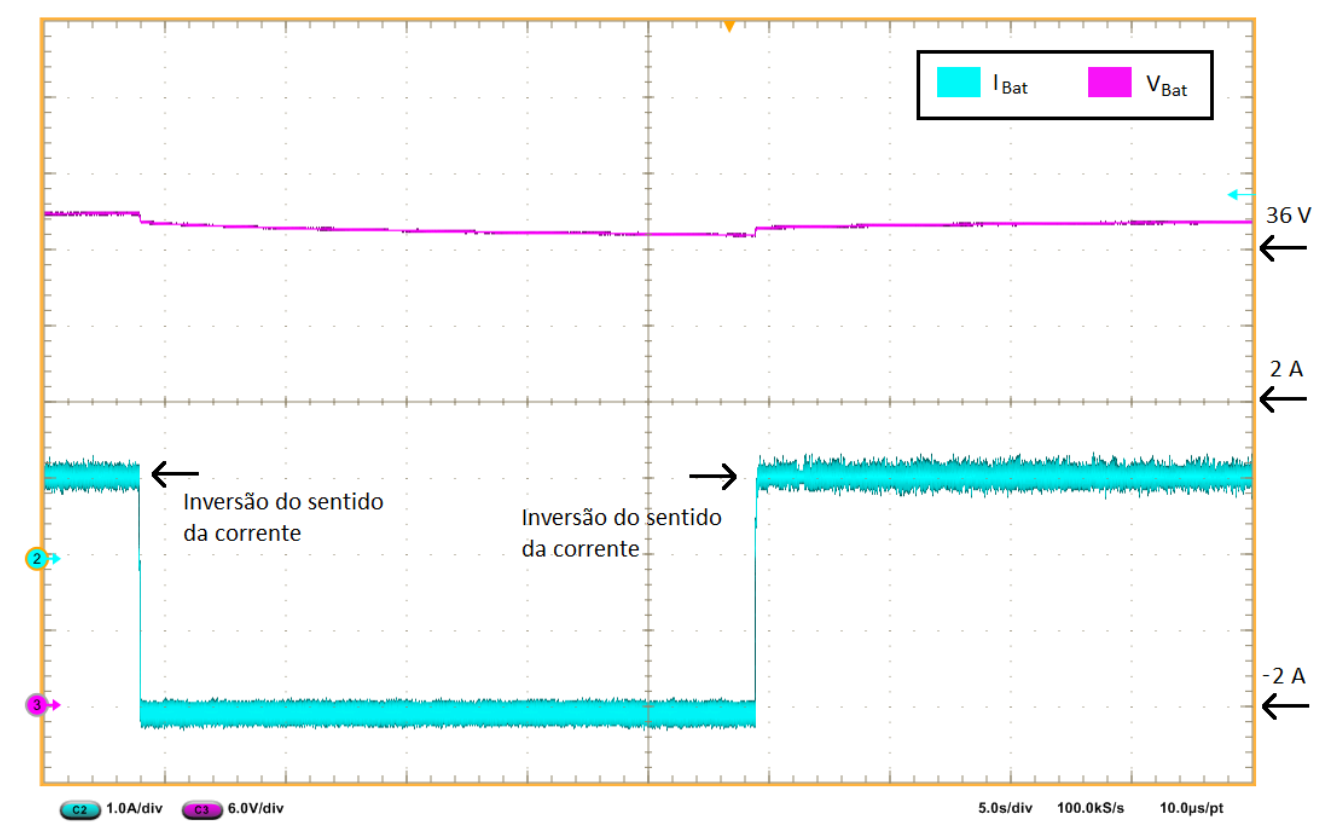

Figura 4.25 - Inversão de corrente na bateria e efeitos sobre a tensão da bateria.

Sabendo que a tensão da bateria não pode aumentar indefinidamente, após um determinado patamar ela deve ser limitada, sendo o controle alterado, passando 
do controle de corrente para o controle de tensão, como definido no método a dois níveis de tensão na seção 2.1.6. A Figura 4.26 mostra a mudança da variável de controle, de corrente para tensão após o limite ser ultrapassado. Como esperado, após o controle de tensão ser ativado a corrente de carga inicia um processo de queda, como descrito no método a dois níveis de tensão.

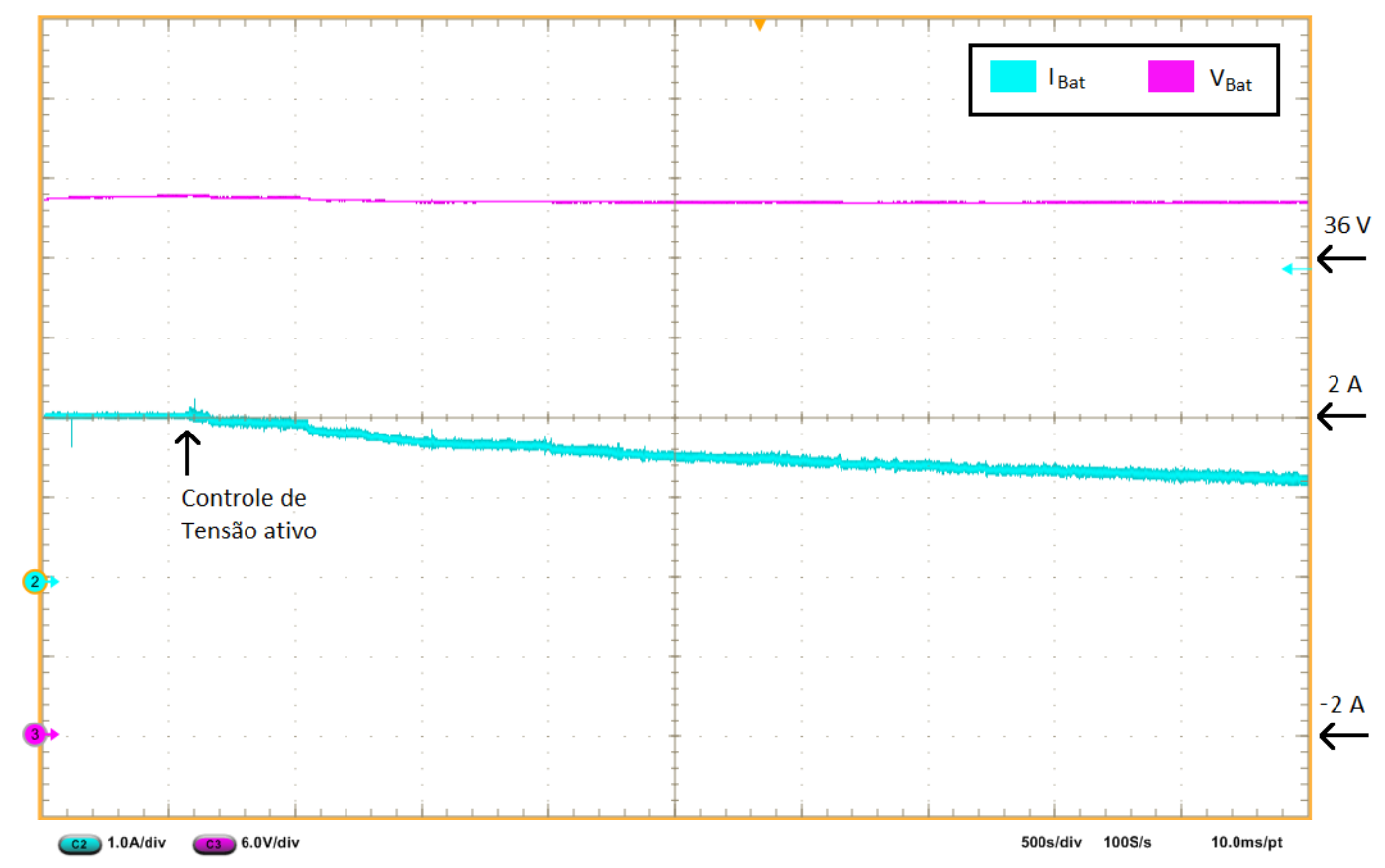

Figura 4.26 - Mudança da variável de controle durante o processo de carga.

Para o cálculo do rendimento do sistema foram usadas as seguintes situações: Painel alimentando a carga e carregando as baterias, painel alimentando somente a carga, painel e bateria alimentando a carga e apenas a bateria alimentando a carga. A Figura 4.27 mostra as situações de fluxo de potência e as equações (52) e (53) mostram o cálculo realizado em cada situação. Nas Tabelas 4.1 e 4.2 são mostrados os resultados obtidos neste experimento. 


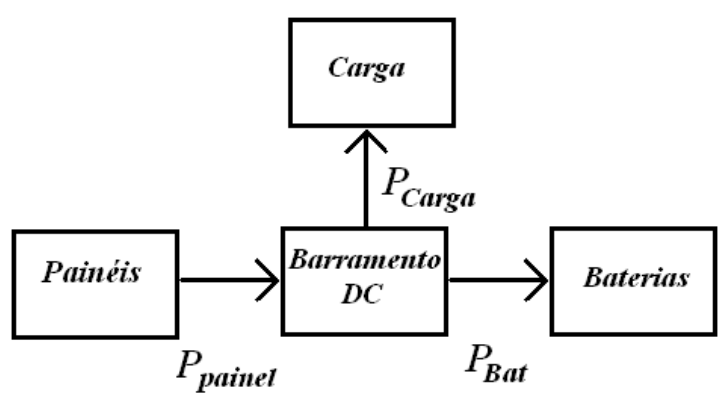

(1)

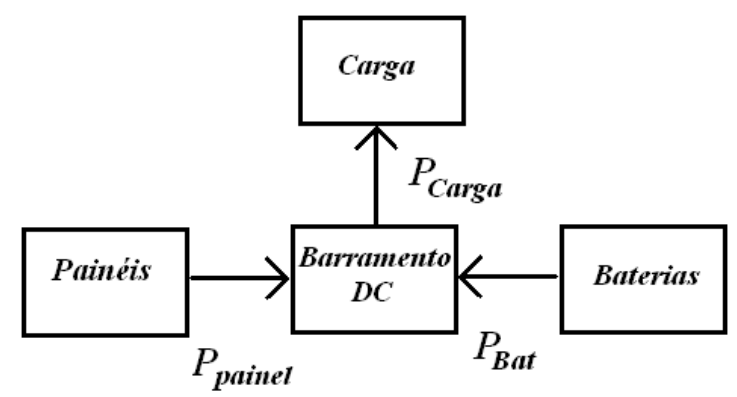

(2)

Figura 4.27 - Situações de Fluxo durante o cálculo do rendimento do sistema.

Para a situação (1) de fluxo tem-se:

$$
\eta=\frac{P_{\text {carga }}+P_{\text {Bat }}}{P_{\text {painel }}}
$$

Para situação (2), tem-se:

$$
\eta=\frac{P_{\text {carga }}}{P_{\text {painel }}+P_{B a t}}
$$

Tabela 4.1 - Rendimento do sistema experimental na situação (1)

\begin{tabular}{|c|c|c|c|c|}
\hline \multicolumn{5}{|c|}{ Situação (1) } \\
\hline$P_{\text {painel }}(\mathrm{W})$ & $P_{\text {Bat }}(\mathrm{W})$ & $P_{\text {carga }}(\mathrm{W})$ & $I_{\text {Bat }}(\mathrm{A})$ & Rendimento (\%) \\
\hline 80 & 40,74 & 28 & 1,07 & 85,9 \\
\hline 140 & 81,69 & 40 & 2,1 & 86,9 \\
\hline 180 & 123,13 & 30,5 & 3,1 & 85,35 \\
\hline 40 & 0 & 34 & 0 & 85 \\
\hline
\end{tabular}

Tabela 4.2 - Rendimento do sistema experimental na situação (2)

\begin{tabular}{|c|c|c|c|c|}
\hline \multicolumn{5}{|c|}{ Situação (2) } \\
\hline$P_{\text {painel }}(\mathrm{W})$ & $P_{\text {Bat }}(\mathrm{W})$ & $P_{\text {carga }}(\mathrm{W})$ & $I_{\text {Bat }}(\mathrm{A})$ & Rendimento $(\%)$ \\
\hline 40 & 73,46 & 100 & 2,02 & 88,1 \\
\hline 80 & 73,46 & 138 & 2,02 & 89 \\
\hline 140 & 73,46 & 197 & 2,02 & 92,2 \\
\hline 180 & 73,46 & 235 & 2,02 & 92,7 \\
\hline 0 & 73,46 & 62 & 2.02 & 84,4 \\
\hline
\end{tabular}


Nota-se comparando as Tabelas 4.1 com Tabela 4.2, que o sistema possui um rendimento superior ao mudar da situação (1) para a situação (2), assim como ocorreu no sistema simulado da seção 3.2 (Figura 3.14), passando de aproximadamente $85 \%$ para aproximadamente $90 \%$ de rendimento, ficando dentro dos limites esperados para conversores Buck e Boost.

Para o cálculo da SOC das baterias durante a operação do sistema, é utilizada a equação (3) da seção 2.1 .5 cuja descrição da metodologia de cálculo do SOC interativo é mostrada. Na Figura 4.28 tem-se o sistema de visualização do SOC mostrado em porcentagem e em Ah, que é calculado pelo DSP e disponibilizado em um LCD monocromático com duas linhas e dezesseis colunas, juntamente com a potência instantânea produzida pela fonte emuladora de painéis fotovoltaicos acoplados ao sistema ajustada para $V_{m p}=40 \mathrm{~V}, I_{m p}=3,5 \mathrm{~A}$.

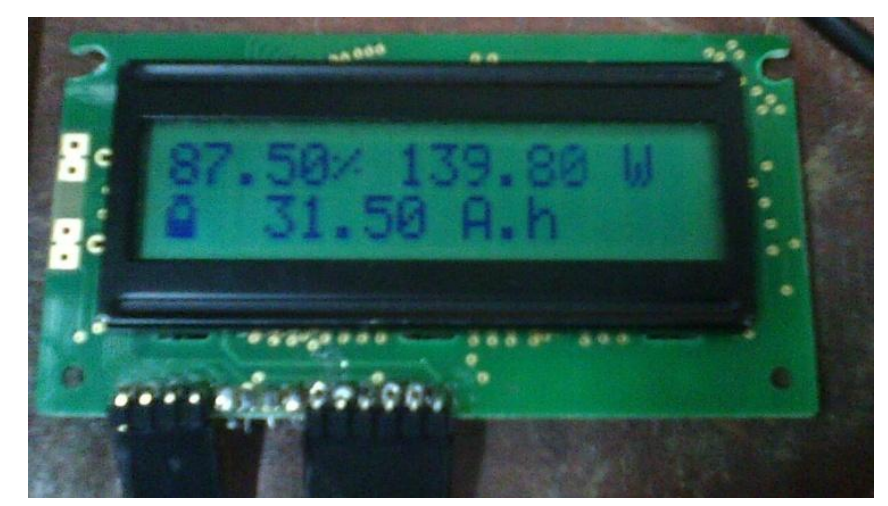

Figura 4.28 - LCD 16x2 monocromático indicando o SOC em porcentagem e em Ah, além da potência instantânea sendo produzida pela fonte emuladora de painéis ajustada para $V_{m p}=40 \mathrm{~V}, I_{m p}=3,5 \mathrm{~A}$.

\subsection{Considerações finais}

Neste capítulo foram mostrados os materiais utilizados na confecção do protótipo, parâmetros do sistema, como valor dos elementos passivos e topologia dos circuitos, além de vários experimentos que comprovam a eficiência do sistema de controle em situações extremas de funcionamento.

É descrita a metodologia de seleção da corrente de carga das baterias, que leva em conta a energia gerada, rendimento do sistema e a energia consumida pelas baterias. Constata-se em diversas situações de queda da irradiação que a corrente se ajusta rapidamente evitando colapsos por falta de energia, podendo inclusive suprir toda a demanda do sistema caso os painéis sejam desconectados. 
De acordo com os parâmetros de máxima potência ajustados na fonte emuladora, constata-se que o algoritmo de busca atua alcançando o valor de máxima potência em poucas interações do algoritmo.

Devido à alta poluição de ruídos nos sinais trabalhados, os ganhos dos controladores tiveram de ser reajustados, causando divergências entre os resultados simulados e resultados experimentais, entretanto caso os ganhos das simulações sejam modificados para os valores utilizados na bancada, os resultados se tornam semelhantes. 


\section{5-Conclusões e trabalhos futuros}

$\mathrm{Na}$ execução deste trabalho é visto que utilizando um controlador fuzzy $\mathrm{P}+\mathrm{I}$ pode-se controlar com precisão a carga e descarga de um banco de baterias de chumbo-ácido, através de um conversor Buck-Boost bidirecional com um rendimento entre $80 \%$ e $90 \%$. Além disso, é possível a estimação do SOC do banco de baterias mesmo durante sua operação, utilizando uma metodologia de medição da tensão de circuito aberto, juntamente, com a integração da corrente da bateria, gerando resultados satisfatórios para intervalos de tempo não muito longos (algumas horas).

Além disso, ao ser inserido um conjunto de painéis fotovoltaicos utilizando algoritmo de busca MPPT por P\&O é necessário o controle do fluxo de potência, uma vez que um desequilíbrio deste balanço produz sobre tensões ou sub tensões, comprometendo a estabilidade do sistema.

Mesmo em condições atmosféricas irregulares com variações bruscas de irradiação, o sistema consegue manter sua estabilidade na corrente de carga da bateria, devido ao sistema de controle da tensão do barramento $\mathrm{CC}$, que durante os transitórios compensa as irregularidades impostas.

Como trabalho futuro, é proposta a construção do sistema de injeção de energia na rede, gerando tensões e correntes sincronizadas com a rede elétrica, sendo seu fluxo de potência controlável. Além da inclusão de fontes alternativas de energia diversas acopladas por um único barramento $\mathrm{CC}$ comum a todas, eliminando a necessidade de um sistema de injeção na rede para cada sistema, formando uma micro rede no lado CC. A Figura 5.1 mostra o diagrama do sistema proposto como trabalho futuro. 


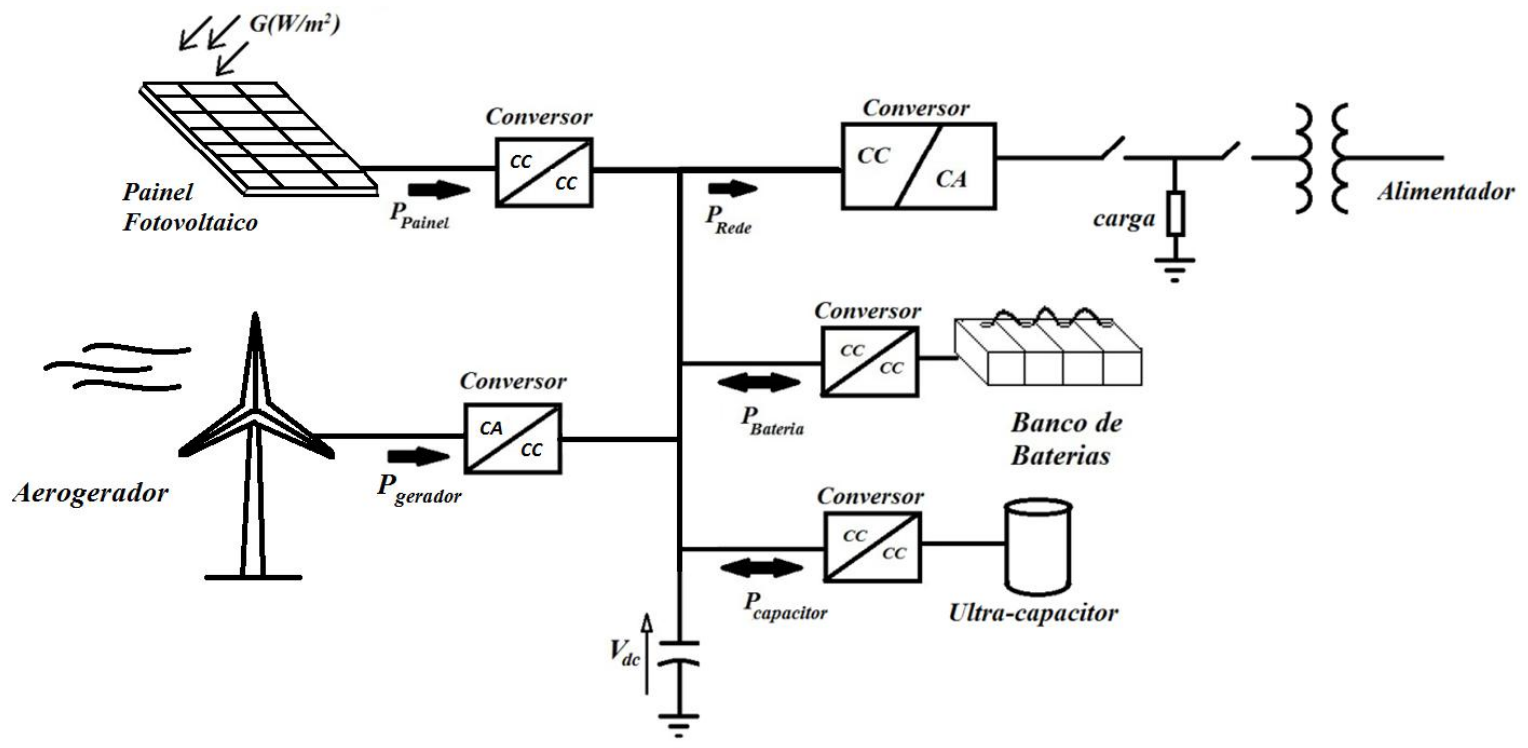

Figura 5.1 - Sistema proposto para trabalhos futuros. 


\section{Referências bibliográficas}

ABOULNAGA, A. A.; EMADI, A. High performance bidirectional Cuk converter for telecommunication systems. Telecommunications Energy Conference, 26th Annual INTELEC, p. 182-189, 2004.

ALVAREZ, J. et al. A fully digital smart and fast lead-acid battery charge system. Power Electronics Specialist Conference, PESC '03, v. 2, p. 913-917, 2003.

AYLOR, J. H.; THIEME, A.; JOHNSO, B. W. A battery state-of-charge indicator for electric wheelchairs. Industrial Electronics, IEEE Transactions on, v. 39, n. 5, p. 398-409, 1992.

BURKE, A. F. Batteries and Ultracapacitors for Electric, Hybrid, and Fuel Cell Vehicles. Proceedings of the IEEE, v. 95, n. 4, p. 806-820, 2007.

CÂNDIDO, D. B. Desenvolvimento de Sistemas estáticos Distribuídos - "Multi String", Para Aplicações em Sistemas Fotovoltaicos Autônomos". Dissertação de Mestrado, UFSM. Santa Maria. 2010.

CEPEL. Energia Solar Princípios e Aplicações - CRESESB/CEPEL, 2006. Disponivel em: $<$ http://www.cresesb.cepel.br/content.php?cid=tutorial_solar $>$.

COELHO, K. D. Estudo de uma Fonte Ininterrupta de Corrente contínua de Baixa Potência Gerenciada por um Microcontrolador. Dissertação de Mestrado, UFSC. Florianópolis. 2001.

DEEPTI, D. J.; RAMANARAYANAN, V. State of charge of lead acid battery. Power Electronics, India International Conference on, p. 89-93, 2006.

EPIA. Solar Generation 6, 2011. Disponivel em: <http://www.epia.org>.

EPIA, E. P. I. A. Photovoltaic Energy - Electricity From the Sun. [S.1.]. 2008.

ERICKSON, R. W.; MAKSIMOVIC, D. Fundamentals of Power Electronics. $2^{\circ}$. ed. [S.1.]: Kluwer Academic Publishers, 2000.

FAKHAM, H.; LU, D.; FRANCOIS, B. Power Control Design of a Battery Charger in a Hybrid Active PV Generator for Load-Following Applications. Industrial Electronics, IEEE Transactions on, v. 58, n. 1, p. 85-94, 2011.

FEMIA, N. et al. Optimization of perturb and observe maximum power point tracking method. Power Electronics, IEEE Transactions on, v. 20, n. 4, p. 963-973, 2005. 
FENT, D. G. An Automatic Universal Boost Charging Algorithm for Lead Acid Batteries. Telecommunications Energy Special Conference, TELESCON, p. 453-456, 1994.

GOW, J. A.; MANNING, C. D. Development of a Photovoltaic Array Model for Use in Power-Electronics Simulation Studies. Electric Power Applications, IEE Proceedings, v. 146, n. 2, p. 193-200, 1999.

MACHADO, R. Q. Sistema de Geração Distribuída com Fontes CA e CC Conectado a Rede Monofásica e Controle Eletrônico da Qualidade da Energia Eletrica. Tese de Doutorado, Unicamp. Campinas. 2005.

MAYER, A. C. et al. Polymer-Based Solar Cells, p. 28-33, 2007. Disponivel em: <http://www.sciencedirect.com/science/article/pii/S1369702107702766 >.

MCCARTHY, S.; WRIXON, G. T. Practical Experience of a $50 \mathrm{kWp}$ Photovoltaic System Supplying Power to a Dairy Farm on Fota Island, Cork, Ireland. IEEE Procedings, v. 134, n. 5, p. 407-412, 1987.

MIURA, Y. et al. Bidirectional isolated dual full-bridge dc-dc converter with active clamp for EDLC. Energy Conversion Congress and Exposition (ECCE), p. 1136-1143, 2010.

MOÇAMBIQUE, N. E. M. Aplicação de Algoritmos de Busca do Ponto de Máxima Potência e Controladores Lineares e/ou Fuzzy para a Regulação da Tensão Terminal de Painéis Fotovoltaicos. Tese de Mestrado, EESC-USP. São Carlos. 2012.

MOCAMBIQUE, N. E. M.; MACHADO, R. Q.; OLIVEIRA, V. A. A fuzzy PD-PI control strategy to track the voltage references of photovoltaic arrays. 9th IEEE International Conference on Control and Automation (ICCA), 2011 , p. 1162-1167, 2011.

MOURA. Manual Técnico Moura Acumuladores. [S.1.]. 2011.

NG, K.-S. et al. State-of-Charge Estimation for Lead-Acid Batteries Based on Dynamic Open-Circuit Voltage. Power and Energy Conference, IEEE 2nd International, p. 972-976, 2008.

NORTHCOTT, D. R.; FILIZADEH, S.; CHEVREFILS, A. R. Design of a Bidirectional Buck-Boost dc/dc Converter for a Series Hybrid Electric Vehicle Using PSCAD/EMTDC. Vehicle Power and Propulsion Conference, VPPC IEEE, p. 1561-1566, 2009.

ORTIZ-RIVERA, E. I.; PENG, F. A novel method to estimate the maximum power for a photovoltaic inverter system. Power Electronics Specialists Conference, PESC 04, v. 3, p. 2065-2069, 2004.

REN21. Renewable Global Status Report. Renewable Energy Policy Network for the 21st Century, 2011. Disponivel em: <http://www.ren21.net/Portals/97/documents/GSR/REN21_GSR2011.pdf>.

RODRIGUEZ, C.; AMARATUNGA, G. A. J. Analytic Solution to the Photovoltaic Maximum Power Point Problem. IEEE Transactions on , v. 54, n. 9, p. 2054-2060, 2007. 
SOUZA, J. D.; SILVA, B. B.; CEBALlOS, J. C. Estimativa da radiação solar global à superfície usando um modelo estocástico: caso sem nuvens. Revista Brasileira de Geofísica, v. 26, n. 1, p. 31-44, 2008.

SUN, K. et al. A Distributed Control Strategy Based on DC Bus Signaling for Modular Photovoltaic Generation Systems With Battery Energy Storage. Power Electronics, IEEE Transactions on , v. 26, n. 10, p. 3032-3045, 2011.

VILlalva, M. G. Conversor Eletrônico de Potência Trifásico para Sistema Fotovoltaico Conectado à Rede létrica. Dissertação de doutorado, Unicamp. Campinas. 2010.

VILlALVA, M. G.; GAZOLI, J. R.; FILHO, E. R. Comprehensive Approach to Modeling and Simulation of Photovoltaic Arrays. Power Electronics, IEEE Transactions on, v. 24, n. 5, p. 1198-1208, 2009.

YIFENG, G.; LIMIN, H. The Charging Technology for Lead-Acid Battery with a Negative Pulse. Power and Energy Engineering Conference (APPEEC), p. 1-3, 2010.

YUAN, L. et al. The Optics of Organic Photovoltaics: Fiber-Based Devices. IEEE Journal of selected Quantum Electronics, v. 16, n. 6, p. 1827-1837, 2010.

YUASA. YUASA INC, Catálogo de Baterias. [S.1.]. 1999. 